Florida International University

FIU Digital Commons

FIU Electronic Theses and Dissertations

University Graduate School

$6-29-2020$

\title{
Latina Youth and Suicidality: A Cross-Sectional and Longitudinal Analysis
}

Janice J. O'Driscoll

jodri002@fiu.edu

Follow this and additional works at: https://digitalcommons.fiu.edu/etd

Part of the Social Welfare Commons

\section{Recommended Citation}

O'Driscoll, Janice J., "Latina Youth and Suicidality: A Cross-Sectional and Longitudinal Analysis" (2020). FIU Electronic Theses and Dissertations. 4493.

https://digitalcommons.fiu.edu/etd/4493

This work is brought to you for free and open access by the University Graduate School at FIU Digital Commons. It has been accepted for inclusion in FIU Electronic Theses and Dissertations by an authorized administrator of FIU Digital Commons. For more information, please contact dcc@fiu.edu. 


\title{
FLORIDA INTERNATIONAL UNIVERSITY
}

Miami, Florida

\section{LATINA YOUTH AND SUICIDALITY: A CROSS-SECTIONAL AND LONGITUDINAL ANALYSIS}

\author{
A dissertation submitted in partial fulfillment of \\ the requirements for the degree of \\ DOCTOR OF PHILOSOPHY
}

in

SOCIAL WELFARE

by

Janice O’Driscoll 
To: Dean Tomás R. Guilarte

Robert Stempel College of Public Health and Social Work

This dissertation, written by Janice O'Driscoll, and entitled Latina Youth and Suicidality: A Cross-sectional and Longitudinal Analysis, having been approved in response to style and intellectual content, is referred to you for your judgement.

We have read this dissertation and recommend that it be approved

Miriam Potocky

Nicole Fava

Jeremy W. Pettit

Mark Macgowan, Major Professor

Date of Defense: June 29, 2020

The dissertation of Janice O'Driscoll is approved.

Dean Tomás R. Guilarte

Robert Stempel College of Public Health and Social Work

Andrés G. Gil

Vice President for Research and Economic Development and Dean of the University Graduate School

Florida International University, 2020 
(C) Copyright 2020 by Janice O’Driscoll

All rights reserved. 


\section{DEDICATION}

This dissertation is dedicated to my family: Without your sacrifices and unconditional love, none of this would be possible. To my father, Thomas O'Driscoll, who always encouraged me to ask questions and never stop learning. To my mother, Mi Yon

O'Driscoll, who instilled in me the importance of hard work and resilience. To Chris Hanna, for not only being my partner but my exemplar of patience, persistence, generosity, and love. 


\section{ACKNOWLEDGMENTS}

This dissertation would never have been made possible without the guidance and encouragement of my Major Professor, Dr. Mark Macgowan. It was a windy road, but I was so fortunate to have you as my mentor. I would also like to thank Dr. Miriam Potocky, who was always so thorough in her interactions with me and has done the most to help me grow as a statistician. Thank you to Dr. Nicole M. Fava, whose previous experience with the National Longitudinal Study of Adolescent to Adult Health gave me a rich perspective into trauma and much needed practical advice on working with such a massive dataset. Thank you to Dr. Jeremy W. Pettit, for meeting with me and cultivating a curiosity about youth suicidality and the implications it might lead to for clinicians.

I would like to extend my gratitude to both the School of Social Work and the University Graduate School for providing me encouragement and funding as a Presidential Fellow. My doctoral adventure would have never begun without their generous funding and resources. The fellowship provided me the opportunity to learn directly from multiple, excellent researchers in their own unique styles: Dr. Stephen E. Wong, Dr. Paul Stuart, Dr. Nicole Ruggiano, and Dr. Shanna L. Burke. Thank you all for letting me see the masters at work. Additionally, the Presidential Fellowship allowed me the opportunity to teach multiple classes at the BSW level. Thank you, Dr. Mary Helen Hayden, for tolerating my abundant questions as a fledgling teaching assistant and for helping me develop as an educator over the years. 


\author{
ABSTRACT OF THE DISSERTATION \\ LATINA YOUTH AND SUICIDALITY: A CROSS-SECTIONAL AND \\ LONGITUDINAL ANALYSIS \\ by \\ Janice O’Driscoll
}

Florida International University, 2020

Miami, Florida

Professor Mark Macgowan, Major Professor

Purpose: This study aimed to understand which factors correlated to a likelihood of suicidal thoughts and suicide attempts in Latina youth and how that may or may not differ from female youth of different racial/ethnic groups. Additionally, this study sought to explore which predictors increased the likelihood of suicide attempts as youth aged into adulthood.

Method: The study was a secondary data analysis of the National Longitudinal Study of Adolescent to Adult Health (Add Health) using binomial logistic regression and generalized estimating equations. The sample consists of 10,480 youth at Wave 1 , who were followed with repeated measures 1, 6, and 13 years after baseline. This investigation utilized a cross-sectional and longitudinal design using multiple logistic regression and generalized estimating equations analyses, respectively. 
Results: For suicidal thoughts, higher scores of depression, a history of forced sexual intercourse, at least one friend suicide attempt, lower scores of mother connectedness, and lower scores father connectedness were statistically significant correlates of suicidal thoughts at Wave I for Latinas. Higher scores of depression, a history of forced sexual intercourse, and at least one friend suicide attempt remained significant correlates of suicide attempts for Latinas at Wave 1. Predictors varied between racial/ethnic groups, with only depression scores being a significant predictor for all groups for both thoughts and attempts. Age, depression score, alcohol use, forced sexual intercourse, family suicide attempt, friend suicide attempt, father as a recipient of public assistance, physical abuse from a parent, attempted removal by social services, mother connectedness, father connectedness, and acculturation were significant predictors of suicide attempts over time for all female youth in the study sample. Race/ethnicity was not a significant predictor of suicide attempts over time.

Conclusion: Identifying the predictors associated with suicide attempt likelihood can help in identification of at-risk youth and the tailoring of appropriate and culturally competent prevention and treatment programs. For Latinas, emphasis should be placed on evaluation for symptoms of depression, the impact of forced sexual contact, the contagion effect of peer suicide, and the perceived quality of the relationship the youth has with each of her parental figures. 


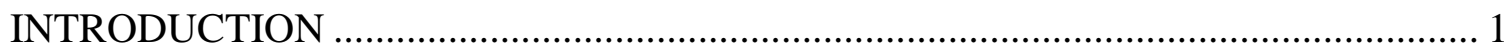

Defining Suicide and Suicide Related Behaviors .................................................... 1

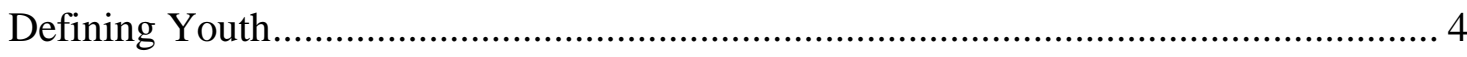

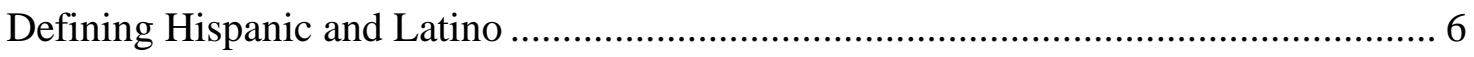

Latina Youth-Specific Suicide Correlates ................................................................. 7

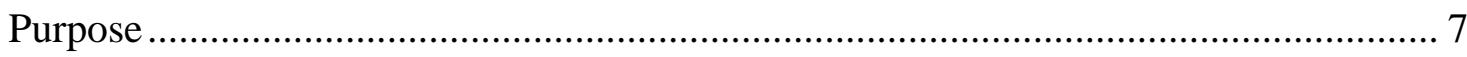

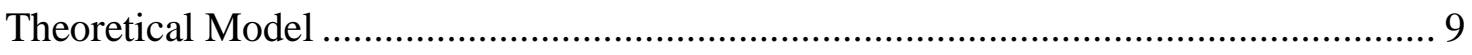

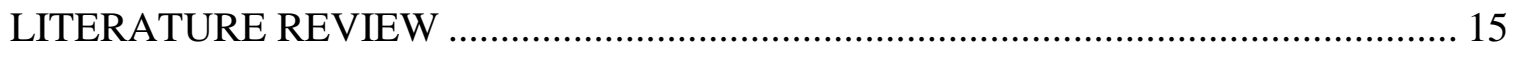

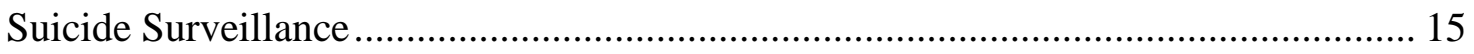

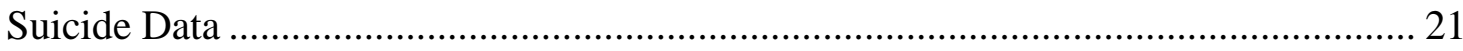

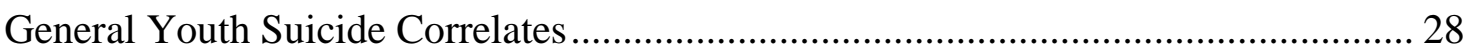

Latina Youth and Suicide Related Behaviors: Theorized Correlates............................. 42

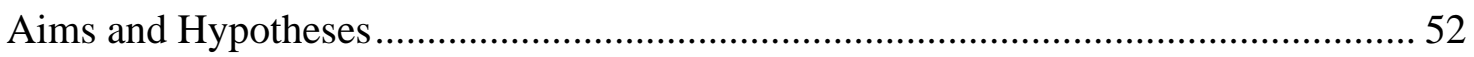

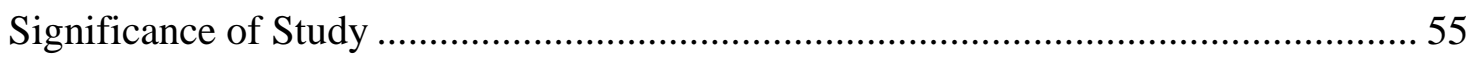

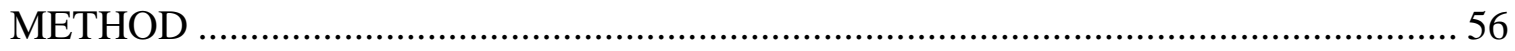

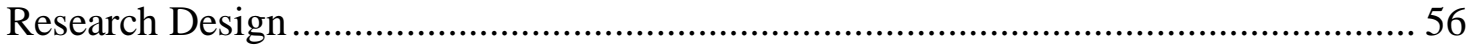

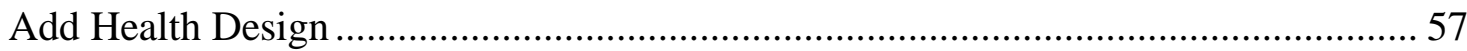

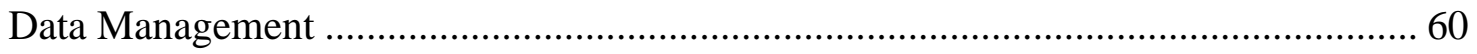

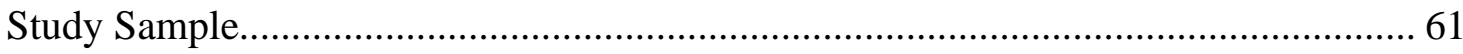

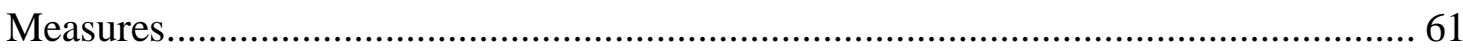

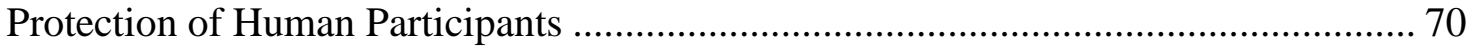

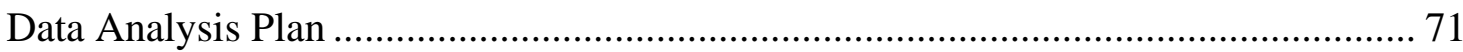

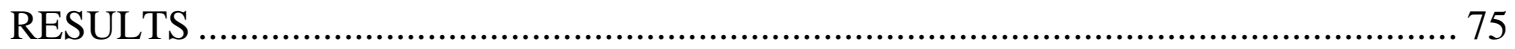

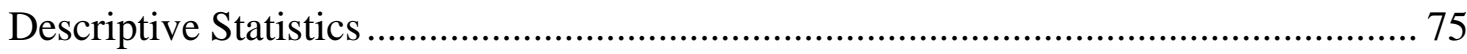

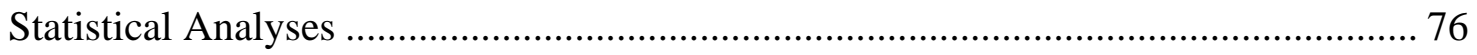

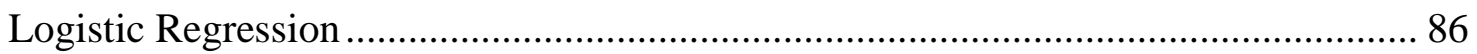

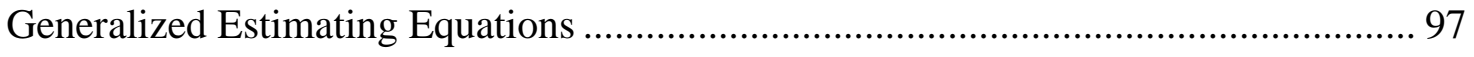




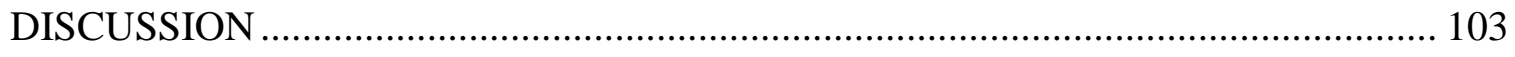

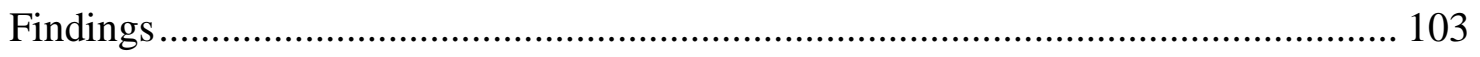

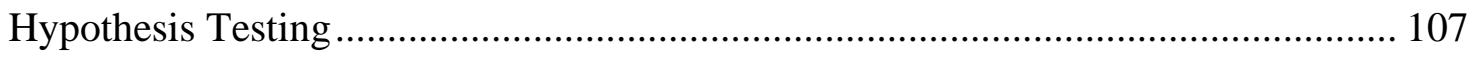

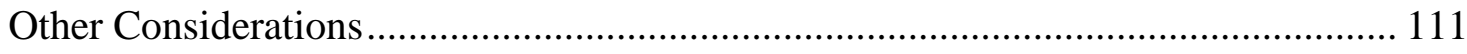

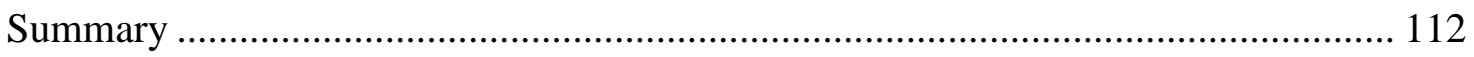

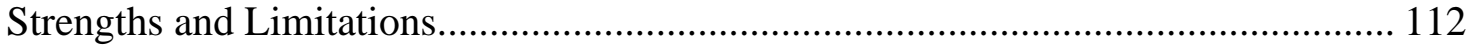

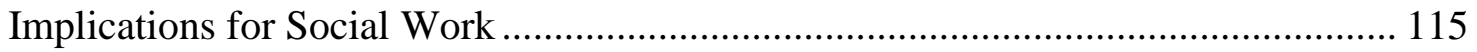

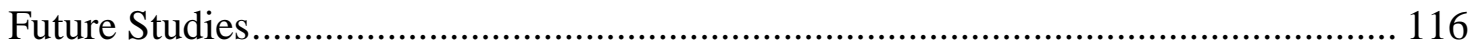

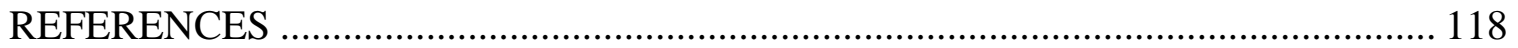

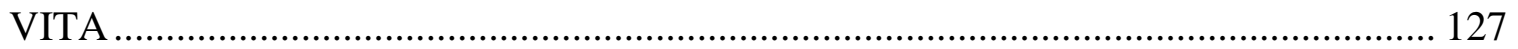




\section{LIST OF TABLES}

TABLE

PAGE

Table 1. Correlates for Female Youth Suicide Morbidity as Identified by the Literature 51

Table 2. Female Respondents to the National Longitudinal Study of Adolescent to Adult Health. 61

Table 3. Past Year Suicide Morbidity by Latina Origin. ............................................. 72

Table 4. Race and Ethnicity in the Female Subset........................................................ 75

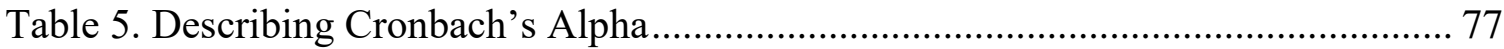

Table 6. Frequency of Race/Ethnicity Categories ........................................................ 84

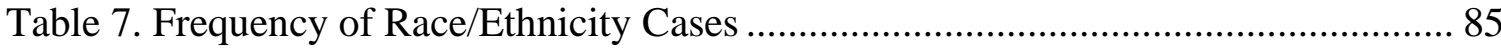

Table 8. Variables with $>1.0 \%$ Missing Response from the Female Only Dataset......... 88

Table 9. Summary of Significant Predictors of Suicidality at Wave 1 .......................... 95

Table 10. Generalized Estimating Equation Parameter Estimates ................................. 98

Table 11. Log-Odds for Thoughts of Suicide When Holding All Other Predictors

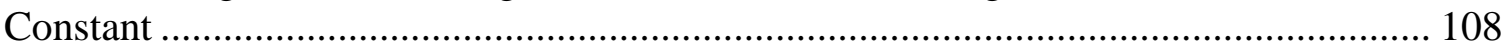




\section{LIST OF FIGURES}

Figure 1. Bronfenbrenner's Ecological Systems Theory ........................................... 10

Figure 2. Vygotsky's Zone of Proximal Development ............................................ 11

Figure 3. Family and Adolescent Ecodevelopmental Context..................................... 12

Figure 4 Proposed Conceptual Model for Research on Suicide Attempts by Adolescent

Latinas

Figure 5. Total Suicides by Year, 1981 to 2017 .............................................................. 22

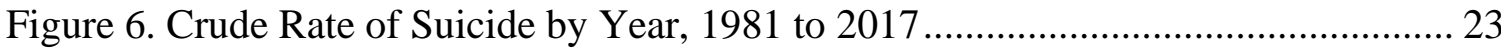

Figure 7. Suicide Rates per 100,000 by Race, Ethnicity and Year, 1990 to 2017 ........... 25

Figure 8. Number of Youth with Suicide Ideation Past Year by Biological Sex ............ 78

Figure 9. Total Number of Past Year Suicide Attempt by Biological Sex ..................... 79

Figure 10. Suicide Attempt by Biological Sex ............................................................ 80

Figure 11. Race and Ethnicity Categories and Suicidal Ideation.................................. 82

Figure 12. Race and Ethnicity Categories and Suicide Attempts ................................. 83 


\section{INTRODUCTION}

Suicide is a significant public health issue in the United States, particularly regarding American youth. Using the most recent data available for the year 2017, suicide is cited as the overall $10^{\text {th }}$ leading cause of death of people of all races, ages, and sexes in the United States (Heron, 2019). The statistics are more troubling when looking at younger age groups, as suicide is the $2^{\text {nd }}$ leading cause of death in youth to young adults 10-14, 15-19, 20-24, and 25-34 years of age (Heron, 2019). These deaths from suicide accounted for 17\% of all deaths among individuals aged 10-24 (Kann et al., 2016). The number of deaths from suicides (Heron, 2019) and self-reported suicide attempts (Kann et al., 2018) have increased, demonstrating a continuing need for suicide research.

\section{Defining Suicide and Suicide Related Behaviors}

Currently, there is difficulty in absolutely defining acts and behaviors related to suicide, because there is no universally agreed upon labeling system (Silverman, 2011; Silverman \& De Leo, 2016). This makes comparisons between nations and states, let alone individual research projects, very challenging. Exchange of information and learning becomes limited by the fuzzy boundaries in naming and describing the problem. Additionally, identifying the actual rates suicide become skewed, with researchers and medical examiners agreeing actual suicide rates to be $10 \%$ to $200 \%$ higher than what is reported, depending on the source (Silverman, 2011). For consistency, this section will define suicide and its related behaviors as it will be used throughout the paper. Definitions are strongly based on the suggested uniform definitions of self-directed 
violence by the Center for Disease Control (Crosby et al., 2011) and the landmark paper by Silverman and colleagues (Silverman et al., 2007) on suggested suicide nomenclature.

\section{Mortality}

Following the suggested uniform definitions of self-directed violence by the Center for Disease Control, suicide is "death caused by self-directed injurious behavior with an intent to die as a result of the behavior" (Crosby et al., 2011). These deaths by suicide are often referred to as mortality. Suicidal intent - some explicit or implicit evidence that at the time of the behavior the individual wished to die and that he or she understood the likely consequences of his or her actions (Crosby et al., 2011) - remains key in defining suicide fatalities. Suicidal intent may not be possible to determine in all cases, as lack of information on the individual and his or her wishes may have an impact on distorting the overall number of suicides reported in the United States. Such may be the problem in distinguishing suicides from non-suicidal self-directed violence that resulted in accidental fatality, where individuals do wish to cause self-injury but had no intention of dying (Crosby et al., 2011). It is recommended that when intent is uncertain, deaths should be labeled as either self-inflicted with undetermined intent or undetermined self-directed violence that resulted in fatality (Crosby et al., 2011; Silverman et al., 2007).

\section{Morbidity}

There exists an entire band of suicide-related behaviors that comprise the category of morbidity. These range from non-fatal suicidal self-directed violence to thoughts of suicide. Additionally, each behavior, ideation, or communication can have its own level 
of intent and level of injury (Silverman et al., 2007). The most common form of morbidity is suicidal ideation. Suicidal ideation involves thoughts or fantasies about suicide. These thoughts may range from casual, transient, passive, active, to persistent (Silverman et al., 2007).

Suicide literature identifies two different types of suicide-related communications: suicide plans and suicide threats. Both of these may also be considered prepatory actions (Crosby et al., 2011). A suicide threat is verbal or non-verbal communication of varying intent to die by suicide (Silverman et al., 2007). However, this term may convey a judgement or value statement on the individual or his or her intentions, and is not suggested for use in suicide surveillance data (Crosby et al., 2011). A suicide plan is a method or outline for how and when to achieve self-directed violence, though this may be with or without any actual intent of carrying out such a plan (Silverman et al., 2007). In practice, an individual with a well-defined and achievable suicide plan may be considered more dangerous than one with only suicidal ideation.

Non-fatal suicidal self-directed violence, to be referred to as a suicide attempt throughout this study, may or may not result in injury and can be due to self-interruption or interruption by another party (Crosby et al., 2011). To clarify, to be a suicide attempt, the intention must be to die; without this intention, the resulting scenario may be called self-harm with or without injuries (Silverman et al., 2007). Some suicidologists agree that when intent is unclear, the event should be labeled an undetermined suicide-related behavior (Silverman et al., 2007). 
In suicide literature and suicide intervention practice, these behaviors are theorized to exist on a continuum of suicide lethality (Asarnow et al., 2008; Firestone \& Seiden, 1990; Lester, 1970; Sveticic \& De Leo, 2012; Tarrier \& Picken, 2011). The model implies a progression of stages in suicide-related behaviors along a continuum that includes suicidal ideation, suicide plan, suicide attempt, multiple attempt, and suicide fatality. However, as research in this area remains unclear and the causes of suicide so varied, it is impossible to determine an individual's specific risk of suicide using this continuum theory (Sveticic \& De Leo, 2012).

\section{Defining Youth}

There is no universally agreed upon definition of youth. Operationalization remains difficult because youth is often a blurry period of transition from childhood to adulthood that varies cross culturally. For example, the United Nations operationalizes youth as persons between the age of 15 and 24 for statistical purposes, but also acknowledges that member countries may define the youth age range differently (United Nations Programme on Youth, n.d.).

The National Longitudinal Study of Adolescent to Adult Health study tracked students in the United States born between the years of 1974 and 1983. At Wave I, these participants were mostly between the ages of 10 and 21 years old. By Wave IV, in 2008, these same participants were 25 to 34 years old. For the purposes of this dissertation, "youth" will be used in general to describe the participants who fall into the ranges studied by the Add Health dataset, 12-34 years old. This will be a more expanded age range as typically studied by the United Nations Programme on Youth. 


\section{Latina Youth}

Of special interest to this study are Latina young people ages 10 to 28 in the United States and their experiences with thoughts of suicide, suicide plans, and suicide attempts. This group has consistently reported higher rates of suicide morbidity than nonLatina White and non-Latina African American counterparts (De Luca, Schmeelk-Cone, \& Wyman, 2015; Kann et al., 2016).

In the 2015 Youth Risk Behavior Survey, researchers found 25.6\% of Hispanic girls reporting having seriously considered attempting suicide in the past 12 months, higher than non-Latina White females $(22.8 \%)$, non-Latina Black females (18.7\%), Hispanic males (12.4\%), non-Latino White males (11.5\%), and non-Latino Black males (11.0\%; (Kann et al., 2016). Hispanic girls (20.7\%) self-reported being more likely to make a suicide plan than non-Latina White females (18.4\%), non-Latina Black females (17.3\%), Hispanic males (10.9\%), non-Latino Black males (10.6\%), and non-Latino White males (9.3\%; Kann et al., 2016). Finally, $15.1 \%$ of all Hispanic girls surveyed selfreported a suicide attempt in the 12 months prior to the survey, more than non-Latina Black females (10.2\%), non-Latina White females (9.8\%), and all male student groups (7.6\% and less; Kann et al., 2016).

In the most recently published Youth Risk Behavior Survey, 2017, researchers found $22.2 \%$ of Hispanic girls reporting having seriously considered attempt suicide in the past 12 months, still higher than non-Latina white females $(21.2 \%)$ but now slightly lower than non-Latina Black females (22.4\%). Again, all female race/ethnicity groups seriously considered attempting suicide at higher rates than their male counterparts (Kann 
et al., 2018). Higher rates of suicide attempts are also reported in Black females (12.5\%) and Hispanic females $(10.5 \%)$ than White females $(7.3 \%)$; once again, all three female groups reported attempting a suicide at higher rates than their male counterparts (Kann et al., 2018).

Youth that self-identified as non-White appeared more likely to have suicidal ideations and suicide attempts, and whatever factor that had historically shown reduced positive responses from Black youth on suicide ideation and suicidality appears to have reduced over time. Looking towards the future, the United States' Latino population is predicted to rise nearly $115 \%$ by 2060 , as opposed to the non-Latino population rising by

$13.1 \%$ in the same time frame (Colby \& Ortman, 2015). These facts potentially forecast a growing problem of suicide-related behaviors for this minority population that merits research attention into what is unique to the Latino American youth experience that heightens risk for suicide morbidity.

\section{Defining Hispanic and Latino}

The United States census follows the U.S. Office of Management and Budget's (OMB) recommendations for defining race and ethnicity (Humes et al., 2011). The words "Hispanic" and "Latino" are used interchangeably depending on United States region, and both refer to an ethnicity, not a race (Office of Management and Budget, 1997). Therefore, individuals who self-identify their ethnicity as Hispanic or Latino may also self-identify their race as White or African-American or other racial choice. Per the census, an individual is of Hispanic origin if they are of "Cuban, Mexican, Puerto Rican, South or Central American, or other Spanish culture or origin regardless of race" (Humes 
et al., 2011, p. 2). Humes and colleagues (2011) continue that this definition includes "the heritage, nationality group, lineage, or country of birth of the person or the person's parents or the ancestors before their arrival in the United States" (p. 2).

\section{Latina Youth-Specific Suicide Correlates}

Few rigorous studies have examined Latina youth's suicide-related behaviors. The following variables have been theorized to influence the unique Latina youth experience, potentially expressing greater influence on this group, as opposed to non-Latina comparison groups: (a) acculturation, (b) familism, and (c) parent-connectedness. These variables, along with general youth suicide risk and protective factors such as mental health, substance abuse, and suicide contagion effects, will be further explored in this paper.

\section{Purpose}

The purpose of the dissertation is to better understand the longitudinal correlates of the Latina youths' suicide morbidity. It builds on existing, but limited, research on what differentiates Latina youth who have suicidal thoughts, plans, and attempts from the Latina youth who do not, and from non-Latina female youth. Much of the existing research has explored the variables of interest with a qualitative methodology (Gulbas, Hausmann-Stabile, De Luca, Tyler, \& Zayas, 2015; Gulbas \& Zayas, 2015; Nolle, Gulbas, Kuhlberg, \& Zayas, 2012; Peña et al., 2011) or piecemeal in quantitative methodologies (Chesin \& Jeglic, 2012; De Luca et al., 2012; Peña et al., 2011; PiñaWatson et al., 2014; Romero et al., 2013; Zayas et al., 2009). None have evaluated these variables together in the same quantitative longitudinal panel study to provide a high 
level of evidence, as suggested by Christiansen, Larsen, Agerbo, Bilenberg, \& Stenager (2014). The results will inform which of the selected variables, if any, have an impact on suicide morbidity behavior as the adolescent progresses into young adulthood. Better understanding the strength and direction of these factors can be used to tailor more effective public health interventions for this group and their families.

Informed by Zayas, Lester, Cabassa, \& Fortuna's (2005) proposed conceptual model for research on suicide attempts by adolescent Latinas, and supplemented by a literature review, 15 variables were identified for further study on Latina youth's suicidal ideation and attempts. As a secondary purpose, the dissertation examined if these variables are of greater impact to Latina youth than female youth from other racial/ethnic backgrounds.

This investigation utilizes a cross-sectional and longitudinal design using multiple logistic regression and generalized estimating equations analyses, respectively. The data was from multiple waves of the National Longitudinal Study of Adolescent to Adult Health (Add Health) dataset. This large and thorough dataset provides a nationally representative sampling of youth, and its longitudinal cohort design allowed for research on outcomes throughout development. Because of the unique opportunity provided by this dataset to track an individual adolescent into adulthood, this dissertation attempted to take advantage of the design to follow suicide morbidity behaviors throughout development. 


\section{Theoretical Model}

A search of the literature did not yield a standalone theoretical model for Latina suicide ideation, though it did produce a model for suicide attempts. After reviewing the relevant literature of the time and their own practice experience, Zayas and colleagues (2005) proposed a conceptual model of Latina suicide attempts to guide future research and treatment. This model incorporates earlier ideas originally presented by Bronfenbrenner (1979) and Vygotsky (1978).

Bronfenbrenner's (1979) ecological systems theory of child development (Figure 1) depicted a system that shaped human development through interactions between the individual and the surrounding environment. The individual, pictured as the center of the system, has immediate contact with his or her microsystem: the family, the school, religious affiliations, peers, and neighbors. Additional systems, drawn as growing concentric circles around the microsystem, represent important environmental aspects that shape the child's life, despite appearing to have a more distanced or subtle impact. For instance, the macrosystem, the representation of the larger cultural context, can shape the attitudes and values of the society in which the individual lives. Additionally, these systems are subject to change over time, and may reflect how individuals influence the meso- or macrosystem in turn. 
Figure 1. Bronfenbrenner's Ecological Systems Theory

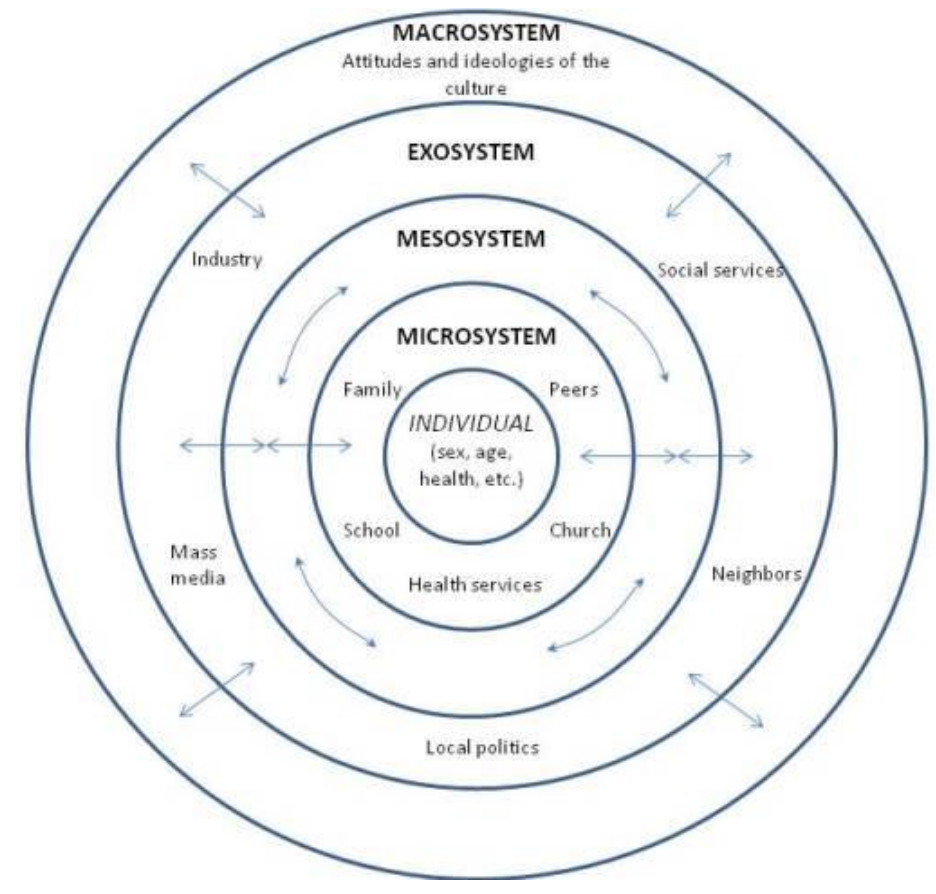

Figure 1. Concentric circle model for Bronfenbrenner's (1979) Ecological Systems Theory. Reprinted from "Bronfenbrenner's Ecological Systems Theory" by Hchokr, 2012, Wikimedia Commons,

https://commons.wikimedia.org/wiki/File:Bronfenbrenner\%27s_Ecological_Theory_of Development_(English).jpg. Creative Commons licensed under CC BY-SA 3.0. 
Vygotsky's (1978) zone of proximal development (Figure 2) was another influencing concept in the area of developmental psychology. To Vygotsky, the social interactions between children and the individuals in their immediate environment, such as the family, was the environment for cognitive and cultural development. In the zone of proximal development, the individual learns and grows with guidance from others. This guidance is generally passed through tradition and cultural norms, and these cultural norms are assimilated into the child as the child develops.

Figure 2. Vygotsky's Zone of Proximal Development

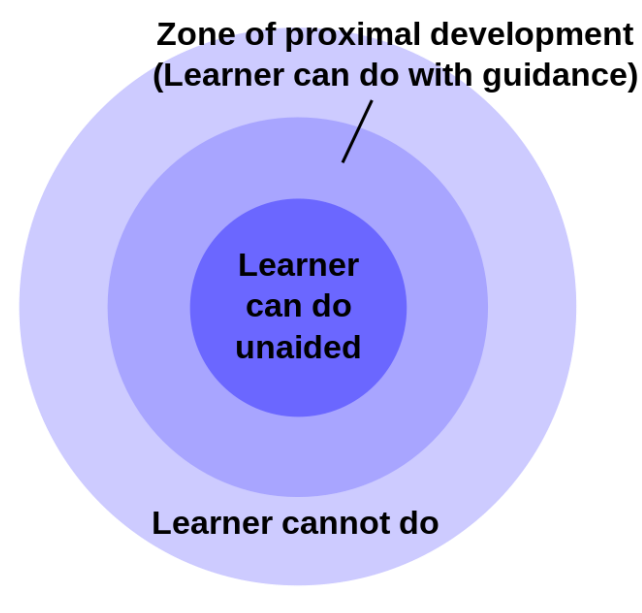

Figure 2. Concentric circle model depicting the impact of interaction on learning and psychological development. Reprinted from "Zone of Proximal Development". By Dcoetzee, 2012. Wikimedia Commons, https://commons.wikimedia.org/wiki/File:Zone_of_proximal_development.svg. Creative Commons licensed under CCO 1.0. 
Zayas and colleagues (2005) united Bronfenbrenner's and Vygotsky's models, nesting the zone of proximal development into the microsystem (Figure 3).

Figure 3. Family and Adolescent Ecodevelopmental Context

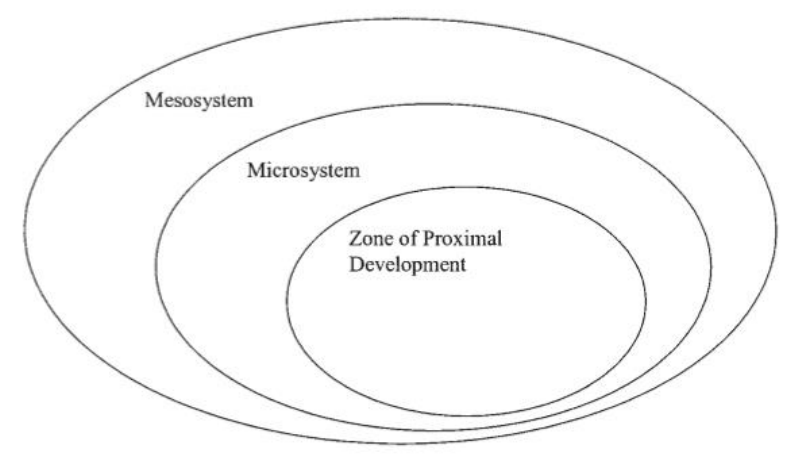

Source: Zayas, L. H., Lester, R. J., Cabassa L. J., \& Fortuna, L. R. (2005). Why do so many Latina teens attempt suicide? A conceptual model for research. American Journal of Orthopsychiatry, 75(2), 275-287. https://doi.org/10.1037/0002-9432.75.2.275

With these existing frameworks in mind, Zayas and colleagues (2005) created their proposed conceptual model for research on suicide attempts by adolescent Latinas (Figure 4). This model focuses on the family sociocultural environment, which can also be viewed as the individual's family microsystem or zone of proximal development. According to the researchers (Zayas et al., 2005), opposing forces in cultural traditions and the adolescent's development may cause conflict and interpersonal disconnection in the family sociocultural environment. This can be exacerbated by the individual's psychological vulnerability and the subjective perception of a family crisis, thereby creating an environment for a possible suicide attempt. While this model appears to have 
informed the authors' later qualitative research, the model was never statistically tested in later publications.

Figure 4. Proposed Conceptual Model for Research on Suicide Attempts by Adolescent Latinas

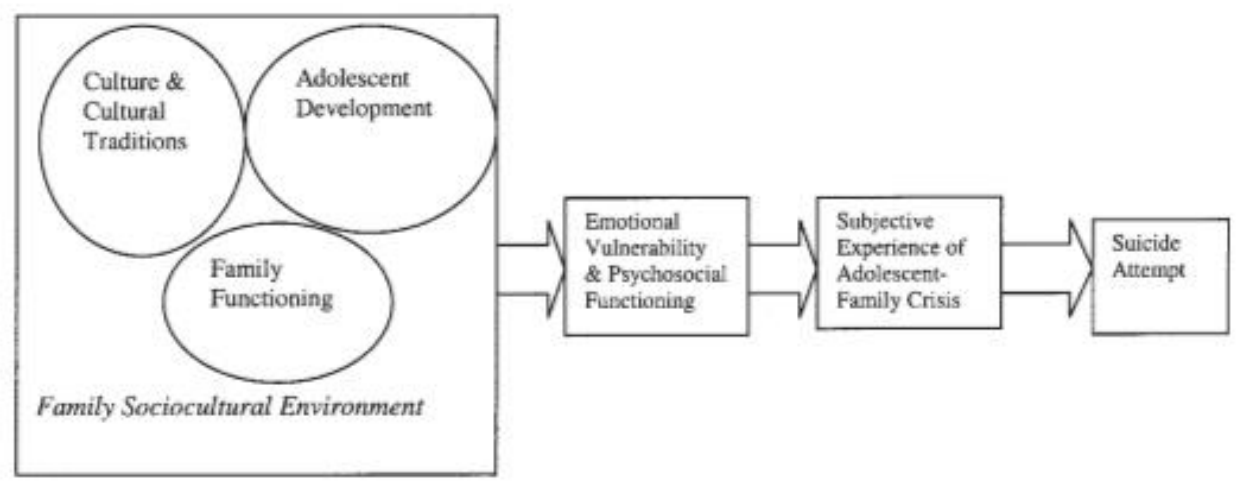

Source: Zayas, L. H., Lester, R. J., Cabassa L. J., \& Fortuna, L. R. (2005). Why do so many Latina teens attempt suicide? A conceptual model for research. American Journal of Orthopsychiatry, 75(2), 275-287

The above conceptual model was used to inform the creation of the research questions for the dissertation. So far, in the published literature, researchers have either used qualitative methods to explore reoccurring themes relevant to the Latina youth's decision to attempt suicide or not, or the studies have used quantitative methods to analyze limited variables, evaluating only partial pieces described in the proposed model. Relevant publications using the Add Health database have so far only looked at parent, teacher, and peer relationships to predict suicide behavior (De Luca et al., 2012); and parent-connectedness, autonomy granting, and parent interest in school life to predict suicidal ideation (Piña-Watson et al., 2014). Additionally, both studies only focused on 
Wave 1 data, and were cross-sectional in nature, giving no indication of changes in suicide behavior over time. Given the understudied nature of the topic the existing literature is informative, but this study hopes to create a greater context for predicting suicide related behaviors in such a specific population. 


\section{LITERATURE REVIEW}

The purpose of this section is to describe what is currently known about suicide and suicide-related behaviors, present its known correlates, and understand how this affects the Latina youth population. Additionally, this section will also describe the current sources of suicide surveillance data, their quality, and their limitations.

\section{Suicide Surveillance}

\section{Mortality Sources}

As all deaths in the United States require the completion of a death certificate by law, suicide mortality data gives the public a starting point to evaluate the problem of suicide. There are currently two main sources of national mortality data, the National Vital Statistics System and the National Violent Death Reporting System.

The National Vital Statistics System. That National Vital Statistics System is the oldest source of information on deaths in the United States. Vital statistics data are collected at the state level and include such information as marriages, divorces, annulments, live births, fetal deaths and deaths. The information is then shared with the Federal Government through cooperative agreements between the state or independent registration areas and the National Center for Health Statistics (NCHS), a division of the Centers for Disease Control and Prevention (CDC). Since its inception, efforts have been made to improve the quality of data, its validity and its comparability from state to state (Hetzel, 1997).

The National Vital Statistics System provides a dataset that allows for following public health trends over a long period. It is available online and made freely accessible 
(https://www.cdc.gov/nchs/nvss/index.htm). Reports are released multiple times per year on a variety of mortality topics. Death certificates include cause-of-death information as reported by the medical examiner, coroner, physician, or other public safety professional, allowing for suicide mortality research. However, as there is sometimes not enough information to determine intent, suicides may go unreported. If a death is determined to be a suicide later, after investigation, death certificate information and subsequent reporting may not be amended. Additionally, a death may not be reported as a suicide to protect the victim or the family from stigma or other consequence. In a systematic review of suicide reliability studies, seven of the 31 studies being from North America, Tøllefsen, Hem, \& Ekeberg, (2012) found that while 13 studies reported reliable suicide statistics or underreporting of $0 \%$ to $10 \%, 52 \%$ found more than $10 \%$ underreporting, and $39 \%$ found $30 \%$ or greater underreporting of suicide.

For suicide research, it should be noted that there is a large limitation in considering death information and race and ethnicity, particularly when dealing with information from the National Vital Statistics System. This is because death certificate information is relayed by funeral directors who have received information through an informant or, lacking that, through observation. This information on race and ethnicity may not agree with information given by the deceased in life as to their racial and ethnic background, causing an underestimation of deaths and death rates for American Indian and Alaskan Native populations, Asian and Pacific Islander populations, Hispanic populations, and individuals of mixed descent (Heron, 2016). Additionally, issues in collecting U.S. census data such as undercounting, bias the death rates by race and 
ethnicity. The most recent 2010 U.S. census undercounted non-Latino Black, non-Latino white, Hispanic, and American Indian or Alaskan Native populations (Heron, 2016).

Like the issues regarding the classification of race and ethnicity in death certificate and census data, the U.S. Census Bureau has also acknowledged a large issue of undercounting children, especially between 0 and 4 years of age. In the 2010 Census, it is estimated that almost 1 million children were undercounted, demonstrating a $1.4 \%$ increase in young children undercount rates since 1980, despite the adult population rising from an undercount of $1.4 \%$ to an overcount of $0.7 \%$ in the same timeframe (Decennial Statistical Studies Division, 2016). Still, given the physical and mental developmental capabilities of this age group of children, it is unlikely that to affect suicide data in a substantial way.

\section{National Violent Death Reporting System. The National Violent Death} Reporting System (NVDRS) was established in 2002 and then made available online in 2013. This database presents information on homicides, suicides, deaths where individuals are killed by law enforcement, unintentional firearm injury deaths, and deaths of undetermined intent. The NVDRS is also funded by the CDC, and the data is made freely available online (https://www.cdc.gov/injury/wisqars/nvdrs.html). It includes more sources than the National Vital Statistics System, using death certificates, coroner/medical examiner reports, law enforcement reports, and toxicology reports. However, the NVDRS only funds 18 of the 50 states to provide this in-depth violent death information. Therefore, the NVDRS is not considered a nationally representative data set. As states enter and leave the program, results from analyses are most helpful for 
the individual states involved or for preliminary guidance for prevention and policy in non-member states or nationwide initiatives.

\section{Morbidity Sources}

Suicide mortality data, while thorough and accessible, give an incomplete picture of the continuum of suicide related behaviors. As not all suicidal thoughts or suicide attempts result in death, mortality data alone is myopic. Information regarding suicide related behaviors are often a topic of great interest in many studies. While potential valid sources of morbidity information are numerous, several datasets require mentioning and greater evaluation in this paper.

Youth Risk Behavior Surveillance System. The Center for Disease Control's Youth Risk Behavior Surveillance System (YRBSS) is a nationally representative survey of $9^{\text {th }}$ to $12^{\text {th }}$ grade students in the United States. The survey has been administered every two years since 1991. National datasets are available online at no cost, while specific state, regional, territory, or tribal government datasets are available by request (https://www.cdc.gov/healthyyouth/data/yrbs/data.htm). The survey is cross-sectional, and designed to track health behaviors over time.

The self-reported nature of the Youth Risk Behavior Survey (YRBS) allows for investigation into suicide related behaviors such as suicidal thoughts, suicidal plan making, suicide attempts, and suicide attempts that resulted in treatment by a health care professional. The nature of the responses allows for capturing information that may not have been officially recorded elsewhere, such as with students without professional health care or mental health care or with suicide attempts that did not result in medical 
treatment. This provides a more complete view of suicidal behavior and its associations with other risk factors in the YRBS, but it is subject to reporting biases such as recall bias or social desirability bias. YRBS responses allow for distinctions in suicidal behavior by some racial and ethnic groups, but it does not allow for a deeper investigation into why certain inter-group differences may or may not exist. Additionally, as the YRBS is administered in schools, it does not capture the answers of youth who are not enrolled in formal education.

National Longitudinal Study of Adolescent to Adult Health. The National Longitudinal Study of Adolescent to Adult Health (Add Health; http://www.cpc.unc.edu/projects/addhealth) is a comprehensive, longitudinal and nationally representative survey of adolescents. Wave I began in 1995 with students in grades 7-12. Many of these students were re-interviewed in later waves with Wave II in 1996, Wave III in 2001-2002, and Wave IV in 2008. Wave V data began collection in 2016, with the full dataset not currently available. The Add Health survey asks about suicidal thoughts and attempts in the past year before the interview. The scope and time requirements of the data collection process were massive, making the Add Health database a unique resource. As a limitation, the Add Health data does not include participants not in the school system or individuals who immigrated later in life. Also, the self-reported nature of the data may be subject to social desirability bias and recall bias. Additionally, to maximize the protection of Add Health participants, the dataset is in two types, public and private. While public use data is freely available, private use data comes at a cost that may be prohibitive for some researchers. 
National Comorbidity Survey. The National Comorbidity Survey (NCS; https://www.hcp.med.harvard.edu/ncs/) is a nationally representative mental health diagnostic survey initiated in 1990 on an adult population. This population was reinterviewed in the NCS-2 in 2001. Additionally, in 2001, 10,000 new adult respondents were interviewed in the NCS Replication study (NCS-R) and 10,000 adolescents were surveyed in the NCS-A. The NCS includes questions on suicide, thoughts, plans and attempts, as well as the age of first behavior and most recent behavior. The use of diagnostic tools allows for the application of diagnostic labels to respondents. However, the age of the dataset creates problems as some diagnostic criteria for mental illnesses have changed since the data's original publication. Additionally, panel data, being collected a decade apart, does not well control for extraneous variables. Unfortunately, the NCS-A dataset is only cross-sectional, and the variables do not lend themselves to the study of immigrant, minority, and acculturation issues as well as the Add Health database.

National Survey on Drug Use and Health. The National Survey on Drug Use and Health (NSDUH; https://nsduhweb.rti.org/respweb/homepage.cfm) is a massive annual survey of 70,000 randomly selected participants aged 12 and over in the United States. The goal of the study is to provide information on alcohol, tobacco, and illegal drug use trends over time. The NSDUH also collects information on mental health issues, but this information is on adults only (aged 18 and above). The information is meant to give context to formal mental health service use and co-occurring disorders. Of the presented data sources, NSDUH appears best suited to track trends in adult suicide, mental health, and substance use in the United States over time as the NSDUH collects 
information on suicide, suicide planning, and suicide attempts. However, this dataset lacks the appropriate variables to study adolescent, immigrant, minority, and acculturation issues in detail.

\section{Suicide Data}

Suicide was the overall 10th leading cause of death in for all age groups in the United States, and the second leading cause of death for adolescents and young adults in 2014 (Heron, 2016). The CDC estimates that the crude rate for suicide mortality in 2015 was 1.98 per 100,000 individuals aged $10-14,9.76$ for individuals aged $15-19$, and 15.08 for individuals aged 20-24 years old (Centers for Disease Control and Prevention \& National Center for Injury Prevention and Control, 2005). In total, there were 42,773

reported deaths by suicide in the United States in 2014 (Heron, 2016). The rate of death by suicide increased by $3.9 \%$ from the previous year (Heron, 2016), and it has been increasing since 2000 (Figure 5, Figure 6). 
Figure 5. Total Suicides by Year, 1981 to 2017

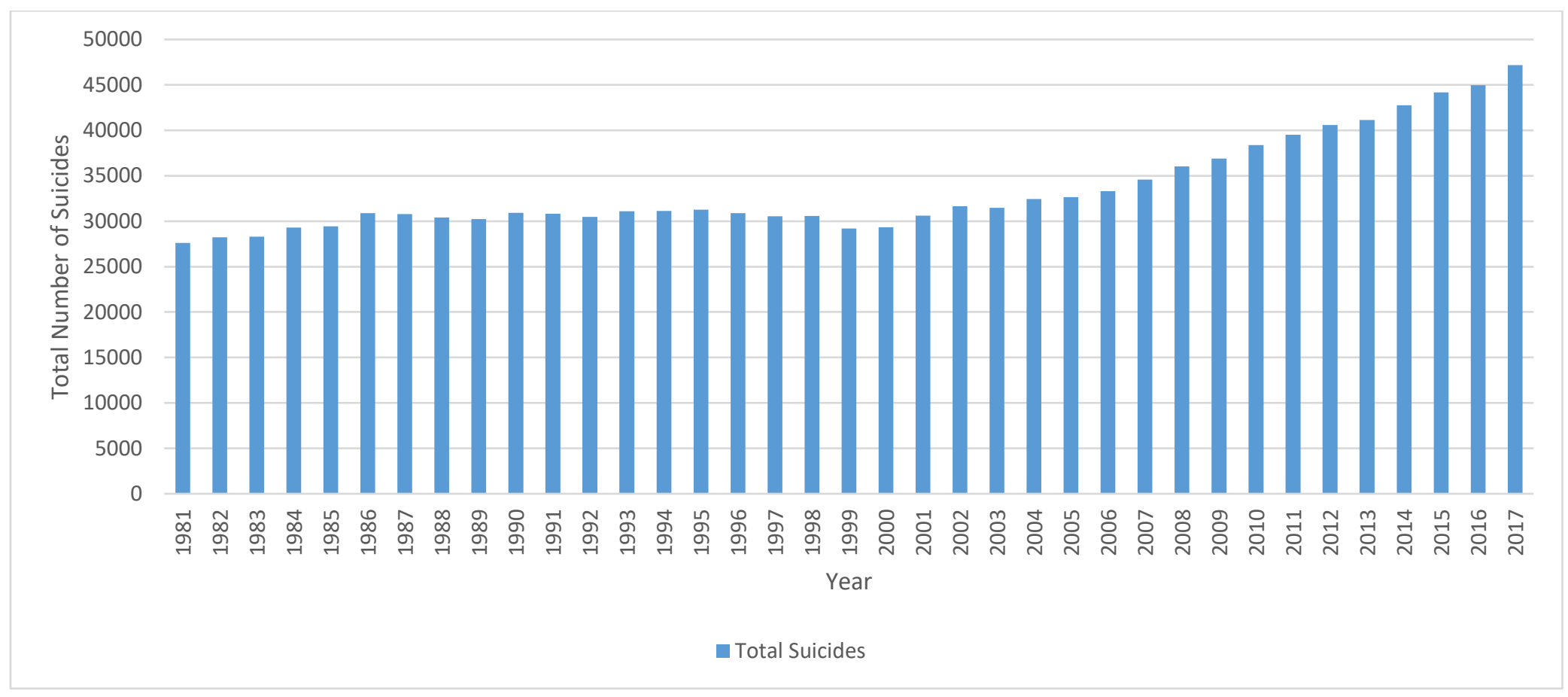

Source: Centers for Disease Control and Prevention. (2019). Web-based Injury Statistics Query and Reporting System (WISQARS) [Online]. National Center for Injury Prevention and Control, Centers for Disease Control and Prevention (producer). Retrieved from https://www.cdc.gov/injury/wisqars/fatal_injury_reports.html on July 7, 2019. 
Figure 6. Crude Rate of Suicide by Year, 1981 to 2017

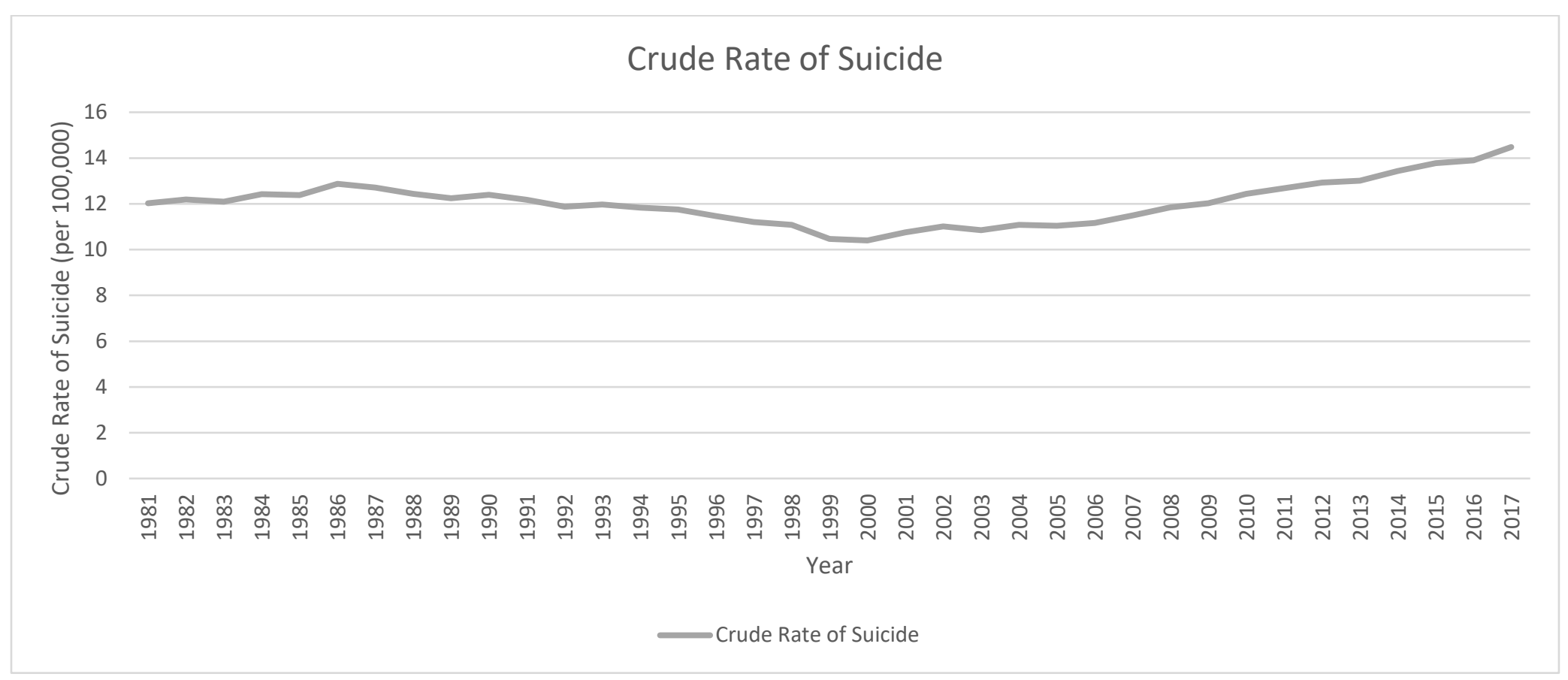

Source: Centers for Disease Control and Prevention. (2019). Web-based Injury Statistics Query and Reporting System (WISQARS) [Online]. National Center for Injury Prevention and Control, Centers for Disease Control and Prevention (producer). Retrieved from https://www.cdc.gov/injury/wisqars/fatal_injury_reports.html on July 7, 2019. 


\section{Racial and Ethnic Differences in Suicide Mortality}

Interesting trends emerge when dividing the vital statistics data by racial or ethnic group. Suicide affects different populations at different rates. The United States acknowledged that suicide was of pressing concern for the American Indian and Alaska Native group, and in response, politicians created the Garrett Lee Smith Memorial Act (Garrett Lee Smith Memorial Act, 2004). Even for the most recent data for the year 2017, suicide is the $8^{\text {th }}$ leading cause of death for non-Hispanic American Indian or Alaska Native individuals ( $3.1 \%$ of all deaths), while it is the $9^{\text {th }}$ leading cause of death for nonHispanic white individuals $(1.7 \%), 11^{\text {th }}$ leading cause of death for individuals of nonHispanic Asian or Pacific Islander descent (1.9\%), and the $16^{\text {th }}$ leading cause of death for non-Hispanic black individuals (Heron, 2019).

Vital statistic information also includes identification as Hispanic, in addition to a race, meaning, for example, one can be categorized as a Hispanic white or a Hispanic black. When including ethnic background information, suicide was the $9^{\text {th }}$ leading cause of death, accounting for $2 \%$ of all deaths, for all individuals of Hispanic descent in 2017 (Heron, 2019). The rates of death by suicide demonstrate a slightly higher risk in this ethnic group than their non-Hispanic Black and Asian American and Pacific Islander counterparts, following only non-Hispanic American Indian and Alaskan Natives and Whites (Figure 7). 
Figure 7. Suicide Rates per 100,000 by Race, Ethnicity and Year, 1990 to 2017

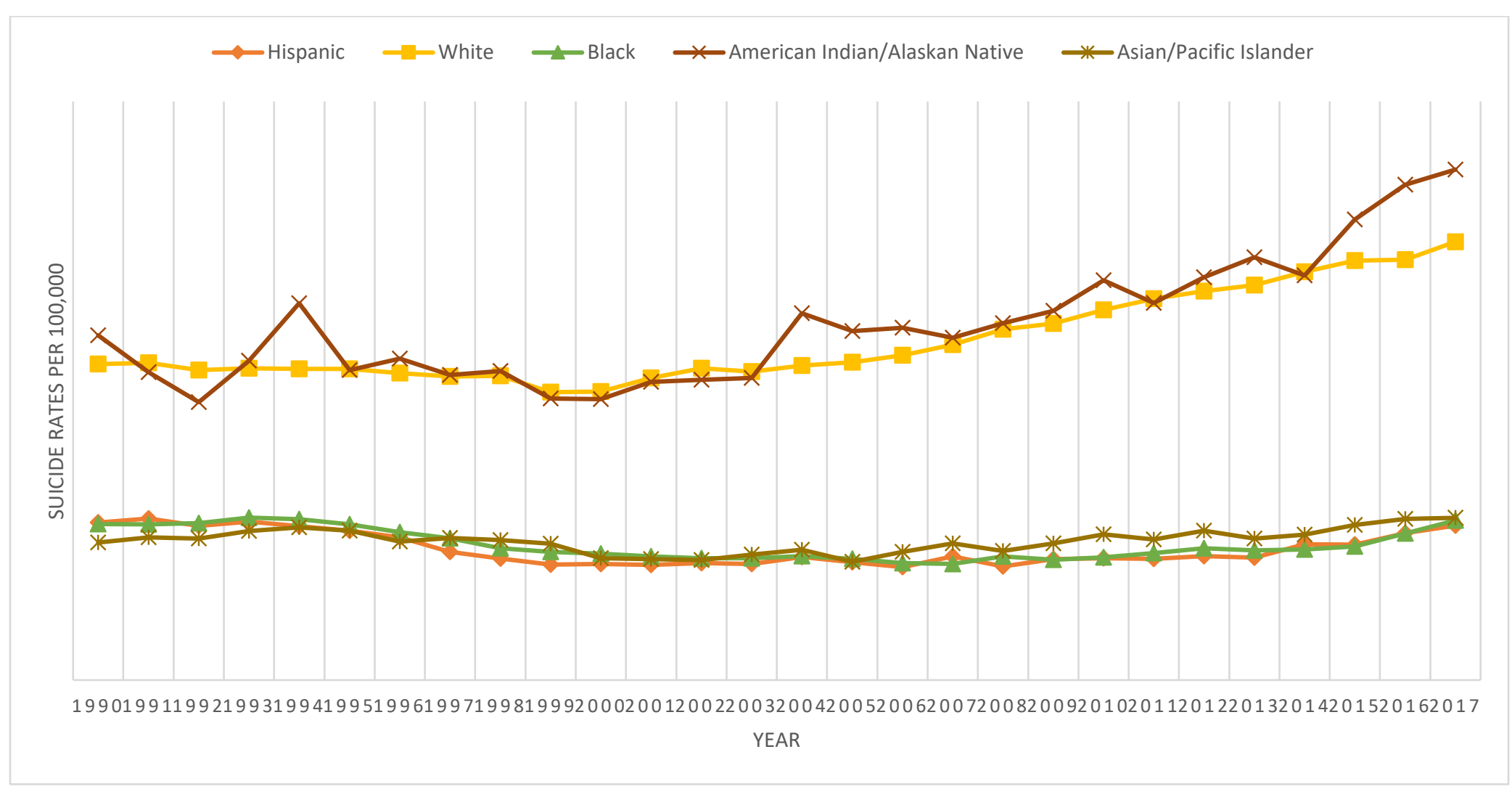

Source: Centers for Disease Control and Prevention. (2019). Web-based Injury Statistics Query and Reporting System (WISQARS) [Online]. National Center for Injury Prevention and Control, Centers for Disease Control and Prevention (producer). Retrieved from https://www.cdc.gov/injury/wisqars/fatal_injury_reports.html on July 7, 2019. 


\section{Mortality, Morbidity, Race, Ethnicity and Age}

Despite the apparent low death rates for certain racial and ethnic groups, suicide rates remain high in overall young age groups. Suicide is the second leading cause of death, after accidents, for age groups 10-14, 15-19, 20-24, and 25-34 (Heron, 2019). This is compared to suicide as the $10^{\text {th }}$ leading cause of death for all people (Heron, 2019). Suicide mortality appears to be an especially important problem of the young in the United States.

Realizing that suicide-related behaviors affect youth at much higher rates than older age groups, the annual YRBS, cited earlier, has the most up to date information on suicide morbidity in middle- and high-school aged populations. This survey polled youth in five areas related to suicide: feeling so sad or hopeless every day for two or more weeks in a row that they stopped doing some usual activities, seriously considering suicide, making a suicide plan, attempting suicide at least once, and having a suicide attempt that required treatment by a nurse or doctor. Overall, feeling sad or hopeless was higher among Hispanic students (33.7\%) than white (30.2\%) or black (29.2\%) students (Kann et al., 2018). Hispanic students were more likely to seriously consider attempting suicide (16.4\%) than non-Hispanic Black students (14.5\%) but less likely than nonHispanic White students (17.3\%; Kann et al., 2018). This was a shift from the previous report, when Hispanic students were more likely to consider attempting suicide than all other groups (Kann et al., 2016). In 2015, Hispanic students were more likely to have made a suicide plan (15.7\%) than non-Hispanic White (13.9\%) or non-Hispanic Black (13.7\%) students (Kann et al., 2016). In 2017, the range of response rates shrank with $13.5 \%$ of Hispanic respondents endorsing the creation of a suicide plan, versus $12.9 \%$ of 
non-Hispanic Black respondents and $12.6 \%$ of non-Hispanic White respondents (Kann et al., 2018). Finally, Hispanic students were more likely to attempt suicide (11.3\%) than non-Hispanic White (6.8\%) or non-Hispanic Black (8.9\%) students in the 2015 report (Kann et al., 2016). In the follow-up report, Black students were most likely to report attempted suicide (9.8\%) compared to Hispanic students $(8.2 \%)$ and non-Hispanic White students (6.1\%; Kann et al., 2018).

\section{Morbidity, Mortality, Age and Sex}

The research thus far has presented the relationship between race, ethnicity and suicide and age and suicide. Another known factor is sex. In 2017, death by suicide was the $8^{\text {th }}$ leading cause of death for males of all races, origins, and ages, accounting for $2.6 \%$ of all recorded deaths (Heron, 2019). For females of all races, origins, and ages, suicide was not one of the top 10 causes of deaths, which means that it accounted for less than 1.6\% of all deaths in this group in 2017 (Heron, 2019). Despite this, suicide is not inherently a male problem. In fact, information from the YRBS imply that females are more likely to endorse feeling sad or hopeless ( $41.1 \%$ vs. $21.4 \%$, respectively), seriously

considering attempting suicide (22.1\% vs. $11.9 \%)$, making a suicide plan (17.1 vs. $9.7 \%)$, attempting suicide $(9.3 \%$ vs. $5.1 \%)$, and having a suicide attempt that resulted in treatment by a doctor or nurse (3.1\% vs. $1.5 \%)$ than their male counterparts (Kann et al., 2017). The data implies that while males experience more suicide lethality, females, when asked to self-report, experience higher rates of suicidality, or males are underreporting their feelings of suicide morbidity behaviors 


\section{General Youth Suicide Correlates}

Evaluation of accepted sources of suicide morbidity and mortality data have presented several salient demographic factors that affect the rate of suicides, suicide attempts, and suicidal thoughts: racial and ethnic background, age, and sex. This section will explore the existing research in suicidology to discover additional variables relevant to youth suicide morbidity and mortality. The information is presented with Bronfenbrenner's ecological theory of development (Bronfenbrenner, 1979) and Vygotsky's zone of proximal development (Vygotsky, 1978) in mind, first focusing on the individual, and then moving outwards to that individual's family and peer relationships, organizational relationships, and relationships with the broader environment. These theories of development are further explained below, with the proposed theoretical model.

\section{Individual}

It has been previously mentioned that suicide and suicide related behaviors are theorized to exist on a continuum of lethality (Asarnow et al., 2008; Firestone \& Seiden, 1990; Lester, 1970; Sveticic \& De Leo, 2012; Tarrier \& Picken, 2011). In many studies on risk factors associated with suicide, previous suicidal ideation (Holland et al., 2016; O'Mara \& King, 2009; Thompson et al., 2009; Thompson \& Light, 2011), having a suicide plan (Stack, 2014), a history of self-injury (Taliaferro \& Muehlenkamp, 2014), easy access to lethal means (Centers for Disease Control and Prevention, 2016), and at least one previous suicide attempt (Centers for Disease Control and Prevention, 2016; Holland et al., 2016; O'Mara \& King, 2009; Pelkonen \& Marttunen, 2003) have all been found to correlate positively with suicide mortality. Additionally, self-injury was cited as 
the most important factor distinguishing youth, especially males, who solely consider suicide from those who self-reported a suicide attempt (Taliaferro \& Muehlenkamp, 2014). This empirical evidence gives growing credence to the applicability of the continuum theory in identifying individuals at high risk for suicide mortality.

Emotional distress and mental illness. Mental illness has long been indicated as a correlate of suicide related behaviors (Centers for Disease Control and Prevention, 2016; Pelkonen \& Marttunen, 2003). The presence of mental illness was found to be as high as $81-95 \%$ of child and adolescent suicides in psychological autopsy studies (Pelkonen \& Marttunen, 2003). However, this umbrella concept is comprised of a wide variety of behaviors, disorders, and component symptomologies. Foremost in empirical study is the relationship between suicide and depression.

Depression. Depression is the most commonly identified mood disorder in the psychological autopsy studies of child and adolescent suicide completions (Pelkonen \& Marttunen, 2003). The self-reporting of depression increased the odds of a self-reported suicide attempt, and it has been statistically shown to differentiate suicide attempters from individuals with thoughts of suicide (Stack, 2014; Taliaferro \& Muehlenkamp, 2014). Depression appears to remain a significant risk factor throughout youth, regardless of specific age (Fried et al., 2013). In a single study that tracked individuals for suicide risk from adolescence to adulthood, researchers found that individuals that developed suicide risk in adulthood and individuals whose suicide risk persisted from adolescence to adulthood had higher scores of depression that individuals who never had an observed suicide risk or whose suicide risk diminished upon measurement in adulthood (Hooven et 
al., 2011). Additionally, Thompson and Light (2011) found depression at baseline to be a salient factor in predicting suicide risk both one and seven years after baseline in their study of the Add Health database. This demonstrates that the importance of depression may persist throughout youth and into adult development.

Isolation and Connectedness. A concept related to, but not specific to, depression that is a commonly suggested risk factor of suicide is social isolation (Centers for Disease Control and Prevention, 2016). In a review of population-based psychological autopsies and clinical studies, Pelkonen and Marttunen (2003) presented a single study where non-working, non-student youth were much more likely to complete suicide. While the authors related this to the role of social isolation predicting suicide, this may also be due to the presence of extreme obstacles or stressors in a youth's life that prevent school attendance or the ability to seek or hold employment. Related to this area, in a study of Canadian youth's enjoyment, stress, and participation in a variety of activities, greater levels of engagement in non-problem behavior were correlated to self-esteem, connectedness to others, health, and lower depressive symptoms, which predicted lower suicide risk (Ramey et al., 2010). This supports the findings of other studies where family, peer, and teacher connectedness protected against suicide. The authors suggest that whereas isolation may increase suicide risk, engagement and connectedness protect against suicide risk.

Hopelessness. Like isolation, hopelessness may be studied as either part of the constellation of behaviors related to depression or as its own stand-alone variable. Hopelessness is often cited as a risk factor for suicide (Centers for Disease Control and 
Prevention, 2016; O'Mara \& King, 2009; Thompson et al., 2009), though empirical evidence for hopelessness as a stand-alone variable in youth specific suicidality was difficult to locate. In a nationally representative cross sectional study on high school aged youth, Taliaferro \& Muehlenkamp (2014) found both hopelessness and depression as important factors to distinguish youth with thoughts of suicide or youth with at least one suicide attempt from youth without suicidality.

History of trauma. Traumatic events in a youth's life are experiences where the individual or another person in that individual's life encounters or is threatened by compromised safety, serious injury, or death (Singer \& Smith, 2013). These events may leave lasting emotional responses that impact day-to-day life, and traumatic events have been linked to the psychological diagnoses such as posttraumatic stress disorder, acute stress disorder, adjustment disorder, and depression (Mastnak \& Resick, 2004). While trauma can take many forms, of special interest in relation to youth suicide are events of physical and sexual abuse.

Physical and sexual abuse are both recognized risk factors of suicide (Centers for Disease Control and Prevention, 2016; E. Christiansen et al., 2011; O’Mara \& King, 2009). In a study of Canadian street youth researchers found those individuals that selfreported a suicide attempt in the previous six months were also more likely to report some type of childhood abuse: $40.6 \%$ endorsed childhood physical abuse and $26.5 \%$ reported childhood sexual abuse (Hadland et al., 2012). However, given the small and marginalized population, the snowball sampling method used may not provide accurate or generalizable statistics. Better evidence may come from Fried et al. (2013), whose 
analysis of the Add Health database provided evidence that of a nationally representative selection of students from the United States, childhood sexual abuse was predictive of suicide attempts in high school $11^{\text {th }}$ graders.

Substance use. General accepted knowledge on suicide risk warns of a connection to substance abuse. The public is warned specifically of a relationship to a history of alcohol or substance abuse, both in adults and youths (Centers for Disease Control and Prevention, 2016; Davidson, Potter, \& Ross, 1999; O’Mara \& King, 2009). Studies of psychological autopsies have found diagnoses of substance abuse or dependence in approximately $25 \%$ to $66 \%$ of studied adolescent suicides, with additional evidence of substance misuse in more deaths where the diagnostical criteria of substance abuse and dependence was not met (Pelkonen \& Marttunen, 2003). In their study of longitudinal survey data, Hooven and colleagues (2011) did not find a significant difference between youths at risk for suicide and not at risk for suicide during their adolescence in terms of drug involvement or other high-risk behaviors, but these same predictors in young adulthood were correlated to suicide risk in adulthood. The youths in the Hooven study ranged from $9^{\text {th }}$ grade to $12^{\text {th }}$ grade, and they are not further distinguished by age. When specifically breaking down the youth's age groups to compare $9^{\text {th }}$ graders to $11^{\text {th }}$ graders, Fried and colleagues (2013) found a seemingly contradictory result with a study of the Add Health dataset: illegal drug use was a significant predictor of suicide attempt at $9^{\text {th }}$ grade but not for older high schoolers in $11^{\text {th }}$ grade. A study on engagement of Canadian youths and suicide risk might shed more information; youths that listed a problem behavior such as substance abuse as their most important activity had significantly more risk for suicidal thoughts and attempts than 
youth engaged om other activities or even youth that did not report any important activities (Ramey et al., 2010). This suggests an area of exploration where it is not just drug use or frequency, but commitment to drug use as an important part of the youth's life. Additionally, type of drug used may also further distinguish suicide risk. Stack (2014), in a study of youth suicide morbidity from the Youth Risk Behavior Survey, found that of marijuana use, cocaine use, and alcohol binge use, only cocaine use could significantly distinguish suicide ideators from attempters. Cocaine had the second strongest statistical relationship in this particular study, following only 'having a suicide plan', ahead of violence, major depression diagnosis, risky sexual behavior, school integration, and demographic factors (Stack, 2014).

Aggression and violence. The Surgeon General's report on suicide (Davidson et al., 1999) and Centers for Disease Control and Prevention (Centers for Disease Control and Prevention, 2016) present a relationship between impulsivity, aggressive tendencies and suicide risk. It should be noted that evidence exists for a relationship between both perpetrators and victims of aggression and violence to suicide risk. In a study of Asian American and Pacific Islander youth living in Hawaii, researchers found significant relationships between suicidal thoughts, plans, and attempts for victims of anger and emotional abuse, social status inequality, intimidation, threats, sexual coercion, isolation and exclusions, peer pressure, and physical violence (Else et al., 2009). In the same study, students that had thoughts, plans, and attempts of suicide were also more likely to be perpetrators of anger or emotional abuse, intimidation, threats, isolating or excluding behaviors, exerting peer pressure, and physical violence (Else et al., 2009). In an analysis of the Youth Risk Behavior Survey dataset, researchers found that violence, particularly 
fighting resulting in injury, dating violence, and weapon carrying, differentiated both suicide ideators from suicide attempters and suicide attempters from non-suicidal youth (Stack, 2014). Therefore, when considering violence and suicide, interventionists should evaluate both perpetrators and victims carefully for suicide risk.

Help seeking and problem solving. There is some evidence that individuals who have learned how to problem solve or are at least willing to seek help for suicide are better protected from suicide. It is generally accepted that ongoing skill building in problem solving, conflict resolution, and nonviolent ways of handling conflict build resiliency against suicide in youth (Centers for Disease Control and Prevention, 2016; Davidson et al., 1999), whereas poor social problem-solving abilities (O'Mara \& King, 2009) and an aversion to seeking help, potentially because of the stigma of mental health treatment and suicidality (Centers for Disease Control and Prevention, 2016; Davidson et al., 1999), exacerbate suicide risk. These problem-solving skills and help seeking behaviors can be built into the youth's repertoire of crisis and suicide de-escalation.

Curiously, the empirical evidence for this is ambiguous. In a study of Canadian youth engagement, researchers found a relationship between perceived coping ability and suicidality, but this relationship was not as statistically strong as depressive symptoms, low self-esteem, connectedness to others, and health concerns were in predicting suicide risk (Ramey et al., 2010). Additionally, being in counseling, presumably the setting where youth can learn and exercise help seeking and social problem solving skills, was predictive of suicide risk in $11^{\text {th }}$ grade students in the United States (Fried et al., 2013). This finding is related, but complicated. With careful reading of the methodology, it may 
be that being in counseling, without knowing the type or for what reason, was more likely in students with advanced mood disorder symptomology or existing suicidality. The area of focus was on the reduction of harm as opposed to the prevention of future crises. While the assertion that help-seeking and problem-solving skills would be protective of suicide risk makes theoretical sense, that data to support such claims for United States youth is currently lacking.

Academic Achievement. The school is an important setting in youth life and a site of interest in studies related to suicide. Researchers have found that academic achievement and fondness for school were associated with a reduced likelihood of suicide attempts in both male and female youth and could distinguish between suicide attempters versus individuals with no suicidality (Taliaferro \& Muehlenkamp, 2014). In a review of population-based psychological autopsy suicide studies, problems in school such as failing a grade, being suspended from school, and dropping out of school were found to be a risk factors for suicide (Pelkonen \& Marttunen, 2003). Additionally, a recent legal or disciplinary crisis was also associated with an increased risk in suicide attempts (O'Mara \& King, 2009; Pelkonen \& Marttunen, 2003).

Biology. Some sources have suggested that individuals with thoughts of suicide, suicide attempts, or completed suicides may be physiologically different from others. Age has already been discussed as influential on suicide morbidity and mortality. Additionally, normal physical development may influence suicide morbidity at certain points of adolescence. In their study of $9^{\text {th }}$ and $11^{\text {th }}$ graders, Fried et al. (2013) found that delayed or matured physical development, as determined by onset of puberty and self- 
reports of physical development in comparison to their peers, made $9^{\text {th }}$ grade females four times more likely to attempt suicide than those that reported normal development; $9^{\text {th }}$ grade males with delayed physical maturity were less likely to attempt suicide than their on-time or matured counterparts. However, these physical predictors were no longer relevant by the time the sample group reached the $11^{\text {th }}$ grade (Fried et al., 2013), suggesting a narrow window of time where physical changes related to puberty strongly influence suicidal morbidity.

Other biological explanations have revolved around biologically based causes of depression. Many theories have been presented by the medical fields, such as abnormalities in serotonin functioning (O’Mara \& King, 2009). Many of these such theories, as gene and environment interaction, abnormal neurotransmitter activity, or disturbed interactions between the parts of the brain, remain relevant and worthy of further study but are outside the scope of this social science investigation.

\section{Interpersonal}

Youth relationships with peers and romantic partners may impact the likelihood of suicide ideation or suicide attempts. These social relationships may increase youth emotional distress. One of the reviewed emotional stressors included interpersonal loss, which increased the likelihood of completed suicide for both sexes but had a greater impact on males than females (Pelkonen \& Marttunen, 2003). Other emotional stressors were relationship problems or relational loss (Centers for Disease Control and Prevention, 2016). As with family relationship problems, peer and dating partner relationship problems were commonly found in completed suicides in in the United 
States of youth aged 11-15 recorded in the National Violent Death Reporting System (Holland et al., 2016). The loss of a romantic relationship is commonly cited as a precipitating event for youth suicide (O’Mara \& King, 2009).

Related to youth loss, researchers have identified a suicide contagion effect. Individual youths are at higher risk to attempt or complete suicide if a friend has had a history of suicide (Fried et al., 2013; Thompson et al., 2009; Thompson \& Light, 2011). Individual youths are also more likely to attempt or complete suicide if there has been a local epidemic of suicide (Centers for Disease Control and Prevention, 2016; Davidson et al., 1999; O’Mara \& King, 2009). Some researchers have suggested that youth suicides may be prevented by responsible reporting of local suicide events (Pelkonen \& Marttunen, 2003), but empirical evidence on the topic is currently lacking.

\section{Family}

The family microsystem exists as the individual's most immediate connection to the larger community. In some theoretical models, such as Vygotsky's zone of proximal development, it is also the setting of an individual's learning of norms, traditions, and culture (Vygotsky, 1978; Zayas et al., 2005). Interactions, and the quality of those interactions, between a youth and his or her family can have a strong impact on that youth's thoughts and behaviors. Current research has shown that there are common factors related to family that make an individual youth more likely to attempt or complete suicide.

Family history of mental health problems. Parental mental health issues have been regarded as indicators of risk for youth suicide (O’Mara \& King, 2009). Population- 
based psychological autopsy studies have suggested the presence mental health problems in the parents of youth suicides ranging between 15\% to $47 \%$ of studied cases (Pelkonen \& Marttunen, 2003). In one population based study of all Danish individuals born between 1983 to 1989 and their biological parents, researchers found that youth who had a suicide attempt were more than twice as likely to have parents with mental health issues, defined as ever having seen a psychiatrist for care, as opposed to youth without a suicide attempt (Christiansen et al., 2011). However, admitting that the Danish register encountered many of the same issues as other countries in the undercounting of death or injury as suicide or suicide attempt, the researchers acknowledge that the true number may be higher with some youth with suicide-related history being used as false-controls in the calculation of incidence rate ratios (Christiansen et al., 2011).

\section{Parental death and family history of suicide or suicide attempt. Less common}

than the presence of parental mental illness, parental death by suicide or parental suicide attempt has also been regarded as a significant risk factor for youth suicide (Centers for Disease Control and Prevention, 2016; Davidson et al., 1999; O’Mara \& King, 2009). In a review of suicide studies, the presence of a family history of suicide or suicide attempt ranged from $2 \%$ to $30 \%$ of youth suicides (Pelkonen \& Marttunen, 2003). In the same study of the Danish population mentioned above, youth with a suicide attempt were 1.56 to 1.73 times more likely than controls to have a dead biological parent, but if that parent was recorded as dead from suicide, the likelihood of youth suicide attempt increased, especially for males (E. Christiansen et al., 2011). Danish youth with a suicide attempt were more than three times more likely to have a parent with a suicide attempt (E. 
Christiansen et al., 2011). Of all parental risk factors, biological parent death by suicide had the greatest mathematical impact on youth suicide (E. Christiansen et al., 2011).

Despite being a population-based study, the results' relevance to the American population may be in question. Looking at the Add Health database, a nationally representative sampling of students in the United States, researchers found a correlation between family suicide or suicide attempt to youth suicide attempt at both one and seven years after baseline, but they also found that while non-suicide parental loss increased the likelihood of suicide at 1 year after baseline it was not statistically significant at 7-year follow up (Thompson \& Light, 2011). The study did not distinguish parental suicide attempts from parental deaths by suicide. While a death in the family can be traumatic, parental death by suicide may have a longer-lasting impact on the youth through his or her development. Additionally, while parental suicide or suicide attempt history may be an uncommon risk factor, much rarer than the presence of mood disorder or lower income, it may be of greater relevance to the interventionist or the creation of a suicide prevention plan.

Family connectedness. Growing empirical research has suggested that perceived support from family and the community can protect against suicide (Centers for Disease Control and Prevention, 2016; Davidson et al., 1999; Hooven et al., 2011). Family connectedness seems to be of great importance in youth suicide studies. This connectedness appears to move beyond the simplified classifications of divorced, deceased, or absent parents. Large scale reviews of psychological autopsy studies of youth suicides found that while youth who had completed suicide were more likely to 
come from non-intact families of origin, poor communication with either parent and general parent-child discord were more likely and potentially more influential in youth suicide cases (Pelkonen \& Marttunen, 2003). A qualitative study of medical examiner and law enforcement reports on youth suicides in the United States supports these findings with their own results: relational issues between the youth and his or her parents were one of the most common antecedents to suicide found in post mortem investigations (Holland et al., 2016). As with academic achievement and community engagement, in massive nationally representative samples of youth, parental connectedness appears to protect against suicidal thoughts, attempts, and completed suicides (Taliaferro \& Muehlenkamp, 2014). This empirical support gives interventionists a strong starting setting for suicide prevention - examining the relationship between the youth and his or her family members.

Low income. Youth at risk of suicide may come from families with low incomes. In a study of the entire Danish population, youth with completed suicides were more likely to have parents whose incomes put them in the lowest third of all earners (E. Christiansen et al., 2011). In the United States, studying youth from the Add Health database, researchers found that having a mother on welfare was a risk factor for a suicide attempt in the $9^{\text {th }}$ grade but not for those same students as they reached the $11^{\text {th }}$ grade (Fried et al., 2013). In either case, the exact mechanisms as to why being low income is a risk factor, one that a youth may or may not grow out of, are unclear. Having a lack of capital at a family's disposal is a stressor that may spur family conflict, and a lack of community resources in low income areas is an obstacle to early information, identification, and treatment of suicidality. 


\section{Broad Environmental Conditions}

Several other factors from the broader social environmental context have also been acknowledged in the literature for their impact on suicidality. First, researchers found that perceived neighborhood safety had a protective impact on self-reported suicide morbidity. Higher levels of perceived neighborhood safety were associated with a reduced likelihood to have a suicide attempt versus no suicidality and to distinguish suicide attempters from individuals with only suicidal ideation (Taliaferro \& Muehlenkamp, 2014). This falls in line with previous research associating safe neighborhoods with improved individual and community health.

Secondly, cultural and religious beliefs regarding suicide have been acknowledged by the Department of Health and Human Services as being important in addressing suicide related behaviors (Davidson et al., 1999). These can exist as either risk or protective factors. Professionals must utilize cultural intelligence to work with diverse populations self-reporting suicide morbidity, as beliefs may range from defining suicide as a "noble resolution of a personal dilemma" (Davidson et al., 1999, p. 9) to a violation of the sanctity of life (Centers for Disease Control and Prevention, 2016).

Third, access to effective physical, mental health, and substance abuse care in the community has been reported as a protective factor against suicide morbidity and mortality. In the Surgeon General's Call to Action to Prevent Suicide (1999), access to clinical interventions, supportive medical and mental health care relationships, and general support for help seeking enhance suicide resilience. Additionally, barriers to care, 
stigma in seeking help, or lack of help resources were all found to be risk factors for suicide (Centers for Disease Control and Prevention, 2016; Davidson et al., 1999).

\section{Latina Youth and Suicide Related Behaviors: Theorized Correlates}

The initial evaluation of the existing suicide morbidity data raises an interesting question: Why are Latina youth in the United States more likely to feel sad or hopeless, more likely to seriously consider suicide, more likely to have made a suicide plan, and more likely to have attempted suicide than Non-Hispanic White youth? Some researchers posit that cultural factors lead to the increased risk of Latina youth for suicide, particularly those factors that impact the relationship between the Latina American youth and her family. To cast a broad net, a literature review of Latina suicide research was conducted on articles published in the past decade. The results were limited, but they were categorized, summarized and briefly critiqued below.

\section{Acculturation}

Primary in these discussions of Latina youth suicide are issues of acculturation. Acculturation refers to the process of transformation and adaptation that occurs at the intersection of two cultures on the individual or macro level, whether this is a unidirectional or bidirectional exchange, and also the resultant level of adaptation by the group or individual (Harrison, 2003). In this case, it is the Latina youth and her family's encounter with the majority culture of the United States. Acculturative stress results from conflicts between the majority and minority cultures that are problematic for day to day life but can be overcome by the individual during the acculturation process (Berry, 2006). However, if there are stressors resulting from acculturation that can't be coped with, the 
result is psychopathology, requiring outside assistance to re-establish healthy functioning (Berry, 2006). Other authors present a definition of acculturative stress that relates the unique stresses of the immigration experience. Here acculturative stress may result from pre-immigration conditions, the reasons prompting immigration, family disruption and separation due to immigration, concerns about legal status of family members, conflicts between expectations and the reality of immigration, economic stress, discrimination, prejudice, racism, and differing rates of adjustment between the generations of the family (Rogers-Sirin et al., 2014).

In an exploratory, qualitative study comparing adolescent Latinas with nonsuicidal self-injurious (NSSI; $n=18$ ) behaviors, adolescent Latinas with at least one suicide attempt $(n=29)$, adolescent Latinas who used both NSSI and also had at least one suicide attempt $(n=8)$, and adolescents with no reported lifetime self-harm $(n=29)$, Gulbas, Hausmann-Stabile, De Luca, Tyler, and Zayas (2015) found that many participants reported transnational stress, defined as the "explicit and communicated desire by participants to return to their country of origin as a result of the stress produced by their daily life in the United States" (p. 309). A fragmented family structure, from divorce, separation, death, or immigration, also impacted girls' decision to self-harm or commit suicide, as did distress from their separation from families members, even after reunification (Gulbas et al., 2015). Given the small sample size and qualitative nature of the study, the authors' attempts to quantify how often common themes occurred throughout the interviews seems statistically inappropriate and are not included in this review to distinguish suicide attempters from the NSSI group. However, the results do 
give preliminary credence to the assumption that acculturative stress is relevant to Latina youth suicide behaviors.

In the above study, participants also cited bullying, including racial and ethnic discrimination, prior to NSSI or suicide attempt (Gulbas et al., 2015). In an earlier study, Romero and colleagues (2013) found Latina girls bullied at school were 1.5 times more likely to report a suicide attempt in the past year, 1.32 times more likely to create a suicide plan, and 1.2 times more likely to have suicidal ideation. Interestingly, in the same study, Romero et al. (2013) found that being a bully at school made the Latina girl more 1.5 times more likely to have suicide ideation, 1.4 times more likely to create a suicide plan, and 1.28 times more likely to have a suicide attempt in the last year. However, bullying was not specifically defined as being due to discrimination or minority status. Additionally, not all results were found to be statistically significant, though these discoveries create a thought-provoking starting point for further investigation.

\section{Familism}

Also, key in the discussion of Latino cultures is the complicated construct of familism or familismo. In the development of an inclusive definition of familism, Lugo Steidel \& Contreras (2003) described four key components: the belief that the family as a whole comes before the individual, even to the point of sacrificing the needs and desires of the individual; the obligation of the individual to maintain a strong emotional and physical connection with the family, as evidenced in such ways as geographical proximity, daily socializing, or caregiving; the expectation that family members will 
provide support to one another in times of need; and finally that all family members are expected to maintain and defend the family honor. In a qualitative study on both Latina girls who had attempted suicide and Latina girls who had never attempted suicide, Nolle and other researchers (2012) found that both groups reported sacrificing themselves for the greater family good, including emotional sacrifices, material sacrifices, and rationalizing one's death as a way to make things better for the family.

Familismo, with its high levels of interpersonal connectedness and tight-knit family groups, has been conceptualized as a protective factor for adolescents, keeping them from engaging in risky behaviors (Gulbas \& Zayas, 2015). Peña and colleagues (2011) found that that participants who reported high levels of familism were more likely to be from what researchers described as "tight-knit families" (p. 335); these families were high in cohesion and low in conflict. Moreover, tight-knit families were less likely to have a Latina adolescent suicide attempt than "loose-knit families" or "intermediate families" (Peña et al., 2011). While this study provides provisional evidence for the Gulbas and Zayas hypothesis, methodological difficulties requires that more work be done in this area - sampling was non-random and therefore non-generalizable, the sample size only consisted of 107 suicide attempters and 109 suicide non-attempters, and the design is cross sectional which cannot determine whether suicide attempts were due to family type or vice versa, among other issues.

Other researchers have suggested that familism comes into conflict with the Latina youth's development of autonomy, threatening the family unit (Zayas et al., 2005). This may be more evident when the Latina youth is at a different level of acculturation 
than the parents, displaying different cultural values, and may find familism to be oppressive in developing individual autonomy and identity (Gulbas \& Zayas, 2015). It is hypothesized that intergenerational acculturation differences lead to interpersonal conflicts within the family unit which in turn creates an environment for suicidal behaviors to develop (Zayas \& Pilat, 2008).

\section{Connectedness}

It is possible that Latinas turn to suicide and suicide-related behaviors within an environment of cultural conflict because of a disconnectedness or a lack of social support, particularly from family members. Family stressors are often cited by Latina girls, as opposed to peer group stressors, as antecedents to suicide-related behavior (Zayas \& Pilat, 2008). In a mixed methods study on New York City Latina youth and their mothers, Zayas and fellow researchers (2009) found no significant differences between suicideattempters and non-attempters on scale results for acculturation and familistic attitudes. Instead, the researchers found a difference in mutuality, or "how attuned the girls and mothers felt they were with each other" (p. 359), and mother-daughter communication, with suicide attempters rating both variables as lower than non-attempters (Zayas et al., 2009). Additionally, researchers in the same study found that small increases in the measures of mutuality and communication decreased the probability of suicide attempt (Zayas et al., 2009). However, Zayas \& Pilat (2008) theorized that intergenerational differences in acculturation may be connected to poor mutuality as parents are inexperienced with dealing with the child's problems and day-to-day experiences, further developing an environment for interpersonal conflict. 
In a quantitative study using the National Longitudinal Study of Adolescent to Adults Health (Add Health; (Piña-Watson et al., 2014), mother connectedness and father connectedness were both negatively correlated with suicidal ideation, though neither was found to be statistically significant. However, parents' interest in the adolescent's school life was statistically significant in models where the child had one parent or both parents (Piña-Watson et al., 2014). In another study using the Add Health dataset, De Luca et al. (2012) found that suicide attempts were associated with having a suicidal friend and lower perceived parental support, and suicidal ideations were associated with having a suicidal friend, lower perceived teacher support, lower perceived father support, and lower overall parental care.

Several studies have made efforts to describe the environment that fosters suiciderelated behaviors in Latina adolescent girls following analysis of qualitative interviews. Latina adolescent females that had attempted suicide or displayed NSSI both mentioned themes of family conflict and parental criticism as a precursor to their actions (Gulbas et al., 2015). Many interviewees describe recurring themes of subjective distress, interpersonal discord and emotional isolation that precede a suicide attempt (Gulbas \& Zayas, 2015). Additionally, following the idea of the influence of mutuality, researchers have attempted to describe the families of attempters and non-attempters as reciprocal, asymmetrical, or detached in their styles of commitment, respect, authority, and awareness towards its members; families of non-attempters tended to be reciprocal in nature while families of former suicide attempters were categorized as asymmetrical or detached (Gulbas et al., 2011). A quantitative study that attempted to categorize family types, this time a tight-knit, intermediate-knit, or loose-knit, was published in the same 
year, found families that researchers described as tight-knit (high cohesion, less conflict) were significantly less likely to have teens who attempted suicide (Peña et al., 2011). The researchers theorized that in this scenario, familism was a protective factor, strengthening the family environment to prevent risk of suicide (Peña et al., 2011).

\section{Mental Health}

As expected, depression was found to be significantly related to suicide related behavior in multiple studies. In college-aged Latinas, Chesin and Jeglic (2012) determined that depression, loneliness, hopelessness, delinquency, and a less positive social problem solving orientation were all statistically significant predictors of suicidality. In younger Latina groups, Romero et al., (2013) concluded that girls that reported depression in the past year were 5.1 times more likely to consider suicide, 3.4 times more likely to plan a suicide, and 4.7 times more likely to attempt suicide than girls that did not report depression in the past year. Using the Add Health database, depression was a significant predictor of suicidal ideation using logistic regression data analyses (Piña-Watson et al., 2014). All the above studies were cross-sectional in nature. At this point, it is impossible to say that depression itself is the root cause of later suicide related behaviors, or that some other factor, perhaps the family context, extends its influence over both variables.

\section{Substance Use}

Associations between Latino youth suicide related behaviors and substance use remains unclear. In an analysis of the Youth Behavior Risk Survey, Latina high schoolers were more likely to report suicidal ideation in the past year with greater lifetime cigarette use and greater lifetime marijuana use (Eaton et al., 2011). However, this association 
with lifetime cigarette use was also shared by the non-Latino white group and the association with lifetime marijuana use was also shared by the non-Latino white and the non-Latino black/African-American groups, showing these risk factors to be poor indicators of the differences in suicide ideation and attempt rates between racial groups (Eaton et al., 2011). In a later study of the YRBS, Pena, Matthieu, Zayas, Masyn, \& Caine (2012) published that Latinas with previous suicide attempts were more likely to be categorized as low substance use and violent behaviors. Curiously, Hispanic boys were more likely to endorse extreme substance use and violent behaviors (Pena et al., 2012). While substance use in this population is an area that requires more study, substance use alone is a poor indicator of suicide related behaviors in the Hispanic youth population.

\section{Critique}

The conceptual model of Latina suicide attempts (Zayas et al., 2005) appears to make theoretical sense after evaluating the reviewed empirical research. The studies evaluated were exploratory in nature but focused on the target population and have been carried out with high-quality methodologies. However, these conclusions, drawn from Latina-specific samples may not necessarily Latina-specific.

The Hispanic cultural concept of familism has been measured quantitatively by analyzing parent-child connectedness and child independence, but the argument could be made that many cultures share this family-first mentality with deference to the parents until adulthood or even marriage, muddying the applicability of these two predictors in distinguishing Latina suicide morbidity from all suicide morbidity. 
Additionally, acculturation is not a Hispanic-only predictor, and this predictor may potentially apply to all minority populations, including non-immigrant minorities such as Native Americans or Alaskan Native peoples.

Finally, mental health and substance use were common predictors in studies of Latinas and suicide morbidity, but both predictor variables are commonly accepted in suicidology as important risk factors in general. While Zayas and colleagues provide ample reasoning for these factors to be important in the evaluation of Latina suicide, there is no specific explanation that the model could not apply to all female youth, regardless of racial/ethnic background.

Table 1 provides the variables the empirical literature most consistently suggest have a relationship with suicide and or suicidality and such variables are measured in the Add Health dataset. Given the lack of mortality data, the focus of this study is on suicide morbidity, thoughts of suicide and suicide attempts as reported by the female youth. Further, this study intends to stay close to the conceptual model of Latina suicide (Figure 4). To describe the family sociocultural environment, this study evaluates age and gender as representation of adolescent development. A measurement of acculturation levels reflects the individual's culture and cultural traditions. Public assistance use, mother connectedness, and father connectedness reflect overall family functioning. Autonomy granting, used to express familism, represents a dynamic relationship between all three of the above areas of the family sociocultural environment. The individual's emotional vulnerability and psychosocial functioning are demonstrated with a measure of their feelings of depression, alcohol use, drug use, history of sexual abuse, history of family 
suicide, history of peer suicide, feelings of neighborhood safety, and feelings of teacher's care.

Table 1. Correlates for Female Youth Suicide Morbidity as Identified by the Literature

\begin{tabular}{lll}
\hline \multirow{2}{*}{ Individual } & \multicolumn{1}{c}{ Risk Factors } & \multicolumn{1}{c}{ Protective Factors } \\
\cline { 2 - 3 } & Age & Acculturation \\
& Racial/ethnic self- & \\
identification & \\
& Feelings of depression & \\
Alcohol use & \\
& Drug use & \\
Sexual abuse & \\
Family & Family suicide & Mother connectedness \\
Public assistance & Father connectedness \\
Network & Peer suicide & Teacher care \\
& & Neighborhood safety \\
\hline
\end{tabular}




\title{
Aims and Hypotheses
}

The overarching purpose of this study is to investigate correlates related to female youth suicide morbidity, their differences and similarities in strength of relationship across racial/ethnic groups, and to determine if there is an impact on suicide attempts over time. The variables used for this study were selected from previous research in youth and Latina suicide and influenced by the proposed model of Latina suicide attempts (Figure 4). These variables were conceptualized as individual, family, and other risk and protective factors (Table 1). Secondary data from the National Longitudinal Study of Adolescent to Adult Health, Waves I-IV, will be used to perform both concurrent multivariate and generalized estimating equations analyses.

The aims and hypotheses of the study are as follows:

\begin{abstract}
Aim 1. To explore the concurrent relationship between Latina suicide ideation and the variables of interest.
\end{abstract}

Hypothesis 1.1: Higher reported age, score of depression, level of alcohol use, level of drug use, a history of sexual abuse, family use of public assistance, a history of parental suicide, and a history of peer suicide will be associated with a higher likelihood of suicide ideation.

Hypothesis 1.2: Higher reported level of acculturation, feeling of mother connectedness, feeling of father connectedness, feeling of teacher care, level of autonomy granting, and feeling safe in one's neighborhood will be associated with a lower likelihood of suicide ideation. 
Aim 2. To determine if the relationship between the variables of interest and Latina suicide ideation is different from the relationship between the variables of interest and suicide ideation in other, non-Latino racial/ethnic groups.

Hypothesis 2: The strength of the relationship between thoughts of suicide and acculturation, autonomy granting, mother connectedness, and father connectedness will be stronger in Latina youth compared to non-Latina female youth. All other factors will not be statistically different in Latina youth compared to non-Latina female youth.

Aim 3. To explore the concurrent relationship between Latina youth suicide attempts and the variables of interest.

Hypothesis 3.1: Higher reported age, score of depression, level of alcohol use, level of drug use, a history of sexual abuse, family use of public assistance, a history of parental suicide, and a history of peer suicide will be associated with a higher likelihood of suicide attempt.

Hypothesis 3.2: Higher reported levels of acculturation, feeling of mother connectedness, feeling of father connectedness, feeling of teacher care, level of autonomy granting, and feeling safe in one's neighborhood will be associated with a lower likelihood of suicide attempt.

Aim 4. To determine if the relationship between the variables of interest and Latina suicide attempts is different from the relationship between these factors and suicide attempts in other, non-Latina racial/ethnic groups. 
Hypothesis 4: The strength of the relationship between suicide attempts and acculturation, autonomy, mother connectedness, and father connectedness will be stronger in Latina youth compared to non-Latina female youth. All other factors will not be different in Latina youth compared to non-Latina female youth.

Aim 5. To evaluate the longitudinal impact between the variables of interest and female youth suicide attempts over time.

Hypothesis 5: There is a statistical relationship between all factors and suicide attempts at 1,6 , and 13 years after baseline.

Aim 6. To explore whether racial/ethnic group has a longitudinal impact on female youth suicide attempts 1, 6, and 13 years after baseline.

Hypothesis 6: Racial/ethnic self-identification will significantly impact the likelihood of suicide attempts at 1,6 , and 13 years after baseline.

In general, it is hypothesized that the presence of any individual risk factor will be associated with increased likelihood of suicidal ideation and suicide attempts.

Alternatively, it is expected that higher levels of acculturation, mother connectedness, father connectedness, and autonomy granting will be associated with reduced reports of suicidal ideation and suicide attempts. Individuals who neither report suicidal ideation nor suicide attempts will be more likely than their counterparts to score higher on protective factors and lower on risk factors. 


\section{Significance of Study}

An overview of the existing literature has demonstrated that Latina youth in the United States are more likely to feel sad or hopeless, more likely to seriously consider suicide, more likely to have made a suicide plan, and more likely to have attempted suicide than White or African American youth. Additionally, while Latinos in the United States remains one of the largest growing subpopulations, more research is required to better understand the correlates and triggers of Latina suicide morbidity and mortality. The information will be foundational in the evaluation of suicide risk and the formation of public health and therapeutic interventions. Finally, this study will track suicide morbidity risk over time, which will be a unique use of the dataset. 


\section{METHOD}

\section{Research Design}

This study used a quantitative, cross-sectional research design with secondary data from a nationally representative survey of United States youth to investigate Hypotheses 1 through 4. Data from Wave I, in-home interviews of the Add Health (Harris \& Udry, 2015) was used as it provides the largest possible sample for the variables of interest. This Wave I data and analysis also provided foundational information that can be used to guide future research on short- and long-term health outcomes for individuals who experienced suicide related behaviors in their youth. Wave I Add Health data was collected during in-home interviews conducted between April and December 1995. At this timepoint participants were 10 to 21 years old.

Hypotheses 5-6 were investigated using longitudinal analyses. Generalized Estimating Equations was used to model repeated measures with a binomial outcome. In this study, the there are two outcomes of interest: serious thoughts of suicide and suicide attempts. This methodology used the 20 risk and protective factors identified in Waves I through IV of the Add Health dataset, and it incorporated the outcome data from those same waves. Add Health researchers collected this follow-up data from 1996 to 2008, reinterviewing the participants from the original Wave I cohort.

The variables of interest to be examined for this study are: (a) age, (b) feelings of depression in the past week, (c) alcohol use in the past 12 months, (d) illicit drug use in the past 30 days, (e) history of suicide in the family, (f) history of peer suicide, (g) level of acculturation, (h) mother connectedness, (i) father connectedness, (j) level of 
autonomy granting, (k) neighborhood safety, (1) teacher care, (m) childhood social welfare encounters, (n) childhood physical abuse, (o) childhood forced sexual intercourse, and (p) mother or father public assistance use. The dependent variables of interests are (a) serious thoughts of suicide in the past 12 months and (b) number of suicide attempts in the last 12 months.

\section{Add Health Design}

The dissertation utilized Waves I-IV of the Add Health dataset (http://www.cpc.unc.edu/projects/addhealth). There are two forms of the Add Health dataset: public use and restricted use. The restricted use dataset provides access to information from all participants surveyed and interviewed throughout the data collection process. Due to the larger number of available participants, the restricted use dataset was used for this study.

The Add Health project was initiated in 1994, surveying students in grades 7-12. While it is not an annual survey, it continues to re-interview the initial cohort on a variety of new topics of interest to the study. This makes the Add Health project a massive undertaking that has followed the youth into adulthood, tracking social, behavioral, and biological information.

The emphasis on Wave I interview design was to collect information on factors that influence health and risk behaviors in adolescent students, including, but not limited to, family make-up, social and romantic relationships, personal traits, schools, and communities. While Wave I is comprised of an in-school interview sample and an inhome sample, the study uses the in-home sample. This is because individuals in the in- 
school sample were also available to be interviewed for the in-home sample, and the inhome interview includes the variables of interest, whereas the in-school sample does not.

Wave II was a follow up in-home interview that occurred in 1996, approximately one year after the completion of Wave I data collection. Most of the almost 15,000 students interviewed in Wave II were part of Wave I with several exceptions. Firstly, older youth that were in the $12^{\text {th }}$ grade in Wave I were not re-interviewed if they were not part of the genetic subsample. Students who were only in the disabled subsample in Wave I were not re-interviewed either. Also, 65 adolescents who were in the genetic subsample but not in the Wave I interview were interviewed at Wave II. Interview questions were like those in Wave I, with the omission of functional limitation questions, the removal of many demographic attribute questions already answered in Wave I, and the inclusion of sun exposure and nutrition questions.

Wave III data collection occurred between 2001 and 2002, six to seven years after Wave I and five to six years after Wave II. At this timepoint, most respondents were adults between 18 and 26 with 24 respondents between the ages of 27 and 28 years old. Of the respondents from Wave I, 15,170 were re-interviewed at home for Wave III. As the respondents were now adults, the nature of the questions changed significantly to reflect variables relevant to young adult health such marriage, cohabitation, sexually transmitted infections and diseases, and economic data. New in Wave III, though unused in this study, was the collection of biological specimens.

Wave IV data collection via in-home interview happened in 2008. The interviews lasted approximately 90 minutes and utilized both computer-assisted personal interview 
and computer-assisted self-interview, the mode changing with the sensitivity of the questions. At this timepoint, most respondents ranged in age from 24 to 32 with some participants up to 34 years old. Investigating variables salient to young adulthood, while many questions from the original Wave I questionnaire remained, new areas of focus included education, economic status, occupation, financial resources and stressors, sleep, nutrition, illness, fertility, romantic relationships, childhood mistreatment, substance abuse, criminal history, and military service. Additional genetic information was also collected.

Wave V data collection began in 2016 and continues into 2018. At the time of the study, the full dataset was not available for release. For future research, however, Wave $\mathrm{V}$ will be notable for its information on deaths of Add Health participants.

\section{Sampling strategy}

The Add Health study utilized a school-based stratified random cluster sample of United States high schools. To be included, high schools had to include an $11^{\text {th }}$ grade and have at least 30 students enrolled. The primary sampling frame of 80 United States high schools which were systematically chosen to be representative of all United States' high schools in terms of: region of the country (Northeast, South, Midwest, or West), urbanicity (urban, suburban, or rural), student body size, type of school (public, private, or parochial), and (5) ethnicity. These 80 participating high schools identified feeder schools, from which the researchers chose one to be paired with the high school, unless the high school included a grade seven; high schools with a grade seven were left unpaired. The result was 132 total schools. 
Students enrolled in these schools were nationally representative of all students in the United States enrolled in grades 7 through 12 in the 1994-1995 school year. Students were then stratified by school, grade, and biological sex. For the in-home interviews, approximately 17 students were randomly selected per stratum.

All students enrolled in the core sample schools, plus special population oversamples were also potentially available to be selected for the second phase of Wave I data collection: the in-home interview. These oversampled groups are important, as they include individuals of Latinx decent, including 450 adolescents of Cuban heritage and 437 adolescents of Puerto Rican heritage. In total, 12,105 adolescents were interviewed in-home for Wave I.

In-home interviews were primarily conducted in the adolescent's home and took one to two hours to complete, depending on individual responses. Responses were recorded electronically, with computer-assisted personal interviewing by a trained interviewer for topics deemed less sensitive and computer-assisted self-interviewing for sensitive topics. This additional layer of privacy was designed to maintain data security and minimize outside influence on student responses. Follow up samples draw directly from original respondents to Wave I, even if incarcerated or having moved from the original address. Respondents that moved out of the country could not be tracked.

\section{Data Management}

The Add Health data was obtained from the Carolina Population Center at the University of North Carolina at Chapel Hill. Access to the dataset is dependent on the creation of a new Add Health contract and the development of a data security plan. The 
Add Health contract includes expectations for the confidentiality of participant information. Application required the payment of a $\$ 850$ processing fee. Upon approval, data is delivered as SPSS data files with relevant codebooks.

\section{Study Sample}

For the dissertation, a subsample was selected from the total number of originally interviewed adolescents from the Wave I in-home interview. The subsample consisted of all female adolescents, $n=10,480$. This number changes with attrition and re-establishing of communication with respondents in subsequent waves of Add Health survey. Table 2, below, provides exact subsample numbers per wave.

Table 2. Female Respondents to the National Longitudinal Study of Adolescent to Adult Health

\begin{tabular}{lll}
\hline Wave & Female & Percentage of Total \\
\hline I & 10480 & 50.52 \\
II & 7556 & 51.27 \\
III & 8030 & 52.84 \\
IV & 8352 & 53.19 \\
\hline
\end{tabular}

\section{Measures}

\section{Dependent Variables}

This dissertation evaluated two separate outcome variables: suicide ideation and suicide attempts. 
Suicide ideation. Participants self-reported dichotomous answers to the question "During the past 12 months, did you ever seriously think about committing suicide?" (variable names H1SU1, H2SU1, H3TO130, H4SE1).

Suicide attempts. Participants self-reported ordinal answers to the question "During the past 12 months, how many times did you actually attempt suicide?" (variable names H1SU2, H2SU2, H3TO131, H4SE2). Potential answers were "0 times", "1 time", "2 or 3 times", "4 or 5 times", and "6 or more times". These were recoded into binomial outcomes with the levels "yes" or "no" due to limited responses in some of the previous levels such as "6 or more times".

\section{Factors and Covariates}

From the literature, 14 risk and protective factors were identified as covariates for the dissertation.

Age. Age was determined by subtracting the birth year $(\mathrm{H} 1 \mathrm{G} 1 \mathrm{Y})$ from the year the interview was completed (IYEAR).

Depression. A modified version of the Center of Epidemiological Studies Depression Scale (CES-D) was built in to the Add Health questionnaire at multiple data collection points. The original scale was found to be acceptable in use with children, adolescents, depressed patients, and representative young adult to adult community samples (Radloff, 1991). A shortened version of the CES-D was used in a longitudinal study on perceived autonomy and trajectories of depressive symptoms into adulthood, using the Add Health dataset. The authors found their shortened CES-D had adequate 
reliability (Cronbach's Alpha ranging from 0.79 to 0.81; Eagleton, Williams, \& Merten, 2016).

The questionnaire asks, "How often was the following true during the past week...":

“...You were bothered by things that don't usually bother you.” (H1FS1).

“...You didn't feel like eating; your appetite was poor.” (H1FS2).

“...You felt that you could not shake off the blues, even with help from your family and your friends." (H1FS3).

“...You felt you were just as good as other people.” (H1FS4).

“...You had trouble keeping your mind on what you were doing.” (H1FS5).

“...You felt depressed.” (H1Fs6).

“...You felt that you were too tired to do things." (H1FS7).

“...You felt hopeful about the future." (H1FS8).

“...You thought your life had been a failure.” (H1FS9).

“...You felt fearful.” (H1FS10).

“...You were happy.” (H1FS11)

“...You talked less than usual.” (H1FS12).

“...You felt lonely.” (H1FS13). 
“...People were unfriendly to you.” (H1FS14).

“...You enjoyed life.” (H1FS15).

“...You felt sad.” (H1FS16).

“...You felt that people disliked you.” (H1FS17).

“...It was hard to get started doing things.” (H1FS18).

“...You felt life was not worth living.” (H1FS19).

Participants could respond to negatively worded questions with "Never or Rarely" (score $=0$ ), "Sometimes" ( $($ core $=1)$, "A lot of the time" (score $=2$ ), or "Most of the time or all of the time" (score $=3$ ). Positively worded questions are reverse coded. Responses are summed with higher numbers indicating higher levels of depression.

Alcohol use. Participants self-reported ordinal answers to the question "During the past 12 months, how many days did you drink alcohol?" (H1TO15). Potential answers were "every day or almost every day", " 3 to 5 days a week", "1 or 2 days a week", "2 or 3 days a month", "once a month or less (3-12 times in the past 12 months)", "1 or 2 days in the past 12 months", or "never".

Substance use. Past 30 day substance use was determined by the responses to the following questions. Due to the limited number of positive responses in some ordinal categories indicating higher levels of drug use, answers were converted to binomial responses to capture simply "yes" or "no" to past 30 day use of specific drug categories: 
"During the past 30 days, how many times have you used marijuana?"

(H1TO32).

"During the past 30 days, how many times have you used cocaine?" (H1TO36).

“During the past 30 days, how many times have you used inhalants" (H1TO39).

"During the past 30 days, how many times have you used these types of illegal drugs? (LSD, PCP, ecstasy, mushrooms, speed, ice, heroin, or pills)?" (H1TO42).

Abuse. Lifetime sexual abuse was determined by self-reported categorical responses to the female specific question:

"Were you ever physically forced to have sexual intercourse against your will?" (H1CO10).

Childhood physical abuse was determined from self-reported ordinal responses to the retrospective question:

"Before your $18^{\text {th }}$ birthday, how often did a parent or adult caregiver hit you with a fist, kick you, or throw you down on the floor, into a wall, or down the stairs?" (H4MA3)

Other potential forms of abuse and neglect were conceptualized with interval responses to the retrospective question:

"How often had Social Services investigated how you were taken care of or tried to take you out of your living situation?" (H3MA5). 
Family suicide attempt. Self-reported dichotomous answers to the question "Have any of your family members tried to kill themselves during the past 12 months?" (H1SU6).

Public Assistance. Compiled response where the individual responded "yes" to either question:

"Does she [resident mother] receive public assistance, such as welfare?" (H1RM9)

"Does he [resident father] receive public assistance, such as welfare?" (H1RF9).

Peer suicide attempt. Self-reported dichotomous answers to the question "Have any of your friends tried to kill themselves during the past 12 months?" (H1SU4).

Acculturation. The acculturation variable was measured by the Proxy Acculturation Scale 3 (Cruz, 2008) based on three survey questions:

Interview language. As recorded by the interviewer in response to "In what language was the interview conducted?" (H1IR25). Answers of interest include English, scored as 1 , and non-English, scored as 0 .

Language spoken at home. As answered in response to the question "What language is usually spoken in your home?" (H1GI10). Answers of interest include English, scored as a 1, and non-English languages, scored as 0 .

Proportion of life lived in the United States. Individuals born in the United Sates (H1GI11) were assigned a score of 1. For individuals born outside of the United States, interviewers determined the year in which they first moved to the United States 
(H1GI13Y). The difference between interview year and year in which an individual moved to the United States was calculated. Finally, the constructed years lived in the United States variable was divided by the participant's age to determine the proportion of life lived in the United States. The result is a continuous variable with scores ranging from 0 to 1 .

The resulting section scores are summed for a value between 0 and 5 . Unfortunately, the original questionnaire did not distinguish being born in Puerto Rico, a territory of the United States, as being distinct from being born in the United States. Youth both in Puerto Rico would receive a score of 1, automatically, despite their distinct culturally background. Cruz (2008) found the PAS3 scale to have an acceptable Cronbach's alpha of 0.79 .

Mother connectedness. Mother connectedness was be evaluated on the following interview questions:

"How close do you feel to your [resident mother]?" (H1WP9).

"How much do you think she [resident mother] cares about you?” (H1WP10).

"Do you agree or disagree with the following statement? Most of the time your [resident mother] is warm and loving towards you." (H1PF1).

Do you agree or disagree with the following statement? You are satisfied with the way your mother and you communicate with each other." (H1PF4).

"Do you agree or disagree with the following statement? Overall, you are satisfied with your relationship with your mother." (H1PF5). 
Participants responded to all questions on a 5-point Likert scale. Agree or disagree questions were reverse coded so that higher scores indicating higher elements of connectedness for all five questions. The mean response for all answers were used as an indicator for single parent connectedness.

Father connectedness. Father connectedness was determined from the following questions:

"How close do you feel to your [resident father]?" (H1WP13).

"How much do you think she [resident father] cares about you?" (H1WP14).

"Do you agree or disagree with the following statement? Most of the time your [resident father] is warm and loving towards you." (H1PF23).

Do you agree or disagree with the following statement? You are satisfied with the way your father and you communicate with each other." (H1PF24).

"Do you agree or disagree with the following statement? Overall, you are satisfied with your relationship with your father." (H1PF25).

Participants responded to all questions on a 5-point Likert scale. Agree or disagree questions were reverse coded so that higher scores indicating higher elements of connectedness for all five questions. The mean response for all answers were used as an indicator for single parent connectedness.

Both the mother and father connectedness scales were previously validated (Ford et al., 2005; Ream \& Savin-Williams, 2005; Williams \& Chapman, 2012) in which the 
measure displayed high internal consistency; Cronbach's alpha being between 0.83 and 0.91 .

Autonomy granting. The measure of autonomy granting was based on a measure originally used by (Eagleton et al., 2016) based on extensive research on adolescent decision making on both personal and multifaceted issues. This measure consists of seven distinct questions, beginning with "Do your parents let you make your own decisions about...":

“...the time you must be home on weekend nights?” (H1WP1).

“...the people you hang around with?” (H1WP2).

“...what you wear?” (H1WP3).

“...how much television you watch?” (H1WP4).

“...which television programs you watch?” (H1WP5).

“...what time you go to bed on weeknights?” (H1WP6).

“...what you eat?” (H1WP7).

Responses of interest to these questions were dichotomous, with "no" originally scored as 0 , and "yes" originally scored as 1 . The responses to all seven variables are summed, with a higher number indicating higher levels of autonomy. In their study, (Eagleton et al., 2016) found the measure to have moderate reliability (Cronbach's alpha $=0.63)$. 
Neighborhood safety. Dichotomous response to the question "Do you usually feel safe in your neighborhood?" (H1NB5).

Teacher Care. Likert style responses to the question "How much do you feel that your teachers care about you?" (H1PR2).

\section{Protection of Human Participants}

Prior to application for institutional review, the researcher enrolled in the CITI online IRB training course and received a certificate for successful completion of the online class.

The dissertation was approved under expedited review as it involves analysis of secondary data on characteristics and behavior from survey and interview data that contains personally identifiable information. Risks of data use include social damage from potential breaches in confidentiality, as the Add Health study includes data on sensitive topics such as, but not limited to, mental health, physical health, alcohol and drug use, and sexual activity. However, for the purposes of this dissertation, data was deidentified and personally identifiable information such as geographic or genetic markers were not included in the research.

To ensure the protection of Add Health participants, emphasis was placed on the physical and digital security of the Add Health data files. Data are stored on encrypted server in a locked office, only accessible by a small number of people with written authorization from Add Health authorities, using a virtual protected network with multiple levels of researcher authentication. These precautions were approved as 
acceptable by the Add Health's data security plan standards and the local data manager (Professor Mark Macgowan, PhD).

\section{Data Analysis Plan}

\section{A Priori Power Analysis}

Prior to application for the Add Health data set, an A priori power analysis was conducted to determine the minimum number of participants required for multiple regression statistical analysis. With an anticipated effect size of 0.15 , a desired statistical power level of $0.80,20$ predictor variables, and a probability level of 0.05 , the minimum required sample size was determined to be 156 female adolescents for Research Questions 1 through 4. The Add Health sample of female youth $(n=10,480)$ exceeded the minimum required sample size.

A quick count of cases in the Add Health female sample for Wave I is illustrated in Table 3. Of the 10,480 female respondents $83 \%(n=8694)$ self-identified as nonLatina while $16.7 \%(\mathrm{n}=1751)$ self-identified as being of Latina origin. Of the 1751 Latina youth, 305 endorsed serious thoughts of suicide in the year preceding the interview. These 305 were further questioned about suicide attempts in the past year, where 101 Latina youth had at least one suicide attempt by Wave I. 
Table 3. Past Year Suicide Morbidity by Latina Origin.

\section{Latina Origin}

\begin{tabular}{cc}
\hline Non-Latina & Latina \\
\hline 8694 & 1751
\end{tabular}

Past Year Thoughts of Suicide

No

7231

1418

Yes

1397

305

Past Year Suicide Attempt

1 time

2-3 times

4 or 5 times

6 or more times
273

132

27

32
62

25

8

6 


\section{Descriptive Statistics.}

Initial data analysis included univariate statistics on the key variables of interest. Preliminary examinations of this data better informed the results of more complex statistical tests. The chi-square test of homogeneity was used to determine statistically significant differences in probabilities between two independent groups in terms of a multinomial dependent variable.

\section{Multiple Logistic Regression}

To evaluate the relationship of the 20 predictor variables on the dependent, nominal suicidality variables, multiple logistic regression analyses was used to answer research questions 1 through 4 . As the Add Health study provided a study sample that was both large and nationally representative at the time of Wave I, the data met the assumption of independent observations. Additionally, because of the size of the sample, despite the large number of predictor variables, there are more than 10 cases per predictor.

\section{Generalized Estimating Equations}

Generalized estimating equations (GEE) are a flexible nonparametric analysis that allows comparison between groups in a repeated measures design. Cases are assumed to be dependent within subject and independent between subjects (Garson, 2013). Due to the panel nature of the study sample and the multi-wave design of the Add Health dataset, GEE was considered appropriate. Additionally, due to the interest in population changes over time, GEE was favored as the longitudinal analysis. 


\section{Missing Data}

To reduce the impact of missing data for predictor variables on the analysis, the study used multiple imputation by chained equations (MICE) procedures. Multiple imputation was chosen because it can be applied to both cross-sectional and longitudinal data while retaining sampling variability (Statistical Solutions, Ltd., 1997). MICE may also be used with continuous, binary, unordered categorical, and ordered categorical variable types (White et al., 2010). Additionally, the procedure makes no assumptions about the random or non-random nature of the missing data, and it has been recommended as the procedure of choice for datasets made available for analysis outside of the originating agency (Tabachnick \& Fidell, 2013). 


\section{RESULTS}

\section{Descriptive Statistics}

All descriptive statistics were conducted using SPSS software. Of the original 20,745 respondents to the Wave 1 interview, 10,480 (50.5\%) were recorded to be of female sex at Wave 1. Nearly $17 \%$ of the respondents self-reported themselves to be Latina. In the female group, $61.3 \%$ of respondents self-identified as White, $24.2 \%$ as Black or African American, 3.7\% as American Indian, 7.2\% as Asian, and $9.1 \%$ as Other. Respondents could elect multiple racial identifiers. For example, a female participant could be both non-Latina African American and non-Latina American Indian. For this reason, total racial identifications outnumber total participants.

Table 4. Race and Ethnicity in the Female Subset

\begin{tabular}{lllllll}
\hline & White & $\begin{array}{l}\text { African } \\
\text { American } \\
\text { or Black }\end{array}$ & $\begin{array}{l}\text { American } \\
\text { Indian or } \\
\text { Native } \\
\text { American }\end{array}$ & $\begin{array}{l}\text { Asian or } \\
\text { Pacific } \\
\text { Islander }\end{array}$ & Other & Total \\
Non-Latina & 5569 & 2454 & 274 & 43 & 142 & 8482 \\
Latina & 833 & 75 & 115 & 716 & 811 & 2550 \\
Total & 6402 & 2529 & 389 & 759 & 953 & 11032 \\
\hline
\end{tabular}

At Wave I, the participants ranged in age from 12 to 20 , with 14 participants at age 21 or older. The average age at Wave I was 16 years old, while the most common age was 17 years old. 


\section{Statistical Analyses}

\section{Alphas}

The study included variables constructed from multiple questions built into the Add Health interview. These variables included: depression score, mother connectedness, father connectedness, autonomy, and acculturation. Reliability tests were used to compare the current study's alpha scores to that of the literature for the same variables.

The construct 'depression score' consisted of 19 questions and had a good level of internal consistency, Cronbach's alpha of 0.87. Mother connected was composed of five items and had an acceptable internal consistency, Cronbach's alpha of 0.71. Father connectedness was also composed of five items ad had a good internal consistency as evidenced by Cronbach's alpha equaling 0.89. Autonomy was constructed from seven items and presented a questionable internal consistency, the Cronbach's alpha equaling 0.63. Acculturation was constructed from three items and presented a questionable internal consistency, Cronbach's alpha of 0.61 . The internal consistency of neither autonomy nor acculturation could be improved by deleting any of the components of either scale.

This study's reliability scores returned higher internal consistency than measures in the literature for depression scores (Eagleton et al., 2016). It returned similar scores to the existing literature for father connectedness (Williams \& Chapman, 2012) and autonomy (Eagleton et al., 2016). It returned lower than anticipated internal consistency scores for mother connectedness (Williams \& Chapman, 2012) and acculturation (Cruz, 2008). No scores were considered poor or unacceptable. 
Table 5. Describing Cronbach's Alpha

\begin{tabular}{ll}
\hline Cronbach's Alpha & Internal Consistency \\
\hline $0.9 \leq \alpha$ & Excellent \\
$0.8 \leq \alpha<0.9$ & Good \\
$0.7 \leq \alpha<0.8$ & Acceptable \\
$0.6 \leq \alpha<0.7$ & Questionable \\
$0.5 \leq \alpha<0.6$ & Poor \\
$\alpha<0.5$ & Unacceptable
\end{tabular}

Note: Adapted from Scale development: Theory and applications by R. F. DeVellis, pp. 109-110. Copyright 2012 by Sage Publications. 


\section{Biological sex}

A chi-squared test was conducted to determine whether biological sex proportions were equal across the suicide ideation group and the non-suicide ideation group, $\chi^{2}(1, N$ $=20,501)=167.496, p=0.000$, Cramer's $V=0.090$. Following previously published information presented in the above literature review, biological sex had an impact on past year suicide ideation. Female respondents were more likely to have had serious thoughts of suicide than their male counterparts.

Figure 8. Number of Youth with Suicide Ideation Past Year by Biological Sex

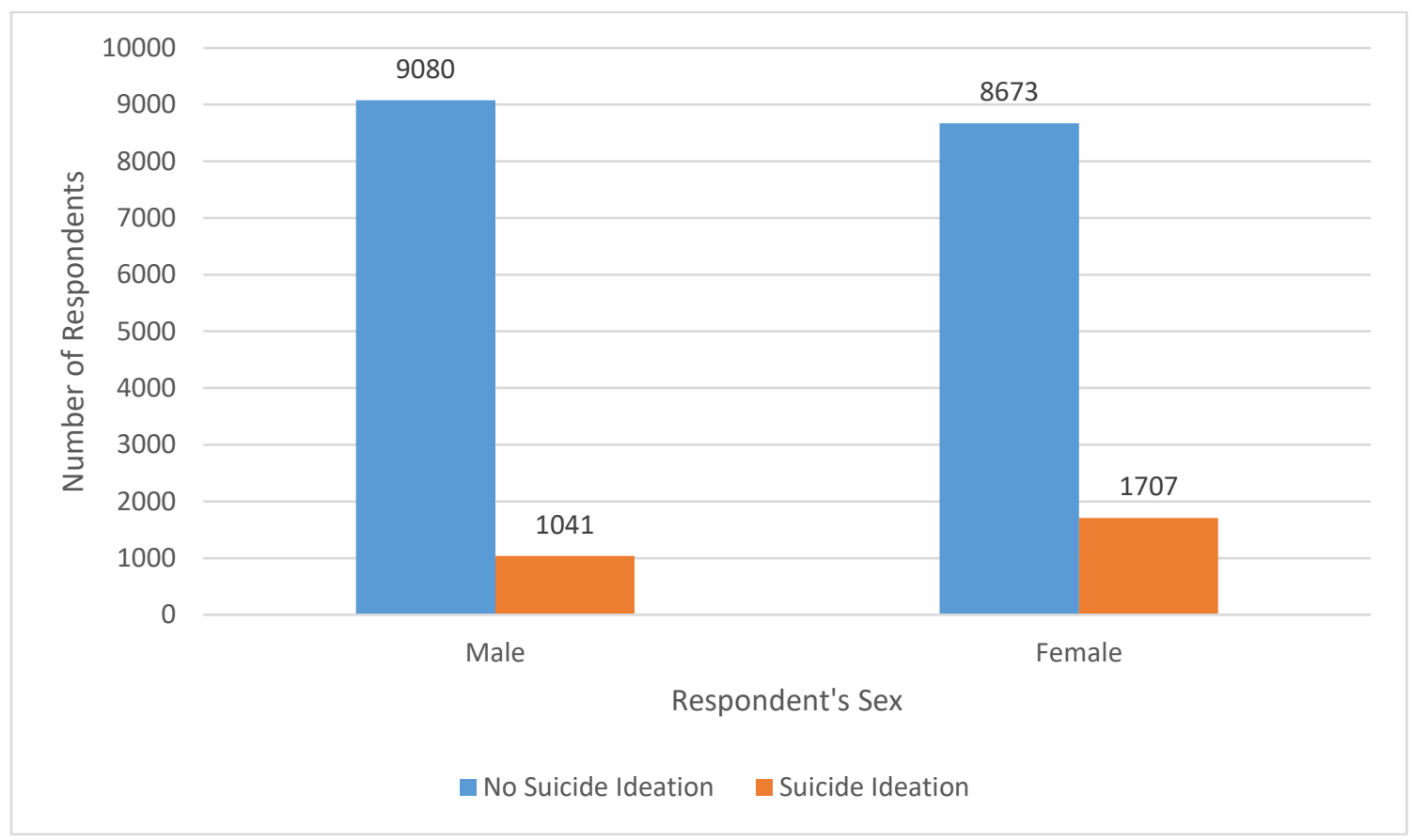

The analysis was repeated on the overall dataset regarding biological sex and past year suicide attempts as an ordinal variable, as originally intended in the survey $\chi^{2}(12, N$ $=20,740)=135.936, p=0.000$, Cramer's $V=0.047$. Here, there continued to be a statistically significant difference between biological sex and a suicide attempt in the past year. Furthermore, a simple descriptive count of how many suicide attempts were 
conducted in the past year by biological sex demonstrated that females were both more likely to have a suicide attempt and more likely to have multiple attempts than the male participants.

Figure 9. Total Number of Past Year Suicide Attempt by Biological Sex

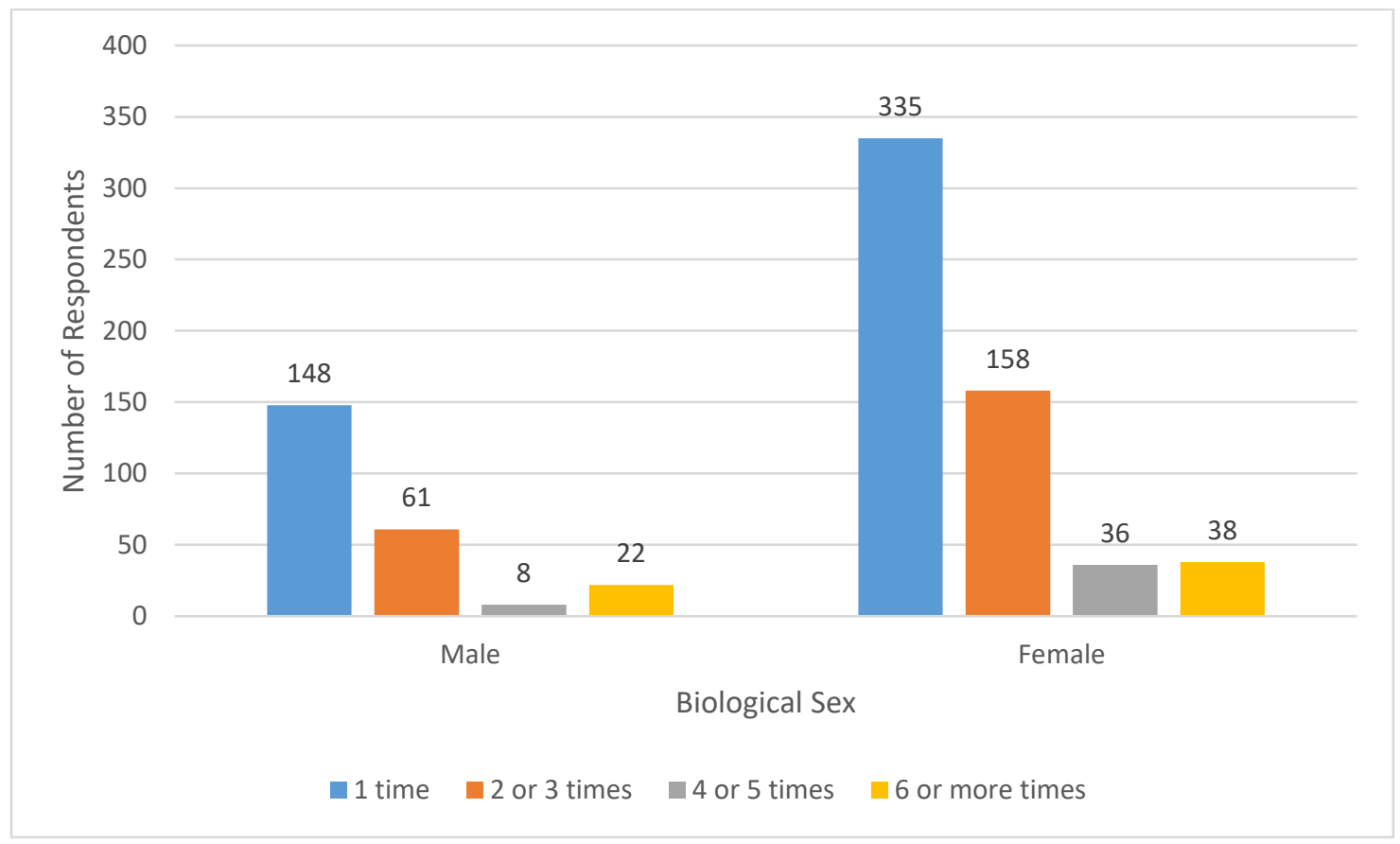

This confirmed previously published information that females self-reported as more likely to attempt suicide than their male counterparts and provides some insight in the realm of multiple attempts. However, the number of cases per cell threaten to become too small to provide adequate statistical information moving forward in more complicated analyses. Past year suicide attempt was then calculated as a binomial variable $(0=$ no, $1=$ yes $)$. With $\chi^{2}(3, N=20740)=131.966, p=0.000$, Cramer's $V=$ 0.080 , it is demonstrated that even as a binomial variable there is a statistically significant biological sex difference in having one or more suicide attempts in the past year with a small to medium effect size. 
Figure 10. Suicide Attempt by Biological Sex

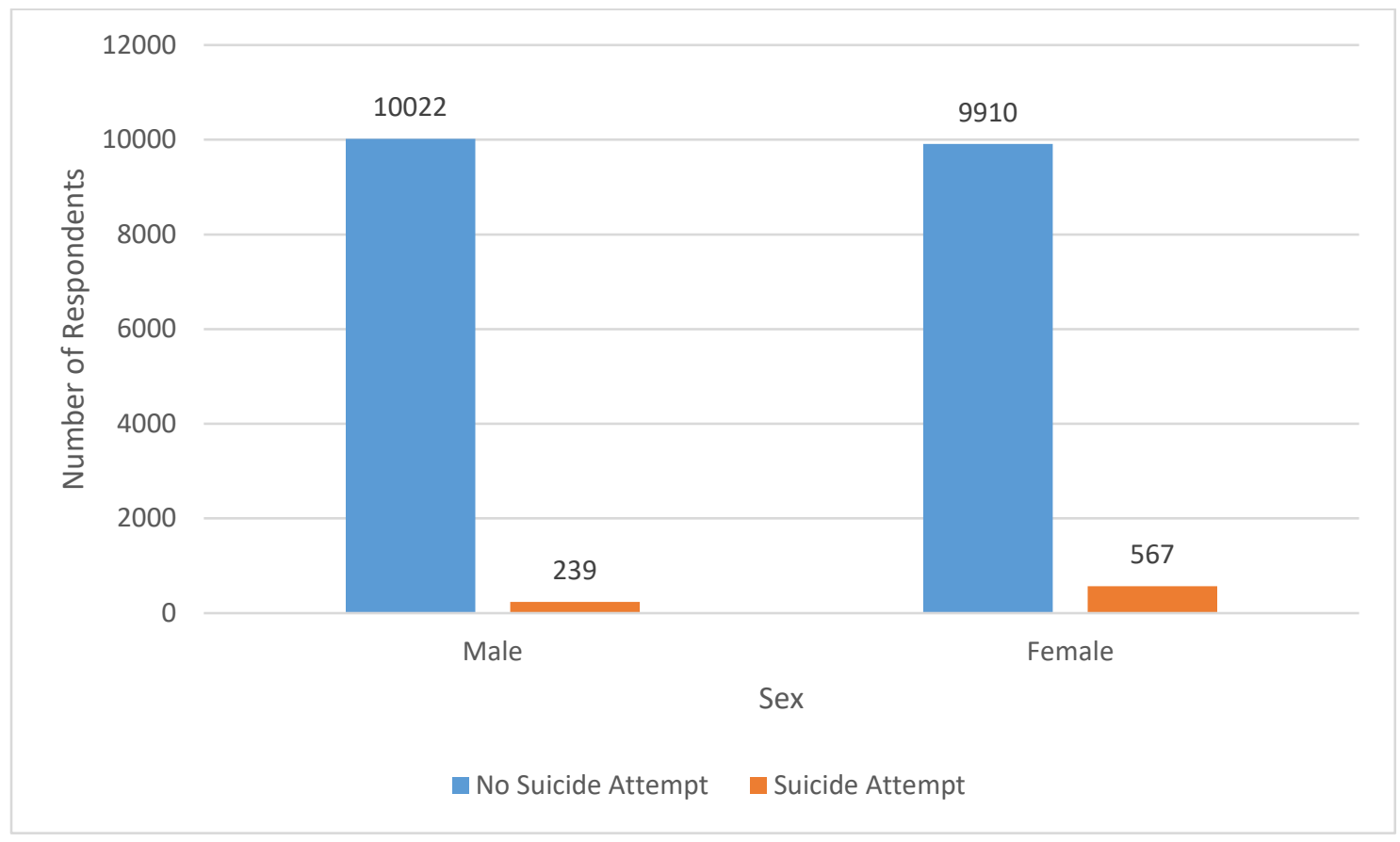

Moving forward, the analyses focused only on the female sex group, the more at risk for suicide ideation and attempts of the two groups.

\section{Latinas}

A chi-squared test was conducted to determine if there was a proportional difference between self-reported Latinas and non-Latinas on suicide ideation, $\chi^{2}(1, N=$ $10351)=2.621, p=0.125$, Cramer's $V=0.015$. The relationship was both nonstatistically significant and weak. The same could be said of self-reporting as Latina and suicide attempts, $\chi^{2}(1, N=10442)=0.525, p=0.469$, Cramer's $V=0.007$. Therefore, self-reported Latina ethnicity alone was not enough in determining any differences in the outcome variables. 


\section{Race}

For further exploration, self-reported Latina status was combined with racial categories to expand the investigation. These new racial/ethnic labels displayed statistical significance for both thoughts of suicide, $\chi^{2}(9, N=10,338)=30.266, p=0.000$, Cramer's $V=0.054$, and past year suicide attempts, $\chi^{2}(9, N=10427)=0.18 .916, p=$ 0.026, Cramer's $V=0.043$. However, not all cells had enough cases for more complicated analyses. There were less than 25 positive responses to suicidal ideation for Latina African American or Black, Latina American Indian or Alaskan Native, and Latina Asian or Pacific Islander participants (Figure 11). The consequences are much the same for the suicide attempt outcome, with the addition of less than 25 respondents in the Non-Latina Other category (Figure 12). Overall, these respondent categories were relatively small to begin with (see Table 6). Due to this, many categories were condensed, which resulted in a form more recognizable to previous large-scale studies of suicidality where Latinas of all races are bundled as a distinct group. 
Figure 11. Race and Ethnicity Categories and Suicidal Ideation

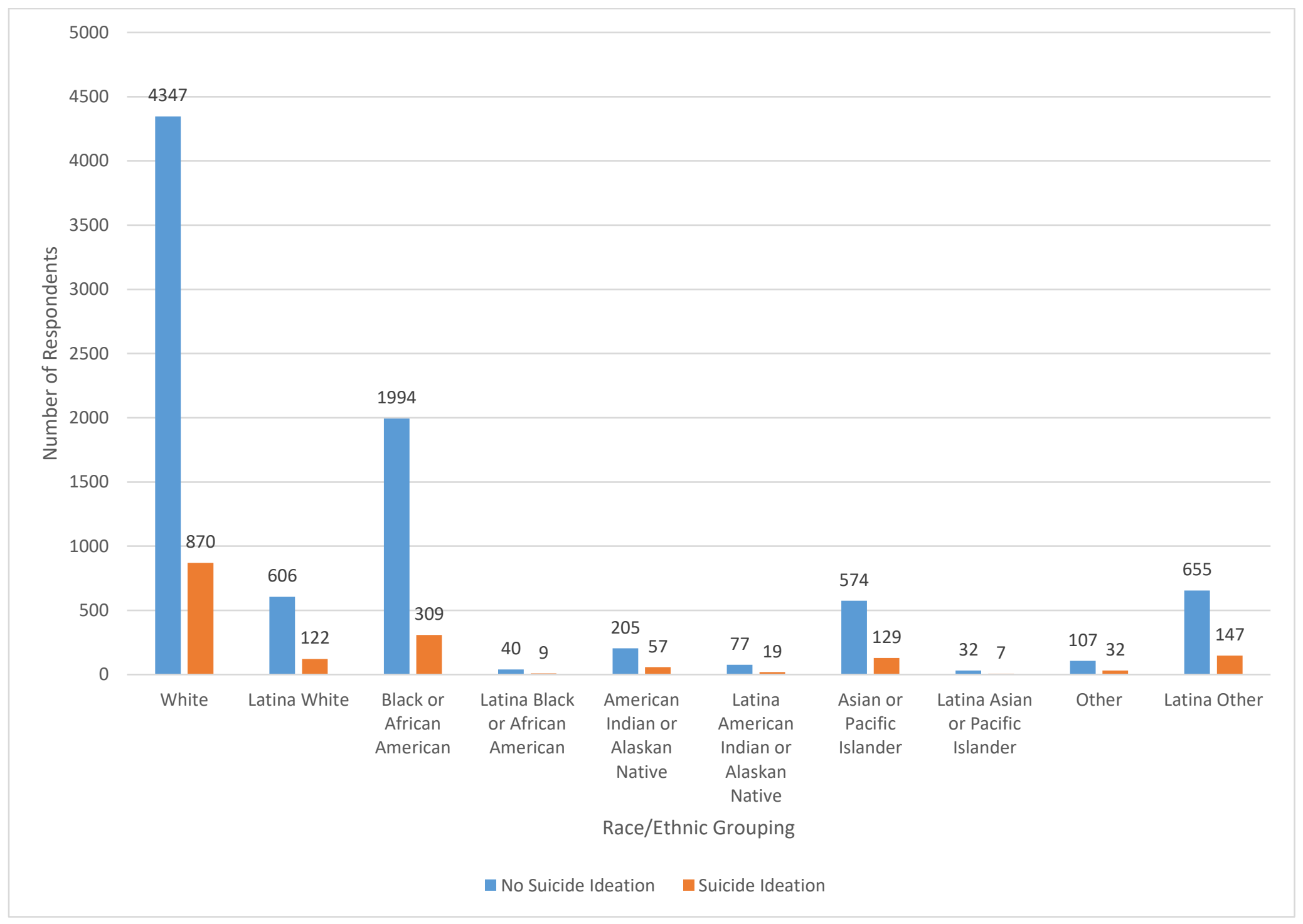


Figure 12. Race and Ethnicity Categories and Suicide Attempts

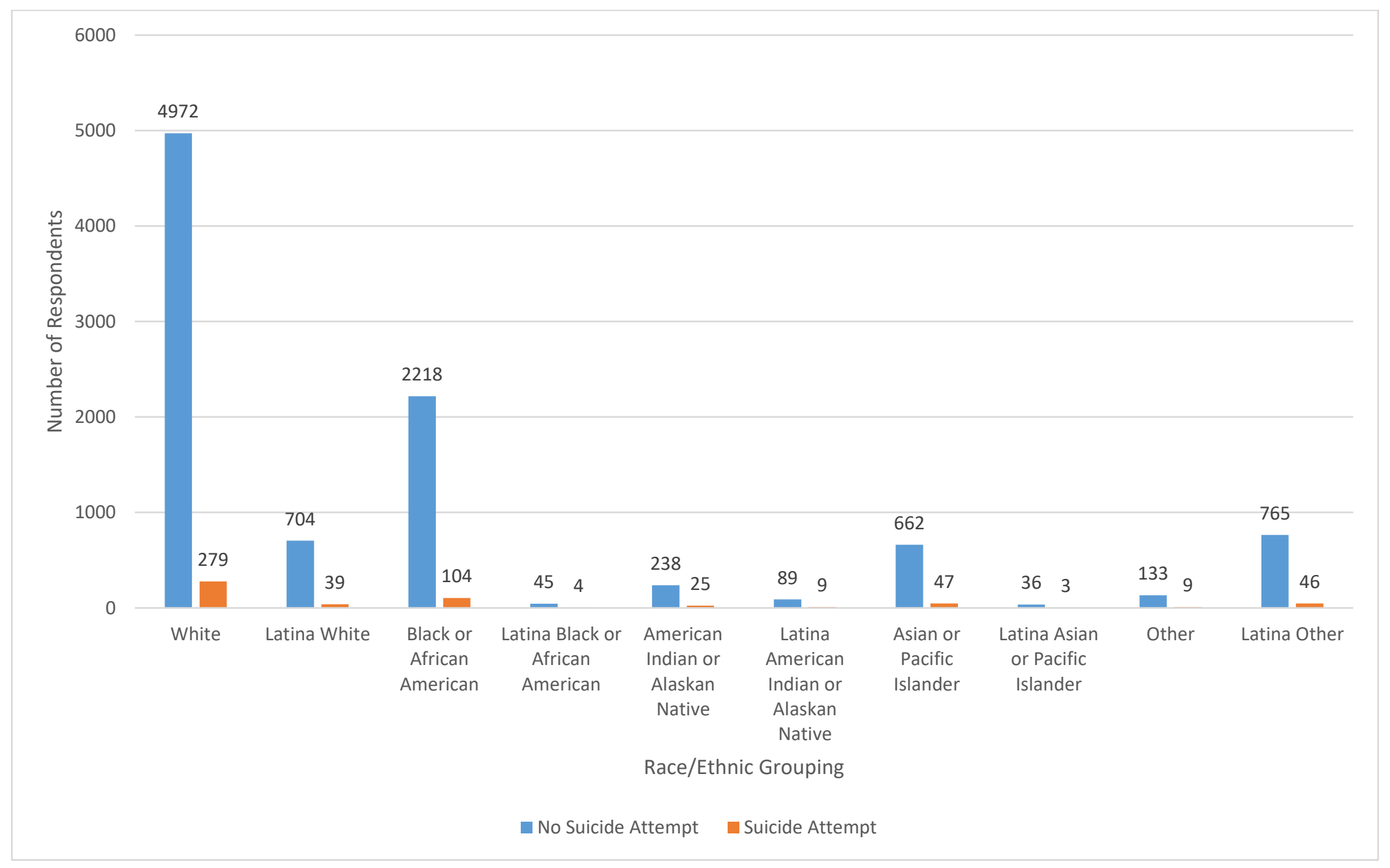


Table 6. Frequency of Race/Ethnicity Categories

\begin{tabular}{lll}
\hline Race/Ethnicity & Frequency & Percent \\
\hline Non-Latina White & 5252 & 50.1 \\
Latina White & 743 & 7.1 \\
Non-Latina Black or African American & 2324 & 22.2 \\
Latina Black or African American & 49 & .5 \\
Non-Latina American Indian or Native Alaskan & 263 & 2.5 \\
Latina American Indian or Native Alaskan & 98 & .9 \\
Non-Latina Asian & 709 & 6.8 \\
Latina Asian & 39 & .4 \\
Non-Latina Other & 142 & 1.4 \\
Latina Other & 811 & 7.7 \\
\hline Total & 10430 & 99.5 \\
\hline
\end{tabular}


Even though Latina self-identification alone was not a significant indicator of the suicide ideation and attempt outcomes, grouping the dataset by Latina versus non-Latina white, non-Latina African American or Black, etc., did demonstrate statistical significance with a small effect size for both suicidal ideation, $\chi^{2}(5, N=10,347)=$ 29.151, $p=0.000$, Cramer's $V=0.053$, and for suicide attempts, $\chi^{2}(5, N=10,438)=$ $15.380, p=0.009$, Cramer's $V=0.038$. Table 7 depicts the final categories for the Race/Ethnicity independent variable and their frequencies.

Table 7. Frequency of Race/Ethnicity Cases

\begin{tabular}{lll}
\hline Race/Ethnicity & Frequency & Percent
\end{tabular}

Latina

1,751

16.7

Non-Latina White

5,252

50.1

Non-Latina Black or African American

2,324

22.2

Non-Latina American Indian or Native Alaskan

263

Non-Latina Asian

709

6.8

Non-Latina Other

142

1.4

Total

10,441

99.6 


\section{Logistic Regression}

\section{Basic Assumptions}

Binomial logistic regression was used due to having one dependent variable that is dichotomous in each test, past year thoughts of suicide or past year suicide attempts. Additionally, there were multiple independent variables measured on either the continuous or nominal scale. Also, there is independence of observations, and the categories of the dependent variable and all nominal independent variables are mutually exclusive and exhaustive. The suggested minimum number of cases per independent variable is 15 to 50 . At 21 independent variables, the existing sample size for the study of 10,430 exceeds the suggested sample size of 315 to 1050 participants.

\section{Testing for a linear relationship between the continuous independent} variables and the logit transformation of the dependent variable. The Box-Tidewell (1962) procedure was used to test for linearity of the continuous variables with respect to the logit of the dependent variable thoughts of suicide. A Bonferroni correction was applied using all 28 terms in the model resulting in statistically significant being accepted when $\mathrm{p}<.00179$ (Tabachnick \& Fidell, 2014). Based on this assessment, all continuous independent variables were found to be linearly related to the logit of the dependent variable. The procedure was repeated for the logit of the dependent variable: suicide attempts. This assumption is therefore met for both statistical analyses.

Testing for multicollinearity. Logistic regression assumes that there must be no multicollinearity between independent variables. Bivariate correlations were conducted to test for multicollinearity. Many of the resulting correlations were significant at the $\mathrm{p}=0.05$ 
level (two tailed). The highest correlation between any two predictor variables was a Pearson correlation of $\mathrm{r}=0.691$ between self-reported Native American and Asian races.

A linear regression analysis was also done. Variance inflation factors (VIF) were within acceptable limits for both outcomes: suicide ideation and suicide attempts. The highest VIF in both scenarios was being of American Indian race (VIF = 3.519 and 3.481 respectively for suicide ideation and suicide attempts). This is within the accepted VIF cutoff of <10 (Hair Jr. et al., 1998). Therefore, it is safely assumed there is no multicollinearity in the independent variables.

Missing Data. A missing variable analysis was conducted in SPSS for all independent and dependent variables to investigate nonresponse. In general, the variables most prone to non-response were either constructed variables or variables from Waves 3 and 4 (Table 8). Data from later waves was prone to participant attrition. Variables constructed from Wave 1 data, like Father Connectedness, Mother Connectedness and Autonomy granting were affected by missing responses in any one of their component scales. Missing values were the highest in Father Connectedness, even more so than other constructed variables. Upon further investigation, nearly 6,282 participants of the overall 20,745 respondents (30.3\% of all Wave 1 respondents) had a legitimate reason to not answer questions about a father figure, potentially from the absence of any such person in their lives.

Other variables that presented with missing responses were suicide ideation, suicide attempts, neighborhood safety, teacher connectedness, acculturation, cocaine use, inhalant use, depression score, and age. Each of these variables were missing $1 \%$ or less 
of their total responses. To solve the problem of missing data, a multiple imputation with chained equations algorithm was applied to the dataset using 2 imputations with a maximum of 1,000 iterations.

Table 8. Variables with $>1.0 \%$ Missing Response from the Female Only Dataset

\begin{tabular}{lllc}
\hline & & \multicolumn{2}{c}{ Missing } \\
\cline { 3 - 4 } Variable & $\mathrm{N}$ & Count & Percent \\
\hline Father Connectedness & 7,050 & 3,430 & 32.7 \\
Physical Abuse as a Child & 8,347 & 2,133 & 20.4 \\
Social Service Investigations & 7,618 & 2,862 & 27.3 \\
Mother Connectedness & 9,841 & 639 & 6.1 \\
Autonomy Granting & 10,161 & 319 & 3.0 \\
\hline
\end{tabular}

\section{Logistic Regression Results}

Overall thoughts of suicide. A binomial regression was performed to ascertain the effects of the predictor variables on the likelihood that the participants had thoughts of suicide in the preceding 12 months. The logistic regression model was statistically significant, $\chi 2(37)=1878.427, \mathrm{p}<.05$. The model explained $27.9 \%\left(\right.$ Nagelkerke $\left.R^{2}\right)$ of the variance in thoughts of suicide and correctly classified $85.3 \%$ of cases. Sensitivity was $24.4 \%$, specificity was $97.3 \%$, positive predictive value was $63.8 \%$ and negative predictive value was $86.8 \%$. Of the predictor values, the following 13 were found to be significant, $\mathrm{p}<.05$ : depression scores, alcohol use, illegal drug use (LSD, PCP, ecstasy, mushrooms, speed, ice, heroin or pills), forced sexual intercourse, past year family suicide attempt, mother receiving public assistance, past year friend suicide attempt, perceived teacher care, age, mother connectedness, father connectedness, acculturation, 
and race/ethnicity. Increased age, mother receiving public assistance, mother connectedness, and father connectedness were all correlated with lower likelihood of thoughts of suicide. Decreased alcohol use was also correlated with a lower likelihood of thoughts of suicide. All results are summarized in Table 9.

Latina thoughts of suicide. A binomial regression was performed on the Latina group to determine the effects of the predictor variables on the likelihood that the Latinas had thoughts of suicide in the preceding 12 months. The logistic regression was statistically significant, $\chi 2(32)=368.152, \mathrm{p}<.05$. The model explained $31.4 \%$ (Nagelkerke $R^{2}$ ) of the variance in thoughts of suicide and correctly classified $84.2 \%$ of cases. Sensitivity was $26.1 \%$, specificity was $96.5 \%$, positive predictive value was $61.0 \%$, and negative predictive value was $86.0 \%$. Of the predictors, the following five variables were found to be statistically significant, $\mathrm{p}<.05$ : depression score, forced sexual intercourse, friend suicide attempt, mother connectedness and father connectedness. Increased levels of mother and father connectedness were correlated with decreased likelihood of thoughts of suicide.

Non-Latina White female thoughts of suicide. A binomial regression was performed on the non-Latina White female group to determine the effects of the predictor variables on the likelihood that the non-Latina White females had thoughts of suicide in the preceding 12 months. The model was statistically significant, $\chi 2(32)=938.159, \mathrm{p}<$ .05 . The model explained 27.5\% (Nagelkerke $R^{2}$ ) of the variance in thoughts of suicide and correctly classified $84.9 \%$ of cases. Sensitivity was $24.5 \%$, specificity was $97.0 \%$, positive predictive value was $62.1 \%$, and negative predictive value was $86.5 \%$. Of the 
predictor variables, the following 11 variables were found to be statistically significant, $p$ $<.05$ : depression score, alcohol use, illegal drug use (LSD, PCP, ecstasy, mushrooms, speed, ice, heroin or pills), forced sexual intercourse, friend suicide attempt, childhood physical abuse, perceived teacher care, age, mother connectedness, father connectedness, and autonomy granting. Increased age, mother connectedness, and father connectedness and decreased alcohol use were correlated with a decreased likelihood for thoughts of suicide.

Non-Latina Black female thoughts of suicide. A binomial regression was performed on the non-Latina Black female group to determine the effects of the predictor variables on the likelihood that the non-Latina Black females had thoughts of suicide in the preceding 12 months. The model was statistically significant, $\chi 2(32)=384.061, \mathrm{p}<$ .05. The model explained $27.9 \%$ (Nagelkerke $R^{2}$ ) of the variance in thoughts of suicide and correctly classified $87.6 \%$ of cases. Sensitivity was $20.8 \%$, specificity was $97.9 \%$, positive predictive value was $60.7 \%$, and negative predictive value was $88.9 \%$. Of the predictor variables, the following eight variables were found to be statistically significant, $\mathrm{p}<.05$ : depression score, illegal drug use, forced sexual intercourse, family suicide attempt, friend suicide attempt, age, mother connectedness, and father connectedness. Increased age, mother connectedness and father connectedness were associated with a decreased likelihood of thoughts of suicide.

\section{Non-Latina American Indian and Alaskan Native female thoughts of suicide.}

At 267 cases of self-identified non-Latina American Indian or Alaskan Native 
respondents in the study, a binomial regression was statistically inappropriate for the number of variables being evaluated.

Non-Latina Asian female thoughts of suicide. A binomial regression was performed on the non-Latina Asian female group to determine the effects of the predictor variables on the likelihood that the non-Latina Asian females had thoughts of suicide in the preceding 12 months. The model was statistically significant, $\chi 2(32)=159.406, p<$ .05. The model explained 32.8\% (Nagelkerke $R^{2}$ ) of the variance in thoughts of suicide and correctly classified $85.1 \%$ of cases. Sensitivity was $33.3 \%$, specificity was $96.6 \%$, positive predictive value was $68.3 \%$, and negative predictive value was $86.7 \%$. Of the predictor variables, the following five variables were found to be statistically significant, $\mathrm{p}<.05$ : depression score, alcohol use, family suicide attempt, friend suicide attempt and father connectedness. Increased levels of father connectedness were associated with a decreased likelihood of thoughts of suicide. Decreased levels of alcohol use were associated with a decreased likelihood of thoughts of suicide.

Non-Latina other female thoughts of suicide. At 142 cases of self-identified non-Latina other respondents in the study, a binomial regression was statistically inappropriate for the number of variables being evaluated.

Overall suicide attempts. A binomial regression was performed to ascertain the effects of the predictor variables on the likelihood that the participants had one or more suicide attempts in the preceding 12 months. The logistic regression model was statistically significant, $\chi 2(37)=976.688, \mathrm{p}<.05$. The model explained $25.9 \%$ (Nagelkerke $R^{2}$ ) of the variance in attempts and correctly classified $94.8 \%$ of cases. 
Sensitivity was $11.1 \%$, specificity was $99.6 \%$, positive predictive value was $61.2 \%$ and negative predictive value was $95.1 \%$. Nine predictor values were found to be statistically significant, $\mathrm{p}<.05$ : depression score, alcohol use, illegal drug use (LSD, PCP, ecstasy, mushrooms, speed, ice, heroin or pills), forced sexual intercourse, friend suicide attempt, perceived teacher care, childhood physical abuse, age, and mother connectedness. Age and mother connectedness were negatively correlated with likelihood of suicide attempt. Decreased levels of alcohol use were associated with decreased likelihood of suicide attempt.

Latina suicide attempts. A binomial regression was performed on the Latina group to determine the effects of the predictor variables on the likelihood that the Latina participants had one or more suicide attempt in the preceding 12 months. The logistic regression was statistically significant, $\chi 2(32)=215.251, \mathrm{p}<.05$. The model explained $32.4 \%$ of the variance in suicide attempts and correctly classified $94.7 \%$ of cases. Sensitivity was $18.8 \%$, specificity was $99.3 \%$, positive predictive value was $63.3 \%$, and negative predictive value was $95.2 \%$. Of the predictors, the following three variables were found to be statistically significant, $\mathrm{p}<.05$ : depression score, forced sexual intercourse, and friend suicide attempt.

Non-Latina White female suicide attempts. A binomial regression was performed on the non-Latina female group to determine the effects of the predictor variables on the likelihood that the non-Latina female participants had one or more suicide attempt in the preceding 12 months. The logistic regression was significant, $\chi 2(32)=517.588, \mathrm{p}<.05$. The model explained $27.6 \%$ of the variance in suicide attempts 
and correctly classified $94.8 \%$ of cases. Sensitivity was $10.0 \%$, specificity was $99.6 \%$, positive predictive value was $56 \%$, and negative predictive value was $95.2 \%$. Predictor variables found to be significant to at least one suicide attempt included: depression score, alcohol use, forced sexual intercourse, friend suicide attempt, perceived teacher care, age, mother connectedness, and acculturation. Increased perceived teacher care, age, and mother connectedness were associated with a decreased likelihood of a suicide attempt.

Non-Latina Black female suicide attempts. A binomial regression was performed to ascertain the effects of the predictor variables on the likelihood that the nonLatina Black female participants had one or more suicide attempts in the preceding 12 months. The logistic regression model was statistically significant, $\chi 2(32)=182.151, \mathrm{p}<$ .05 . The model explained $24.3 \%$ (Nagelkerke $R^{2}$ ) of the variance in attempts and correctly classified $95.5 \%$ of cases. Sensitivity was $7.5 \%$, specificity was $99.7 \%$, positive predictive value was $53.3 \%$ and negative predictive value was $95.8 \%$. Five predictor values were found to be statistically significant, $\mathrm{p}<.05$ : depression score, alcohol use, forced sexual intercourse, friend suicide attempt, and age.

Non-Latina American Indian or Alaskan Native suicide attempts. At 267 cases of self-identified non-Latina American Indian or Alaskan Native respondents in the study, a binomial regression was statistically inappropriate for the number of variables being evaluated.

Non-Latina Asian suicide attempts. A binomial regression was performed to ascertain the effects of the predictor variables on the likelihood that the non-Latina Asian 
female participants had one or more suicide attempts in the preceding 12 months. The logistic regression model was statistically significant, $\chi 2(32)=99.996, p<.05$. The model explained $34.1 \%$ (Nagelkerke $R^{2}$ ) of the variance in attempts and correctly classified $94.1 \%$ of cases. Sensitivity was $25.5 \%$, specificity was $98.9 \%$, positive predictive value was $63.2 \%$ and negative predictive value was $94.9 \%$. Two predictor values were found to be statistically significant, $\mathrm{p}<.05$ : depression score and friend suicide attempt.

Non-Latina Other suicide attempts. At 142 cases of self-identified non-Latina other respondents in the study, a binomial regression was statistically inappropriate for the number of variables being evaluated. 
Table 9. Summary of Significant Predictors of Suicidality at Wave 1

\begin{tabular}{|c|c|c|}
\hline Race/Ethnicity & Suicidal Thoughts & Suicide Attempts \\
\hline \multirow[t]{13}{*}{ Overall } & Depression Scores & Depression Score \\
\hline & Alcohol Use & Alcohol Use \\
\hline & Illegal Drug Use & Illegal Drug Use \\
\hline & Forced Sexual Intercourse & Forced Sexual Intercourse \\
\hline & Family Suicide Attempt & Friend Suicide Attempt \\
\hline & Mother Public Assistance & Perceived Teacher Care \\
\hline & Friend Suicide Attempt & Childhood Physical \\
\hline & Perceived Teacher Care & Abuse* \\
\hline & Age & Age \\
\hline & Mother Connectedness & Mother Connectedness \\
\hline & Father Connectedness & \\
\hline & Acculturation & \\
\hline & Race/Ethnicity & \\
\hline \multirow[t]{5}{*}{ Latinas } & Depression Score & Depression Score \\
\hline & Forced Sexual Intercourse & Forced Sexual Intercourse \\
\hline & Friend Suicide Attempt & Friend Suicide Attempt \\
\hline & Mother Connectedness & \\
\hline & Father Connectedness & \\
\hline \multirow[t]{8}{*}{ White } & Depression Score & Depression Score \\
\hline & Alcohol Use & Alcohol Use \\
\hline & Illegal Drug Use & Forced Sexual Intercourse \\
\hline & Forced Sexual Intercourse & Friend Suicide Attempt \\
\hline & Friend Suicide Attempt & Perceived Teacher Care \\
\hline & Perceived Teacher Care & Age \\
\hline & Age & Mother Connectedness \\
\hline & Mother Connectedness & Acculturation* \\
\hline
\end{tabular}




\begin{tabular}{lll}
\hline & Father Connectedness & \\
Autonomy Granting & \\
Depression Score & Depression Score \\
& Illegal Drug Use & Alcohol Use \\
& Forced Sexual Intercourse & Forced Sexual Intercourse \\
& Family Suicide Attempt & Friend Suicide Attempt \\
& Friend Suicide Attempt & Age \\
& Age & \\
& Mother Connectedness & \\
& Father Connectedness & \\
& Depression Score & Depression Score \\
& Alcohol Use & Friend Suicide Attempt \\
& Family Suicide Attempt & \\
Fsian & Friend Suicide Attempt & \\
& Father Connectedness & \\
\end{tabular}




\section{Generalized Estimating Equations}

\section{Overall Results}

A generalized estimating equations (GEE) analysis was performed on the data to determine the effect of the predictor variables on the likelihood of suicide attempts over time (Garson, 2013; Norusis, 2010). This analysis incorporated the multi-wave design of the Add Health dataset. The GEE analysis was conducted using binary logistic distribution model to determine the likelihood of a suicide attempt. The independent correlation structure was used due to its better goodness of fit $(\mathrm{QIC}=9344.309)$. Due to Huber/White Sandwich Estimators, estimates are valid despite potential working correlation structure misspecifications (Norusis, 2010). Due to the uneven intervals between waves, wave number was analyzed as a categorical variable as opposed to a continuous variable.

In an analysis of all variables of interest, only wave, age, depression score, alcohol use, forced sexual intercourse, family suicide attempt, friend suicide attempt, father as a recipient of public assistance, physical abuse from a parent, attempted removal by social services, mother connectedness, father connectedness, and acculturation were significant predictors of suicide attempts over time. Increased age, mother connectedness, and father connectedness were correlated with a reduced likelihood of suicide attempt over time. Reduced use of alcohol and reduced events of childhood physical reduce resulted in reduced suicide attempts over time. A new estimation for binomial suicide attempts was created using only these predictor variables $(\mathrm{QIC}=$ 9340.858). The results are listed in Table 10. 
Table 10. Generalized Estimating Equation Parameter Estimates

\begin{tabular}{|c|c|c|c|c|c|c|c|}
\hline \multirow[b]{2}{*}{ Parameter } & \multirow[b]{2}{*}{$\mathrm{B}$} & \multirow[b]{2}{*}{ Std. Error } & \multicolumn{2}{|c|}{ 95\% Wald Confidence Interval } & \multicolumn{3}{|c|}{ Hypothesis Test } \\
\hline & & & Lower & Upper & $\begin{array}{l}\text { Wald Chi- } \\
\text { Square }\end{array}$ & df & Sig. \\
\hline (Intercept) & 1.030 & .5706 & -.089 & 2.148 & 3.256 & 1 & .071 \\
\hline \multicolumn{8}{|l|}{ Wave } \\
\hline 4 & -1.618 & .1029 & -1.820 & -1.416 & 247.331 & 1 & .000 \\
\hline 3 & -1.488 & .0980 & -1.680 & -1.296 & 230.595 & 1 & .000 \\
\hline 2 & -.434 & .0632 & -.558 & -.310 & 47.220 & 1 & .000 \\
\hline 1 & $0^{\mathrm{a}}$ & . & . & . & . & . & . \\
\hline \multicolumn{8}{|l|}{ Alcohol Use } \\
\hline Never & -.498 & .2584 & -1.004 & .009 & 3.713 & 1 & .054 \\
\hline $\begin{array}{l}1 \text { or } 2 \text { days in the last } \\
12 \text { months }\end{array}$ & -.178 & .2612 & -.690 & .334 & .464 & 1 & .496 \\
\hline $\begin{array}{l}3 \text { to } 12 \text { times in the past } \\
12 \text { months }\end{array}$ & -.160 & .2660 & -.681 & .362 & .360 & 1 & .548 \\
\hline 2 or 3 days a month & -.127 & .2685 & -.653 & .399 & .224 & 1 & .636 \\
\hline
\end{tabular}




\begin{tabular}{|c|c|c|c|c|c|c|c|}
\hline 1 or 2 days a week & .112 & .2720 & -.421 & .645 & .170 & 1 & .680 \\
\hline 3 to 5 days a week & .136 & .2947 & -.441 & .714 & .214 & 1 & .644 \\
\hline $\begin{array}{l}\text { Every day or almost } \\
\text { everyday }\end{array}$ & $0^{\mathrm{a}}$ & . & . & . & . & . & . \\
\hline \multicolumn{8}{|l|}{$\begin{array}{l}\text { Forced Sexual } \\
\text { Intercourse }\end{array}$} \\
\hline Yes & .388 & .0970 & .198 & .578 & 15.982 & 1 & .000 \\
\hline No & $0^{\mathrm{a}}$ & . & . & . & . & . & . \\
\hline \multicolumn{8}{|l|}{$\begin{array}{l}\text { Family Member } \\
\text { Suicide Attempt }\end{array}$} \\
\hline Yes & .260 & .1071 & .050 & .470 & 5.870 & 1 & .015 \\
\hline No & $0^{\mathrm{a}}$ & . & . & . & . & . & . \\
\hline \multicolumn{8}{|c|}{ Friend Suicide Attempt } \\
\hline Yes & .701 & .0716 & .561 & .841 & 96.018 & 1 & .000 \\
\hline No & $0^{\mathrm{a}}$ & . & . & . & . & . & . \\
\hline
\end{tabular}




\begin{tabular}{|c|c|c|c|c|c|c|c|}
\hline \multicolumn{8}{|l|}{$\begin{array}{l}\text { Father Public } \\
\text { Assistance Recipient }\end{array}$} \\
\hline Yes & -.452 & .1715 & -.788 & -.115 & 6.935 & 1 & .008 \\
\hline No & $0^{\mathrm{a}}$ & . & . & . & . & . & . \\
\hline \multicolumn{8}{|l|}{ Parent Physical Abuse } \\
\hline Never & -.430 & .1544 & -.733 & -.128 & 7.762 & 1 & .005 \\
\hline More than 10 times & -.137 & .1733 & -.477 & .203 & .626 & 1 & .429 \\
\hline Six to Ten times & -.352 & .1995 & -.743 & .039 & 3.113 & 1 & .078 \\
\hline Three to Five Times & .110 & .1960 & -.274 & .495 & .317 & 1 & .573 \\
\hline Two Times & -.257 & .2332 & -.714 & .200 & 1.214 & 1 & .271 \\
\hline One Time & $0^{\mathrm{a}}$ & . & . & . & . & . & . \\
\hline Age & -.228 & .0212 & -.270 & -.187 & 116.366 & 1 & .000 \\
\hline Depression Score & .065 & .0036 & .058 & .072 & 324.814 & 1 & .000 \\
\hline Mother Connectedness & -.187 & .0520 & -.289 & -.085 & 12.991 & 1 & .000 \\
\hline Father Connectedness & -.159 & .0424 & -.242 & -.076 & 14.062 & 1 & .000 \\
\hline Acculturation & .184 & .0727 & .041 & .326 & 6.389 & 1 & .011 \\
\hline
\end{tabular}




\begin{tabular}{lllllllll}
\hline $\begin{array}{l}\text { Social Services } \\
\text { Investigations }\end{array}$ & .071 & .0333 & .005 & .136 & 4.513 & 1 & & .034 \\
\hline
\end{tabular}

a. Set to zero because this parameter is redundant. 


\section{Race/Ethnicity and Suicide Attempts}

Of special interest to this study was the role of race/ethnicity on suicidality. A GEE analysis was run to determine the main effects of Race/Ethnicity and Wave and their interaction effect. For final analyses, the independent correlation structure was selected, though autoregressive and unstructured correlation structures gave similar results $(\mathrm{QIC}=10650.094)$. Due to the uneven intervals between waves, wave number was analyzed as a categorical variable as opposed to a continuous variable.

Only Wave number was found to be significant over time (Wald Chi-Square = 133.723, df=3, $\mathrm{p}<.05)$. As time passed, participants were less likely to attempt suicide. Race/Ethnicity and the interaction of Wave and Race/Ethnicity were not significant to the model. Only one Race/Ethnicity category, Non-Latina American Indian or Alaskan Native appeared to be statistically more likely to have at least one suicide attempt than the Latina group $(\mathrm{B}=.523, \mathrm{p}<.05)$. No other Race/Ethnic groups were significant as a main effect. However, when analyzing the interaction effects of Race/Ethnicity and Wave, Non-Latina Blacks at Wave 4 were statistically more likely to have at least one suicide attempt than the Latina group $(\mathrm{B}=.691, \mathrm{p}<.029)$. 


\section{DISCUSSION}

This study was conducted to explore several areas: identify predictors of Latina suicidal thoughts and suicide attempts, to compare these predictors to those of other racial/ethnic groups, to determine the impact of the predictor variables on suicide attempts over time, and to evaluate the role of race/ethnicity in suicide attempts over time. Many of these predictors have been previously explored in qualitative literature pertaining to Latina suicidality, but this study sought to provide quantitative evidence as to their role in youth suicidal thoughts and attempts. As such, the study was guided by the Proposed Conceptual Model for Research on Suicide Attempts by Adolescent Latinas (Zayas et al., 2005; Figure 4). Better understanding of this topic area was intended to provide data that may assist in the identification of suicidal youth and variables worth consideration in the creation of clinical treatment plans and public health advancements.

\section{Findings}

\section{Concurrent}

Latina thoughts of suicide. Of the variables collected from the literature and tested in the concurrent analysis for thoughts of suicide in the Latina group, the depression score, forced sexual intercourse, friend suicide attempt, mother connectedness and father connectedness were significantly correlated. Higher responses in depression scores, an event for forced sexual intercourse, and an event of a friend's suicide attempt increased the likelihood of thoughts of suicide. Higher scores of mother connectedness and father connectedness were associated with a decreased likelihood of thoughts of suicide. 
Higher (or stronger) mother connectedness and father connectedness were anticipated as important protective factors due to previous research on general and Latina specific populations (Davidson et al., 1999; Gulbas et al., 2011, 2015; Gulbas \& Zayas, 2015; Holland et al., 2016; Hooven et al., 2011; Pelkonen \& Marttunen, 2003; Pena et al., 2012; Piña-Watson et al., 2014; Taliaferro \& Muehlenkamp, 2014; Zayas \& Pilat, 2008). However, a lack of statistical significance for acculturation and autonomy, the operational variables for determining familismo, was not anticipated given their theoretical importance in previous Latina suicide research (Gulbas et al., 2015; Gulbas \& Zayas, 2015; Zayas et al., 2005). Unexpectedly, autonomy was only found significant non-Latina white female youth and their thoughts of suicide, and acculturation was only statistically significant in relation to the overall sample's thoughts of suicide and nonLatina white's suicide attempts. Acculturation and autonomy were primarily discussed in qualitative research, and while they may remain important in the lives of those interviewed, they do not broach the level of statistical significance in this model. Additionally, the proxy scales used to evaluate these factors, while within acceptable alpha limits, may not completely encompass additional relevant subcomponents to prove their importance in potential future works.

The Proposed Conceptual Model for Research on Suicide Attempts by Adolescent Latinas (Figure 4), which informed the creation of this study, may therefore require some review. Family sociocultural environment, which included such factors as familismo, autonomy, and acculturation, may have less of an impact than originally theorized. Another alternative is that this study, due to its secondary and quantitative nature, was not able to capture the subjective experience of the family crisis through the existing Add 
Health variables. Perhaps these subjective experiences would have a significant moderating effect between the variables in question and a suicide attempt.

When compared to the other racial/ethnic groups, the non-Latina White and nonLatina Black groups also found significant correlations between depression score, forced sexual intercourse, friend suicide attempt, mother connectedness, and father connectedness. The non-Latina Asian group lacked a statistically significant correlation with mother connectedness and forced sexual intercourse, but had significant correlations with depression score, friend suicide attempt, and father connectedness.

There were some factors that were relevant to the non-Latina groups, but not the Latina group. Non-Latina whites were further impacted by alcohol use, illegal drug use, perceived teacher care, age, and autonomy grating, whereas Latina youth were not. NonLatina Black female youth were also statistically impacted by illegal drug use, a family suicide attempt, and age, but Latina youth were not. Finally, Non-Latina Asians were statistically impacted by alcohol use and family suicide attempt, while the Latina youth were not.

Latina suicide attempts. Only depression score, forced sexual intercourse, and friend suicide attempt remained statistically significant in considering Latina suicide attempts at Wave 1. Again, the anticipated Latina specific variables of autonomy, acculturation, mother connectedness, and father connectedness were not significant predictors of at least one suicide attempt.

When compared to other racial/ethnic groups, these predictors were also statistically significant for the non-Latina White and the non-Latina Black groups. Non- 
Latina Asians only overlapped in depression scores and friend suicide attempts, meaning forced sexual intercourse was not found to be statistically significant. Non-Latina white female youth had additional factors that were correlated with suicide attempts: alcohol use, perceived teacher care, age, mother connectedness, and acculturation. Additional factors contributing to likelihood of non-Latina Black female youth suicide attempts were alcohol use and age. For non-Latina Asian female youth, there were no additional factors that contributed to suicide attempts.

\section{Longitudinal}

Overall. The results of this study demonstrate an impact of wave number that lessens the likelihood of suicide attempts in the entire sample regardless of race or ethnicity. This supports the literature, in which previous analyses have found suicide ideation and nonfatal attempts lessens with age (Heron, 2019). Additional significant correlates of suicide attempts over time include age, depression score, alcohol use, forced sexual intercourse, family suicide attempt, friend suicide attempt, father as a recipient of public assistance, physical abuse from a parent, attempted removal by social services, mother connectedness, father connectedness, and acculturation. Increased age, levels of mother connectedness, increased levels of father connectedness, and a positive response to a father as the recipient of public assistance all reduced the likelihood of a suicide attempt over time. Reduced levels of alcohol use and reduced events of childhood physical abuse also reduced the likelihood of a suicide attempt over time.

Race/Ethnicity. Race/Ethnicity was not a significant predictor of suicide attempts over time. Non-Latina Whites and Non-Latina Blacks were less likely to have a at least 
one suicide attempt over time, and non-Latina Asians and non-Latina others were more likely than Latinas to have at least one suicide attempt over time than Latinas. However, none of these relationships rose to the level of statistical significance. Overall, only nonLatina American Indians or Alaska Natives were significantly more likely than Latinas to report at least one suicide attempt. Curiously, non-Latina Blacks at Wave 4 were also more likely than Latinas at that same timepoint to report a recent suicide attempt.

\section{Hypothesis Testing}

This section will recap the studies aim and hypotheses in relation to the actual results of the analyses.

Aim 1. To explore the concurrent relationship between Latina suicide ideation and the variables of interest.

Hypothesis 1.1: Higher reported age, score of depression, level of alcohol use, level of drug use, a history of sexual abuse, family use of public assistance, a history of parental suicide, and a history of peer suicide will be associated with a higher likelihood of suicide ideation.

Results 1.1: False. In the Latina group, only higher reported depression scores, forced sexual intercourse, and a friend's suicide was associated with a higher likelihood of thoughts of suicide with any statistical significance. The other factors were not significant.

Hypothesis 1.2: Higher reported level of acculturation, feeling of mother connectedness, feeling of father connectedness, feeling of teacher care, level of autonomy granting, and 
feeling safe in one's neighborhood will be associated with a lower likelihood of suicide ideation.

Results 1.2: False. In the Latina group, only higher feelings of mother connectedness and father connectedness were associated with a lower likelihood of thoughts of suicide with any statistical significance. The other factors were not significant.

Aim 2. To determine if the relationship between the variables of interest and Latina suicide ideation is different from the relationship between the variables of interest and suicide ideation in other, non-Latino racial/ethnic groups.

Hypothesis 2: The strength of the relationship between thoughts of suicide and acculturation, autonomy granting, mother connectedness, and father connectedness will be stronger in Latina youth compared to non-Latina female youth. All other factors will not be different in Latina youth compared to non-Latina female youth.

Results 2: False. Of the above variables, only mother connectedness and father connectedness were statistically significant to Latina thoughts of suicide at Wave I, and it cannot be definitively said that a unit increase in either of these scores resulted in a higher increase in the log-odds of thoughts of suicide when compared to the other racial and ethnic groups (Table 11).

Table 11. Log-Odds for Thoughts of Suicide When Holding All Other Predictors Constant

\begin{tabular}{|c|l|}
\hline & \multicolumn{1}{|c|}{$B$} \\
\hline Latina & \\
\hline Mother Connectedness & -.318 \\
\hline Father Connectedness & -.241 \\
\hline & \\
\hline
\end{tabular}




\begin{tabular}{|c|l|}
\hline Non-Latina White & \\
\hline Mother Connectedness & -.447 \\
\hline Father Connectedness & -.156 \\
\hline & \\
\hline Non-Latina Black & \\
\hline Mother Connectedness & -.435 \\
\hline Father Connectedness & -.285 \\
\hline & \\
\hline Non-Latina Asian & \\
\hline Father Connectedness & -.378 \\
\hline
\end{tabular}

Aim 3. To explore the concurrent relationship between Latina youth suicide attempts and the variables of interest.

Hypothesis 3.1: Higher reported age, score of depression, level of alcohol use, level of drug use, a history of sexual abuse, family use of public assistance, a history of parental suicide, and a history of peer suicide will be associated with a higher likelihood of suicide attempt.

Results 3.1: False. Only depression score, forced sexual intercourse, a friend suicide attempt was correlated with increased likelihood of suicide attempt at Wave I with statistical significance, $\mathrm{p}<.05$.

Hypothesis 3.2: Higher reported levels of acculturation, feeling of mother connectedness, feeling of father connectedness, feeling of teacher care, level of autonomy granting, and feeling safe in one's neighborhood will be associated with a lower likelihood of suicide attempt.

Results 3.2: False. None of these factors were correlated to Latina suicide attempt. 
Aim 4. To determine if the relationship between the variables of interest and Latina suicide attempts is different from the relationship between these factors and suicide attempts in other, non-Latina racial/ethnic groups.

Hypothesis 4: The strength of the relationship between suicide attempts and acculturation, autonomy, mother connectedness, and father connectedness will be stronger in Latina youth compared to non-Latina female youth. All other factors will not be statistically different in Latina youth compared to non-Latina female youth.

Results 4: False. None of these factors were statistically significant to Latina suicide attempts at Wave I.

Aim 5. To evaluate the longitudinal impact between the variables of interest and female youth suicide attempts over time.

Hypothesis 5: There is a statistical relationship between all factors and suicide attempts at 1,6 , and 13 years after baseline.

Results 5: False. Only wave number, age, depression score, alcohol use, forced sexual intercourse, family suicide attempt, friend suicide attempt, father as a recipient of public assistance, physical abuse from a parent, attempted removal by social services, mother connectedness, father connectedness, and acculturation were significant predictors of suicide attempts over time.

Aim 6. To explore whether racial/ethnic group has a longitudinal impact on female youth suicide attempts 1, 6, and 13 years after baseline. 
Hypothesis 6: Racial/ethnic self-identification will significantly impact the likelihood of suicide attempts at 1,6 , and 13 years after baseline.

Results 6: False. Racial/ethnic group did not have a statistically significant impact on female youth suicide attempts over time.

\section{Other Considerations}

Suicide continuum. In relation to the theorized to continuum of suicide lethality (Asarnow et al., 2008; Firestone \& Seiden, 1990; Lester, 1970; Sveticic \& De Leo, 2012; Tarrier \& Picken, 2011), predictors of suicide attempts tend to be a limited selection of predictors of thoughts of suicide (Table 9), tracking with the idea that many but not all individuals move in lethality from thoughts of suicide to suicide attempts. Curiously, one factor was relevant for the overall sample's suicide attempts though it showed no statistical significance for overall thoughts of suicide: childhood physical abuse. A similar event occurred for the non-Latina white group in which acculturation was a relevant factor for suicide attempts, but not for thoughts of suicide.

Suicide contagion or suicide clustering. This study found consistent evidence for a relationship between a friend's suicide attempt and a youth's own suicide attempt across all analyzed racial and ethnic groups, supporting the reviewed literature (Centers for Disease Control and Prevention, 2016; Davidson et al., 1999; Fried et al., 2013; O’Mara \& King, 2009; Pelkonen \& Marttunen, 2003; Thompson et al., 2009; Thompson \& Light, 2011). Previous research has also named parental suicide to be a significant risk factor for youth suicide (Centers for Disease Control and Prevention, 2016; Christiansen et al., 2011; Davidson et al., 1999; O’Mara \& King, 2009; Pelkonen \& Marttunen, 2003). 
Thompson and Light (2011), also using the Add Health dataset, found a significant relationship between family suicide attempt and youth suicide attempt at both one and seven years after baseline, but this study did not have similar findings, perhaps due to the inclusion of additional predictors in this study's model.

\section{Summary}

Predictor variables related to Latina suicidality were more limited than originally hypothesized after a review of the data. There were multiple areas in which all groups overlapped, but each racial/ethnic grouping did demonstrate variability in correlates of suicidal thoughts and suicide attempts. Overall, it seems that screening measures designed to use the common factors of suicide risk such as depression score would capture the at-risk youth, but interventions may be best suited when tailored to the individual's personal context, such as their family dynamics or racial/ethnic background. While the rate of youth dying from suicide is high, the actual counts of suicide ideation and non-fatal suicide attempts remain difficult to investigate. Still, the potential lethality makes it imperative that Latinas receive services related to depression treatment or timely interventions following a peer suicide or forced sexual intercourse event, which this study demonstrates are associated with Latina suicide attempts.

\section{Strengths and Limitations}

As stated before, the National Longitudinal Study of Adolescent to Adult Health dataset provides a unique opportunity to study an exceptionally large group of students from first data collection through their development into adult life. The data used in this study was nationally representative to students of that time period, allowing some 
generalization to the overall student population and the ability to compare within the sample between thousands of youth from diverse demographic backgrounds. The size and scope of the original survey allow for the appropriate use of strong statistical analyses. Additionally, despite being retrospective in nature, the in-depth nature of the questioning and variety of topics allow for the investigation of many different potential predictor variables.

This study, utilizing the Add Health dataset to study female youth suicide morbidity, quantified acculturation, autonomy, and connectedness to evaluate pieces of Latino culture and their relationship to youth suicide in the United States. From a review of the literature, this is a novel approach to research on minority youth and suicide that could expand both the research and practice fields. Additionally, it contributes to social work by strengthening our understanding of an underrepresented group and highlighting areas where practitioners and researchers require greater knowledge that better reflects the diversity of the clients whom social workers empower.

Despite the large sample size of the survey and response set, there are some limitations. Not all variables of interest were available to be studied because of the assumptions made in the original design. For instance, questions on physical abuse were not asked until later waves of the Add Health survey, and questions about sexual abuse were 1 . limited to females, and 2. only asked about forced sexual intercourse, not other forms of sexual harassment or abuse. Questions on certain topics such as connectedness, acculturation, or depression were not specifically asked, but reliable and valid proxy scales were found from previous research to allow for the study of these topics in relation 
to suicide morbidity. Unfortunately, there was not enough information to measure the discrepancy of acculturation rates between the parents and children. Of the proxy scales, acculturation may not be accurately measured of the Puerto Rican youth in the study - by measuring birth nationality the proxy acculturation scale poorly represents the distinct and rich heritage of Puerto Ricans as different from mainland United States citizens. Finally, the Add Health dataset did not provide enough female cases to statistically analyze non-Latina American Indians and Alaskan Natives or non-Latina self-reported "others".

In terms of suicide, the Add Health dataset at Wave 1 can only measure suicide morbidity: thoughts of suicide and suicide attempts in the past year. The focus of the study was on living students and not psychological autopsies. Later follow-up waves allow for coding of attrition from the study due to death by suicide. This provides an interesting starting point for future study, though with its own limitations: follow-up groups are smaller than Wave 1 due to exiting the study for any reason, not all individuals were selected for follow-up, and the study is still on-going. These components may not allow for enough cases for statistically strong study. However, suicide morbidity is one of the strongest predictors of later suicide fatality, so while imperfect, the results of morbidity data can still be used in suicide intervention practice or research. 


\section{Implications for Social Work}

The study was guided by the values of the social work discipline: improving the well-being of people, particularly the vulnerable and underrepresented. At present, the United States faces an alarming number of youth deaths by suicide, with rates that vary between racial and ethnic groups, without an empirically clear understanding of what factors protect some groups more so than others. Researchers specializing in Latina suicide have presented a conceptual model to better describe the environment in which Latina youth suicide occurs. While it is not the purpose of this study to prove or fail to prove the validity of the theoretical model, the model and other existing research has pointed to a selection of risk and protective factors that are either emerging from the qualitative studies with the target population or have been demonstrated in previous quantitative research that was in one way or another methodologically lacking. By improving on this foundational information and the work of researchers who have published before, this project seeks to further advance the knowledge base of suicidology and how social workers can approach suicide research.

The results of this study provide greater understanding to both researchers and practicing social workers on the correlates of Latina youth suicide morbidity and how that may or may not compare with female youth from other racial and ethnic groups. As elements of the conceptual model on Latina suicide are relevant to other groups, not just those of Latino decent, it presents a tool to social workers when approaching female youth with thoughts of suicide, their families, and their cultures. The results can be used to better inform practice, helping social workers not only identify individuals most at risk 
for suicidal thoughts, attempts, and fatalities, but to also better inform problem identification, goal setting, and family work in a culturally competent and empirically informed way. Outside of the therapy setting, this information can be better used in the education of parents, school employees, or others in contact with youth populations on potential warning-signs, risk, or areas that can be fostered to improve youth resiliency against suicide morbidity and mortality.

\section{Future Studies}

Continued studies in the area of youth suicidality in the United States may benefit from incorporating geographic factors into the study. While acculturation measures of this study compare variance from an overall national "normality" of English language and a birth within the United States, these measures do not account for unique ethnic enclaves in specific regions that may provide unique experiences. For example, how would the experience of Latina youth living in Miami, FL vary from that of a Latina youth in Laredo, TX or New York, NY in terms of deciding to commit suicide or not? Would these participants feel better protected from societal pressures, prejudice, and micro-aggressions, and would that impact their likelihood to think of or attempt suicide?

Additionally, future studies could expand on suicidality with other minority groups. Per the results and the literature review, it appears possible that whatever protective factor that had historically kept Black suicidality lower than White or Latinx counterparts may be less impactful over time. Also, the American Indian and Alaskan Native grouping appears to suffer from the highest rates of suicidality in all groups, but also suffers from a lack of research specific to their population in comparison to other 
minority groups. Even in the Add Health dataset, there were not enough non-Latina American Indian or Alaskan Native Youth for individual evaluation using binomial logistic regression. There were also not enough cases on non-Latina other or mixed race respondents, unable to provide insight into minority youths that self-identify as descending from less numerous, unique groups or from multiple cultural groups.

For further study into the Proposed Conceptual Model for Research on Suicide Attempts by Adolescent Latinas (Figure 4), future studies may benefit from mixed method, prospective designs. While this study evaluated variables related to the family sociocultural environment such as acculturation, autonomy, parental connectedness, and childhood abuse, and the youth's mental health experience such as depression scores and sexual abuse, it was unable to incorporate factors related to the subjective experience of the crisis situation preceding a suicide attempt. A marriage of both quantitative and qualitative features may better inform further development of this model.

As further waves of the Add Health dataset are released, it would be interesting to continue to track this cohort as they move from youth into adulthood or middle age. Additionally, future studies may be able to incorporate the attrition through death data in a way that might meaningfully count completed suicides. This data may give a better indication of which factors are more highly correlated with suicide fatality. 


\section{REFERENCES}

Garrett Lee Smith Memorial Act, Pub. L. No. 108-355 (2004). https://www.congress.gov/108/plaws/publ355/PLAW-108publ355.pdf

Asarnow, J. R., Baraff, L. J., Berk, M., Grob, C., Devich-Navarro, M., Suddath, R., Placentini, J., \& Tang, L. (2008). Pediatric emergency department suicidal patients: Two-site evaluation of suicide ideators, single attempters, and repeat attempters. Journal of the American Academy of Child \& Adolescent Psychiatry, 47(8), 958-966. http://dx.doi.org.ezproxy.fiu.edu/10.1097/CHI.0b013e3181799ee8

Berry, J. W. (2006). Acculturative stress. In Handbook of multicultural perspectives on stress and coping (pp. 287-298). Springer. http://link.springer.com/content/pdf/10.1007/0-387-26238-5_12.pdf

Bronfenbrenner, U. (1979). The ecology of human development. Harvard University Press.

Centers for Disease Control and Prevention. (2016). Suicide Risk and Protective Factors. Violence Prevention: Suicide: Risk and Protective Factors. https://www.cdc.gov/violenceprevention/suicide/riskprotectivefactors.html

Centers for Disease Control and Prevention, \& National Center for Injury Prevention and Control. (2005). WISQARS (Web-based Injury Statistics Query and Reporting System)|Injury Center|CDC. Web-Based Injury Statistics Query and Reporting System (WISQARs) [Online]. http://www.cdc.gov/injury/wisqars/index.html

Chesin, M. S., \& Jeglic, E. L. (2012). Suicidal Behavior Among Latina College Students. Hispanic Journal of Behavioral Sciences, 34(3), 421-436. https://doi.org/10.1177/0739986312445271

Christiansen, E., Goldney, R. D., Beautrai, A. L., \& Agerbo, E. (2011). Youth suicide attempts and the dose-response relationship to parental risk factors: A populationbased study. Psychological Medicine, 41(02), 313-319. https://doi.org/10.1017/S0033291710000747

Christiansen, Erik, Larsen, K. J., Agerbo, E., Bilenberg, N., \& Stenager, E. (2014). Risk factors and study designs used in research of youths' suicide behaviour-An 
epidemiological discussion with focus on level of evidence. Nordic Journal of Psychiatry, 68(8), 513-523. https://doi.org/10.3109/08039488.2014.898092

Colby, S. L., \& Ortman, J. M. (2015). Projections of the size and composition of the US population: 2014 to 2060. Current Population Reports, P25-1143. https://pdfs.semanticscholar.org/09c9/ad858a60f9be2d6966ebd0bc267af5a76321. pdf

Crosby, A. E., Ortega, L., \& Melanson, C. (2011). Self-directed Violence Surveillance: Uniform Definitions and Recommended Data Elements, Version 1.0. Center for Disease Control and Prevention, National Center for Injury Prevention and Control, Division of Violence Prevention. http://www.taadas.org/publications/prodimages/Self\%20Directed\%20Violence\%2 OSurveillance.pdf

Cruz, T. H. (2008). Acculturation and the risk of violence among Hispanic adolescents in the United States [Ph.D., The University of North Carolina at Chapel Hill]. http://search.proquest.com.ezproxy.fiu.edu/dissertations/docview/193728948/abst ract/6B162B51E9B445A8PQ/1

Davidson, L., Potter, L., \& Ross, V. (1999). Surgeon General's Call to Action To Prevent Suicide. https://eric.ed.gov/?id=ED452457

Dcoetzee. (2012). Zone of proximal development. Wikimedia Commons. https://upload.wikimedia.org/wikipedia/commons/9/92/Zone_of_proximal_develo pment.svg

De Luca, S., Schmeelk-Cone, K., \& Wyman, P. (2015). Latino and Latina Adolescents' Help-seeking Behaviors and Attitudes Regarding Suicide Compared to Peers with Recent Suicidal Ideation. Suicide and Life-Threatening Behavior, 45(5), 577-587. https://doi.org/10.1111/sltb.12152

De Luca, S., Wyman, P., \& Warren, K. (2012). Latina Adolescent Suicide Ideations and Attempts: Associations with Connectedness to Parents, Peers, and Teachers: Latina Adolescent Suicide. Suicide and Life-Threatening Behavior, 42(6), 672683. https://doi.org/10.1111/j.1943-278X.2012.00121.x

Decennial Statistical Studies Division. (2016). 2020 Census Research and Testing Investigating the 2010 Undercount of Young Children-Examining the Coverage 
of Young Mothers: A New Design for the 21st Century (pp. 1-18). U.S. Department of Commerce, Economic and Statistics Administration, U.S. Census Bureau. http://www2.census.gov/programs-surveys/decennial/2020/programmanagement/final-analysis-reports/2020-report-2010-undercount-childrenmothers.pdf

DeVellis, R. F. (2012). Scale development: Theory and applications (2nd ed.). Sage Publications.

Eagleton, S. G., Williams, A. L., \& Merten, M. J. (2016). Perceived Behavioral Autonomy and Trajectories of Depressive Symptoms from Adolescence to Adulthood. Journal of Child and Family Studies, 25(1), 198-211. https://doi.org/10.1007/s10826-015-0201-z

Eaton, D. K., Foti, K., Brener, N. D., Crosby, A. E., Flores, G., \& Kann, L. (2011). Associations Between Risk Behaviors and Suicidal Ideation and Suicide Attempts: Do Racial/Ethnic Variations in Associations Account for Increased Risk of Suicidal Behaviors Among Hispanic/Latina 9th- to 12th-Grade Female Students? Archives of Suicide Research, 15(2), 113-126. https://doi.org/10.1080/13811118.2011.565268

Else, 'Iwalani R.N., Goebert, D. A., Bell, C. K., Carlton, B., \& Fukuda, M. (2009). The relationship between violence and youth suicide indicators among Asian American and Pacific Islander youth. Aggression and Violent Behavior, 14(6), 470-477. https://doi.org/10.1016/j.avb.2009.07.009

Firestone, R. W., \& Seiden, R. H. (1990). Suicide and the continuum of self-destructive behavior. Journal of American College Health, 38(5), 207-213. http://dx.doi.org.ezproxy.fiu.edu/10.1080/07448481.1990.9936189

Ford, C. A., Pence, B. W., Miller, W. C., Resnick, M. D., Bearinger, L. H., Pettingell, S., \& Cohen, M. (2005). Predicting adolescents' longitudinal risk for sexually transmitted infection: Results from the National Longitudinal Study of Adolescent Health. Archives of Pediatrics \& Adolescent Medicine, 159(7), 657-664.

Fried, L. E., Williams, S., Cabral, H., \& Hacker, K. (2013). Differences in Risk Factors for Suicide Attempts Among 9th and 11th Grade Youth: A Longitudinal Perspective. The Journal of School Nursing, 29(2), 113-122. https://doi.org/10.1177/1059840512461010 
Garson, G. D. (2013). Longitudinal Analysis. Statistical Associates Publishers.

Gulbas, L. E., Hausmann-Stabile, C., De Luca, S. M., Tyler, T. R., \& Zayas, L. H. (2015). An exploratory study of nonsuicidal self-injury and suicidal behaviors in adolescent Latinas. American Journal of Orthopsychiatry, 85(4), 302-314. https://doi.org/10.1037/ort0000073

Gulbas, L. E., \& Zayas, L. H. (2015). Examining the interplay among family, culture, and Latina teen suicidal behavior. Qualitative Health Research, 25(5), 689-699.

Gulbas, L. E., Zayas, L., Nolle, A., Hausmann-Stabile, C., Kuhlberg, J., Baumann, A., \& Peña, J. (2011). Family Relationships and Latina Teen Suicide Attempts: Reciprocity, Asymmetry, and Detachment. Families in Society: The Journal of Contemporary Social Services, 92(3), 317-323. https://doi.org/10.1606/10443894.4131

Hadland, S. E., Marshall, B. D. L., Kerr, T., Qi, J., Montaner, J. S., \& Wood, E. (2012). Suicide and history of childhood trauma among street youth. Journal of Affective Disorders, 136(3), 377-380. https://doi.org/10.1016/j.jad.2011.11.019

Hair Jr., J. F., Anderson, R. E., Tatham, R. L., \& Black, W. C. (1998). Multivariate Data Analysis (5th ed.). Prentice Hall.

Harris, K. M., \& Udry, R. J. (2015). National Longitudinal Study of Adolescent to Adult Health (Add Health) Wave I, 1994-1995. UNC Dataverse, V3.

Harrison, G. (2003). Acculturation. In G. Bolaffi, R. Bracalenti, \& P. Braham (Eds.), Dictionary of Race, Ethnicity \& Culture. Sage UK. http://search.credoreference.com.ezproxy.fiu.edu/content/entry/sageukrace/accult uration/0?searchId=f0da28c2-873e-11e6-9081-1207b0fa605f\&result=0

Hchokr. (2012). Bronfenbrenner's ecological systems theory. Wikimedia Commons. https://upload.wikimedia.org/wikipedia/commons/9/9b/Bronfenbrenner\%27s_Eco logical_Theory_of_Development_\%28English\%29.jpg

Heron, M. (2016). Deaths: Leading Causes for 2014 (Volume 65, Number 5; pp. 1-96). U.S. Department of Health and Human Services, Centers for Disease Control and Prevention, National Center for Health Statistics, National Vital Statistics System. https://www.cdc.gov/nchs/data/nvsr/nvsr65/nvsr65_05.pdf 
Heron, M. (2019). Deaths: Leading Causes for 2017. National Vital Statistics Reports, 68(6), 1-77.

Hetzel, A. M. (1997). US vital statistics system. US Dept. of Health and Human Services, Centers for Disease Control and Prevention, National Center for Health Statistics.

Holland, K. M., Vivolo-Kantor, A. M., Logan, J. E., \& Leemis, R. W. (2016).

Antecedents of Suicide among Youth Aged 11-15: A Multistate Mixed Methods Analysis. Journal of Youth and Adolescence. https://doi.org/10.1007/s10964-0160610-3

Hooven, C., Snedker, K. A., \& Thompson, E. A. (2011). Suicide risk at young adulthood: Continuities and discontinuities from adolescence. Youth \& Society, $0044118 X 11407526$.

Humes, K. R., Jones, N. A., \& Ramirez, R. R. (2011). Overview of Race and Hispanic Origin: 2010 (2010 Census Briefs). United States Census Bureau. http://www.census.gov/prod/cen2010/briefs/c2010br-02.pdf

Kann, L., McManus, T., Harris, W. A., Shanklin, S. L., Flint, K. H., Hawkins, J., Queen, B., Lowry, R., Olsen, E. O., Chyen, D., Whittle, L., Thornton, J., Lim, C., Yamakawa, Y., Brener, N., \& Zaza, S. (2016). Youth Risk Behavior Surveillance-United States, 2015. MMWR. Surveillance Summaries, 65(6), 1174. https://doi.org/10.15585/mmwr.ss6506a1

Kann, L., McManus, T., Harris, W. A., Shanklin, S. L., Flint, K. H., Queen, B., Lowry, R., Chyen, D., Whittle, L., Thornton, J., Lim, C., Bradford, D., Yamakawa, Y., Leon, M., Brener, N., \& Ethier, K. A. (2018). Youth Risk Behavior SurveillanceUnited States, 2017. 67(8), 479.

Lester, D. (1970). Relation between attempted suicide and completed suicide.

Psychological Reports, 27(3), 719-722.

http://dx.doi.org.ezproxy.fiu.edu/10.2466/pr0.1970.27.3.719

Lugo Steidel, A. G., \& Contreras, J. M. (2003). A New Familism Scale for Use with Latino Populations. Hispanic Journal of Behavioral Sciences, 25(3), 312-330. https://doi.org/10.1177/0739986303256912 
Mastnak, J. M., \& Resick, P. A. (2004). Trauma. In W. E. Craighead \& C. B. Nemeroff (Eds.), The Concise Corsini Encycolpedia of Psychology and Behavioral Science (3rd ed.). Wiley.

http://search.credoreference.com.ezproxy.fiu.edu/content/entry/wileypsych/traum $\mathrm{a} / 0$

Nolle, A. P., Gulbas, L., Kuhlberg, J. A., \& Zayas, L. H. (2012). Sacrifice for the sake of the family: Expressions of familism by Latina teens in the context of suicide. American Journal of Orthopsychiatry, 82(3), 319-327. https://doi.org/10.1111/j.1939-0025.2012.01166.x

Norusis, M. J. (2010). PASW Advanced Statistics 18 (1st ed.). Prentice Hall.

Office of Management and Budget. (1997). Final Report on The United States. Federal Register, 62(210). http://www.pedz.uni-mannheim.de/daten/edzath/gdem/04/usa_en.pdf

O’Mara, R., \& King, C. A. (2009). Suicide in Youths. In E. R. Ingram (Ed.), The International Encyclopedia of Depression. Springer Publishing Company. http://search.credoreference.com.ezproxy.fiu.edu/content/entry/spiedep/suicide_in _youths/0?searchId=b9521fdd-27aa-11e7-82410aea1e3b2a47\&result=2\&PHPSESSID=8hfec5dcg4snut534ha9d5hgk4

Pelkonen, M., \& Marttunen, M. (2003). Child and adolescent suicide. Pediatric Drugs, $5(4), 243-265$.

Peña, J. B., Kuhlberg, J. A., Zayas, L. H., Baumann, A. A., Gulbas, L., HausmannStabile, C., \& Nolle, A. P. (2011). Familism, family environment, and suicide attempts among Latina youth. Suicide and Life-Threatening Behavior, 41(3), 330341.

Pena, J. B., Matthieu, M. M., Zayas, L. H., Masyn, K. E., \& Caine, E. D. (2012). Cooccurring risk behaviors among White, Black, and Hispanic US high school adolescents with suicide attempts requiring medical attention, 1999-2007: Implications for future prevention initiatives. Social Psychiatry and Psychiatric Epidemiology, 47(1), 29-42. http://dx.doi.org.ezproxy.fiu.edu/10.1007/s00127010-0322-z 
Piña-Watson, B., Castillo, L. G., Rodriguez, K. M., \& Ray, S. (2014). Familial Factors Related to Suicidal Ideation of Latina Adolescents in the United States. Archives of Suicide Research, 18(2), 213-220. https://doi.org/10.1080/13811118.2013.824827

Radloff, L. S. (1991). The use of the Center for Epidemiologic Studies Depression Scale in adolescents and young adults. Journal of Youth and Adolescence, 20(2), 149166.

Ramey, H. L., Busseri, M. A., Khanna, N., \& Rose-Krasnor, L. (2010). Youth Engagement and Suicide Risk: Testing a Mediated Model in a Canadian Community Sample. Journal of Youth and Adolescence; New York, 39(3), 243258.

Ream, G. L., \& Savin-Williams, R. C. (2005). Reciprocal Associations Between Adolescent Sexual Activity and Quality of Youth-Parent Interactions. Journal of Family Psychology, 19(2), 171-179. https://doi.org/10.1037/0893-3200.19.2.171

Rogers-Sirin, L., Ryce, P., \& Sirin, S. R. (2014). Acculturation, Acculturative Stress, and Cultural Mismatch and Their Influences on Immigrant Children and Adolescents' Well-Being. In R. Dimitrova, M. Bender, \& F. van de Vijver (Eds.), Global Perspectives on Well-Being in Immigrant Families. Springer New York. http://link.springer.com/10.1007/978-1-4614-9129-3

Romero, A. J., Wiggs, C. B., Valencia, C., \& Bauman, S. (2013). Latina Teen Suicide and Bullying. Hispanic Journal of Behavioral Sciences, 35(2), 159-173. https://doi.org/10.1177/0739986312474237

Silverman, M. M. (2011). Challenges to Classifying Suicidal Ideations, Communications, and Behaviours. In R. C. O’Connor, S. Platt, \& J. Gordon (Eds.), International Handbook of Suicide Prevention (pp. 7-25). John Wiley \& Sons, Ltd. http://onlinelibrary.wiley.com.ezproxy.fiu.edu/doi/10.1002/9781119998556.ch1/s ummary

Silverman, M. M., Berman, A. L., Sanddal, N. D., O'Carroll, P. W., \& Joiner, T. E. (2007). Rebuilding the Tower of Babel: A Revised Nomenclature for the Study of Suicide and Suicidal Behaviors: Part 2: Suicide-Related Ideations, Communications, and Behaviors. Suicide \& Life - Threatening Behavior, 37(3), 264-277. 
Silverman, M. M., \& De Leo, D. (2016). Why There Is a Need for an International Nomenclature and Classification System for Suicide. Crisis, 37(2), 83-87. https://doi.org/10.1027/0227-5910/a000419

Singer, J. K., \& Smith, A. M. (2013). Trauma, Psychological. In C. R. Reynolds, K. J. Vannest, \& E. Fletcher-Janzen (Eds.), Encyclopedia of Special Education: A Reference for the Education of Children, Adolescents, and Adults with Disabilities and Other Exceptional Individuals (4th ed.). Wiley. http://search.credoreference.com.ezproxy.fiu.edu/content/entry/wileyse/trauma_ps ychological/0

Stack, S. (2014). Differentiating Suicide Ideators from Attempters: Violence-A Research Note. Suicide and Life-Threatening Behavior, 44(1), 46-57. https://doi.org/10.1111/sltb.12054

Statistical Solutions, Ltd. (1997). SOLAS for missing data analysis 1.0. Statistical Solutions, Ltd.

Sveticic, J., \& De Leo, D. (2012). The hypothesis of a continuum in suicidality: A discussion on its validity and practical implications. Mental Illness, 4(2). https://doi.org/10.4081/mi.2012.e15

Tabachnick, B. G., \& Fidell, L. S. (2013). Using Multivariate Statistics (6th ed.). Pearson Education.

Taliaferro, L. A., \& Muehlenkamp, J. J. (2014). Risk and Protective Factors that Distinguish Adolescents Who Attempt Suicide from Those Who Only Consider Suicide in the Past Year. Suicide and Life-Threatening Behavior, 44(1), 6-22. https://doi.org/10.1111/sltb.12046

Tarrier, N., \& Picken, A. (2011). Co-morbid PTSD and suicidality in individuals with schizophrenia and substance and alcohol abuse. Social Psychiatry and Psychiatric Epidemiology, 46(11), 1079-1086. http://dx.doi.org.ezproxy.fiu.edu/10.1007/s00127-010-0277-0

Thompson, M., Kuruwita, C., \& Foster, E. M. (2009). Transitions in Suicide Risk in a Nationally Representative Sample of Adolescents. Journal of Adolescent Health, 44(5), 458-463. https://doi.org/10.1016/j.jadohealth.2008.10.138 
Thompson, Martie., \& Light, L. S. (2011). Examining Gender Differences in Risk Factors for Suicide Attempts Made 1 and 7 Years Later in a Nationally Representative Sample. Journal of Adolescent Health, 48(4), 391-397. https://doi.org/10.1016/j.jadohealth.2010.07.018

Tøllefsen, I. M., Hem, E., \& Ekeberg, Ø. (2012). The reliability of suicide statistics: A systematic review. BMC Psychiatry, 12(9), 9-19. https://doi.org/10.1186/1471244X-12-9

United Nations Programme on Youth. (n.d.). Definition of Youth. United Nations Department of Economic and Social Affairs. https://link.springer.com/content/pdf/10.1186\%2Fs12889-017-4267-y.pdf

Vygotsky, L. S. (1978). Mind in society: The development of higher psychological processes. Harvard University Press.

White, I. R., Royston, R., \& Wood, W. A. (2010). Multiple imputation using chained equations: Issues and guidance for practice. Statistics in Medicine, 30(4), 377399. https://doi.org/10.1002/sim.4067

Williams, K. A., \& Chapman, M. V. (2012). Unmet health and mental health need among adolescents: The roles of sexual minority status and child-parent connectedness. American Journal of Orthopsychiatry, 82(4), 473-481. https://doi.org/10.1111/j.1939-0025.2012.01182.x

Zayas, L. H., Bright, C. L., Álvarez-sánchez, T., \& Cabassa, L. J. (2009). Acculturation, Familism and Mother-Daughter Relations Among Suicidal and Non-Suicidal Adolescent Latinas. Journal of Primary Prevention, 30(3-4), 351-369. http://dx.doi.org.ezproxy.fiu.edu/10.1007/s10935-009-0181-0

Zayas, L. H., Lester, R. J., Cabassa, L. J., \& Fortuna, L. R. (2005). Why Do So Many Latina Teens Attempt Suicide? A Conceptual Model for Research. American Journal of Orthopsychiatry, 75(2), 275-287. https://doi.org/10.1037/00029432.75.2.275

Zayas, L. H., \& Pilat, A. M. (2008). Suicidal Behavior in Latinas: Explanatory Cultural Factors and Implications for Intervention. Suicide \& Life - Threatening Behavior, 38(3), 334-342. 
VITA

JANICE JUNG O’DRISCOLL

2008

B.S., Psychology

University of Florida

Gainesville, Florida

2012

M.S.W., Social Work

Florida State University

Tallahassee, Florida

2012-2015

Presidential Fellow

Florida International University

Miami, Florida

2013-2016

Graduate Research Assistant

Florida International University

Miami, Florida

2015

Graduate Teaching Assistant

Florida International University

Miami, Florida

2016

Adjunct Professor,

Florida International University

Miami, Florida

2017-Present

Social Worker

Anthem

Tampa, Florida 


\section{PUBLICATIONS AND PRESENTATIONS}

Burke, S., Hu, T., Fava, N., Cottler, L., Duara, R., O’Driscoll, J., \& Alvarez, D. (2018). Factors Influencing Attrition in the National Alzheimer's Coordinating Center's Uniform Data Set. Symposium: Retention and Attrition: Challenges and Solutions for Longitudinal Studies. The Gerontological Society of America Annual Scientific Meeting. Boston, MA. November 14-18, 2018.

Burke, S., Hu, T., Naseh, M., Fava, N. M., O’Driscoll, J., Alvarez, D., Bottler, L. B., \& Duara, R. (2018). Factors influencing attrition in 35 Alzheimer's Disease Centers across the USA: a longitudinal examination of the National Alzheimer's Coordinating Center's Uniform Data Set. https://doi.org/10.1007/s40520-0181087-6

Burke, S., Cadet, T., Alcide, A., O’Driscoll, J., \& Maramaldi, P. (2017). Psychosocial Risk Factors and Alzheimer's Disease: The Associative Effect of Depression, Sleep Disturbance, and Anxiety. Aging and Mental Health, 22(12), 1577-1584. DOI: $10.1080 / 13607863.2017 .1387760$

Wong, S., \& O’Driscoll, J. (2017). Teaching single-case evaluation to graduate social work students: A replication study. Journal of Teaching in Social Work. Advance online publication. DOI: 10.1080/08841233.2017.1319895

Ruggiano, N., O’Driscoll, J., Lukic, A., \& Schotthoefer, L. (2017). "Work is Like a Therapy that Prevents Aging": Perceptions of retirement, productivity and health among minorities and immigrants. Sage Open, 7(1), 1-11. DOI:

$10.1177 / 2158244016687234$

Burke, S., O’Driscoll, J., Alcide, A., \& Li, T. (2016). Moderating risk of Alzheimer's disease through the use of anxiolytic agents. International Journal of Geriatric Psychiatry. Advance online publication. DOI: 10.1002/gps.4614 